\title{
Brain-derived neurotrophic factor in Alzheimer's disease and its pharmaceutical potential
}

\author{
Lina Gao ${ }^{1,2}$, Yun Zhang 3 , Keenan Sterling ${ }^{2}$ and Weihong Song ${ }^{1,2,3,4,5^{*}}$ (D)
}

\begin{abstract}
Synaptic abnormalities are a cardinal feature of Alzheimer's disease (AD) that are known to arise as the disease progresses. A growing body of evidence suggests that pathological alterations to neuronal circuits and synapses may provide a mechanistic link between amyloid $\beta(A \beta)$ and tau pathology and thus may serve as an obligatory relay of the cognitive impairment in AD. Brain-derived neurotrophic factors (BDNFs) play an important role in maintaining synaptic plasticity in learning and memory. Considering AD as a synaptic disorder, BDNF has attracted increasing attention as a potential diagnostic biomarker and a therapeutical molecule for AD. Although depletion of BDNF has been linked with $A \beta$ accumulation, tau phosphorylation, neuroinflammation and neuronal apoptosis, the exact mechanisms underlying the effect of impaired BDNF signaling on $A D$ are still unknown. Here, we present an overview of how BDNF genomic structure is connected to factors that regulate BDNF signaling. We then discuss the role of BDNF in $A D$ and the potential of BDNF-targeting therapeutics for AD.
\end{abstract}

Keywords: Brain-derived neurotrophic factor, Alzheimer's disease, Amyloid $\beta$ protein, Tau protein, Neuroinflammation, Neuronal apoptosis

\section{Introduction}

Alzheimer's disease (AD) is the most common neurodegenerative disorder in the elderly [1]. AD affects $11 \%$ of the population over the age of 65 and nearly half of people aged 85 years and older. However, there is no definitive early diagnostic marker and no effective prevention or disease-modifying treatment for $\mathrm{AD}[2-4]$. As reported by the AD drug development pipeline in 2020, a total of 121 agents are undergoing clinical trials [5]. Most candidate agents $(80.1 \%)$ are disease-modifying therapies targeting disease onset or progression, $9.9 \%$ are symptomatic cognitive enhancers, and $10.0 \%$

\footnotetext{
*Correspondence: weihong@wmu.edu.cn

1 Shandong Collaborative Innovation Center for Diagnosis, Treatment and Behavioral Interventions of Mental Disorders, Institute of Mental Health, College of Pharmacy, Jining Medical University, Jining 272067, Shandong, China

Full list of author information is available at the end of the article
}

are symptomatic agents addressing neuropsychiatric and behavioral changes. On June 7, 2021, the U.S. Food and Drug Administration (FDA) approved aducanumab as a disease-modifying therapy for $\mathrm{AD}$ under its "accelerated approval" pathway, meaning aducanumab demonstrated an effect on a surrogate endpoint that predicts it will be clinically beneficial [6]. This decision is surprising and controversial, especially since the surrogate endpoint used was the reduction of amyloid $\beta(\mathrm{A} \beta)$ rather than clinical efficacy. Moreover, the FDA's advisory committee had previously recommended against aducanumab's approval due to the insufficient evidence to support the drug to improve cognitive decline during the phase 3 trial $[7,8]$. This decision to approve aducanumab as a treatment for $\mathrm{AD}$ is particularly alarming as it does not provide any guidance on which patients would likely benefit. There is no definitive evidence showing that removing amyloid deposits will be therapeutically beneficial for all original author(s) and the source, provide a link to the Creative Commons licence, and indicate if changes were made. The images or other third party material in this article are included in the article's Creative Commons licence, unless indicated otherwise in a credit line to the material. If material is not included in the article's Creative Commons licence and your intended use is not permitted by statutory regulation or exceeds the permitted use, you will need to obtain permission directly from the copyright holder. To view a copy of this licence, visit http://creativecommons.org/licenses/by/4.0/. The Creative Commons Public Domain Dedication waiver (http://creativeco mmons.org/publicdomain/zero/1.0/) applies to the data made available in this article, unless otherwise stated in a credit line to the data. 
individuals diagnosed with $\mathrm{AD}$, especially for patients at more advanced stages of the disease process. Furthermore, many previous drugs targeting amyloid deposits have failed in later-stage clinical testing due to poor efficacy. As a result, there has been a growing emphasis over the past 5 years to pursue intervention strategies that target other damaging features of $\mathrm{AD}$, including those that might mediate the downstream consequences of $A \beta$ accumulation should plaque removal fail to halt disease progression. Current examples include candidate therapies that promote neurogenesis and the protection of neurons and synapses, as well as interventions that target inflammatory, vascular, or epigenetic mediators of $\mathrm{AD}$ pathology [5].

$\mathrm{AD}$ pathology is characterized by an accumulation of two aggregated proteins in the brain, $\mathrm{A} \beta$ and tau, leading to the formation of extracellular neuritic plaques and intracellular neurofibrillary tangles (NFTs), respectively [9]. Following $A \beta$ and tau pathology, AD patients further exhibit synaptic abnormalities, neuronal loss, cognitive decline and memory impairments as the disease progresses [10-13]. $A \beta$ is the central component of neuritic plaques and is a proteolytic product of the amyloid $\beta$ precursor protein (APP) [14]. NFTs are formed from the hyperphosphorylated microtubule-associated protein tau. $A \beta$ - and tau-induced neuroinflammation and neuronal apoptosis contribute to AD pathogenesis $[15,16]$. $\mathrm{AD}$ is a complex and multifactorial disorder. Different hypotheses have been proposed to explain the pathologic process of $\mathrm{AD}$, including the cholinergic hypothesis [17], the tau hypothesis $[18,19]$, the glutamate dysfunction hypothesis [20], the amyloid cascade hypothesis [21, 22], the inflammatory hypothesis [23], and the mitochondrial cascade hypothesis [24]. However, these hypotheses can only account for certain aspects of the disease, and the mechanism leading to $\mathrm{AD}$ pathogenesis remains elusive. As the cognitive impairment in $\mathrm{AD}$ is due to neurodegeneration, neurotrophic factors including brain-derived neurotrophic factor (BDNF) may slow the progression of neurodegeneration and serve as a promising strategy for AD intervention.

BDNF is a well-studied growth factor in the mammalian brain. It plays a vital role in facilitating nerve growth and maturation through development stages and regulating synaptic transmission and plasticity in adulthood $[25,26]$. In the brain, BDNF is mainly synthesized in cell bodies of neurons and glial cells and then transported to presynaptic terminals and postsynaptic dendrites. The localization of BDNF and its receptor, tropomyosin receptor kinase $B(\operatorname{TrkB})$, to glutamate synapses regulates neurotransmitter release, ion channel activity, axonal pathfinding and neuronal excitability [27]. In the context of AD, BDNF depletion is associated with tau phosphorylation, $A \beta$ accumulation, neuroinflammation and neuronal apoptosis [28]. Stimulation of BDNF leads to tau dephosphorylation through activation of TrkB and phosphatidylinositol 3-kinase (PI3K) signaling [29, 30]. $\mathrm{A} \beta$ disrupts BDNF signaling through dysregulation of the glutamatergic $N$-methyl-D-aspartate receptor (NMDAR)/ $\mathrm{Ca}^{2+} /$ calpain signaling cascade [31]. Upregulation of BDNF by the extracellular regulated kinases/cyclic AMP response element-binding protein (ERK/CREB) signaling pathway can ameliorate the $A \beta$-induced neuronal loss and dendritic atrophy [32]. Silencing BDNF antisense RNA can significantly up-regulate BDNF, reduce $A \beta$-induced neurotoxicity, and enhance cell viability [33]. Growing evidence also suggests that the BDNF signaling plays a critical role in modulating the downstream consequences of $\mathrm{A} \beta$ accumulation in $\mathrm{AD}$. BDNF mediates the link between inflammation and neuroplasticity by regulating the release of neurotransmitters (such as glutamate and gamma-aminobutyric acid) following nuclear factor- $\mathrm{kB}(\mathrm{NF}-\mathrm{kB})$ activation $[34,35]$. As the disease progresses, BDNF levels in the brain [36], blood [37] and cerebrospinal fluid (CSF) [38] of AD patients are reduced. In addition, higher serum levels of BDNF have been correlated with improved cognitive function in $\mathrm{AD}$ [39]. These findings have led to an increasing interest in BDNF as a potential biomarker for diagnosis of or as a therapy for AD. In the following, we will discuss the role of BDNF in $\mathrm{AD}$ and the pathways by which BDNF alleviates the progression of $\mathrm{AD}$, highlighting the potential of BDNFtargeting therapeutics for this devastating disease.

\section{Overview of BDNF}

\section{BDNF gene structure, expression and function}

BDNF has a complex gene structure and tissue-specific expression pattern. As shown in Fig. 1a, rodent BDNF genes consist of 9 exons and 9 individual functional promoters [40, 41]. These promoters control the expression of BDNF variants encoding the same BDNF protein. This unique genomic structure allows various factors to regulate BDNF signaling in different ways. Furthermore, each BDNF isoform can be associated with a distinct set of functional outcomes [42]. Selective disruption of BDNF expression from $B d n f$ promoter I, II, IV or VI in mutant mice ( $B d n f$-e1, e2, e4 and e6 mice) is linked with different BDNF-associated molecular and behavioral phenotypes. Compared with wild-type mice, $B d n f$-e1 and e2 mutants show more aggressive behaviors accompanied by increased gene expressions of serotonin transporter 5-HTT (Slc6a4) and 5-HT2A (Htr2a). On the other hand, $B d n f$-e 4 and e6 mutant mice are not aggressive and show altered expression of the 5-HT receptor. Specifically, loss of BDNF from promoters IV and VI suppresses GABAergic neurotransmission, resulting in decreased 


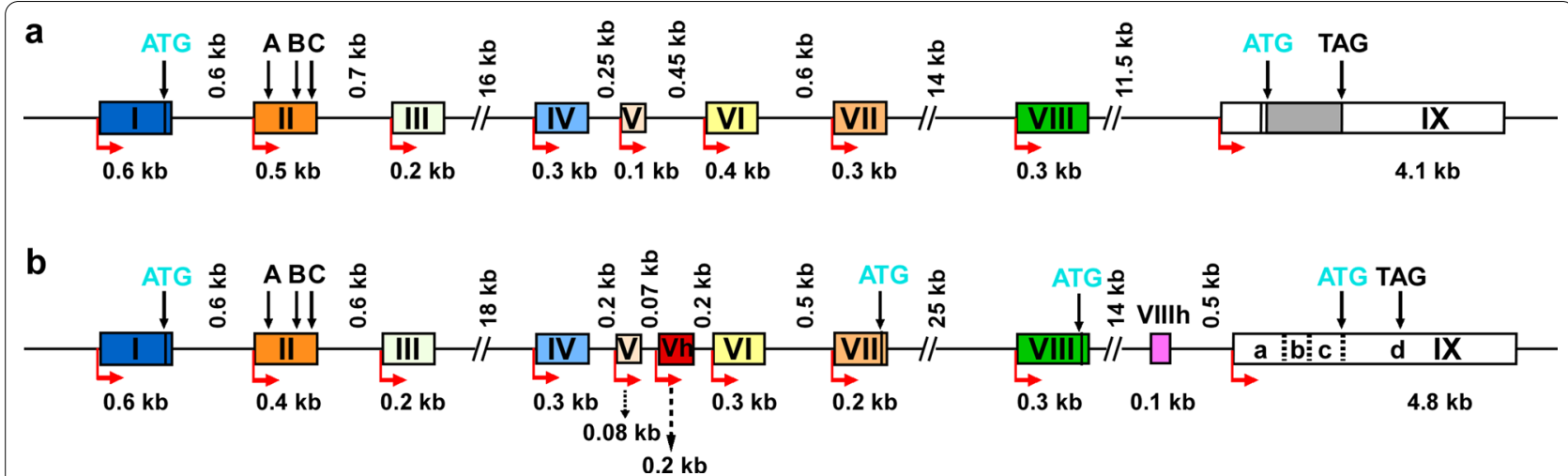

Fig. 1 Rodent and human BDNF gene structures. a Rodent Bdnf gene structure. b Human BDNF gene structure. Exons are shown as boxes and introns are shown as lines. In both structures, the same color indicates that human exons and rodent exons are homologous. The different exons (Vh and VIIIh) are shown as red box and pink box, respectively. In exon II, there are three transcript variants which are marked as $A$, B and C. In human BDNF exon IX, there are four different regions that are marked as $a, b, c$ and $d$. The numbers above the introns and below the exons indicate their base pair sizes. The red arrows indicate the positions in which the transcription starts. ATG represents the sites of the translational start and TAG marks the location of stop codons

expression of genes involved in peptide and hormonal signaling in the brain, including somatostatin (Sst), corticotropin-releasing factor-binding protein (Crhbp), cortistatin (Cort) and tachykinin (Tac1). Quantitative analysis of BDNF protein further showed that the individual $B D N F$ transcripts have a region-specific expression pattern in the hypothalamus, prefrontal cortex, and hippocampus [42]. For example, BDNF promoters I and II mainly contribute to the total BDNF levels in the adult hypothalamus, while promoters IV and VI contribute more to BDNF levels in the prefrontal cortex and hippocampus.

Epigenetic changes in chromatin structure can also regulate the activity-dependent BDNF transcription. Specifically, neuronal activation is associated with increased production of BDNF and exon IV promoter activity (promoter upstream of BDNF exon IV) in mice [43]. Moreover, the transcription of $B d n f$ from the exon IV promoter is enhanced in the brains of DNA methyltransferase 1 null (Dnmt1) $)^{-/-}$mice at embryonic day 18 . This alteration may be associated with reduced CpG methylation within the Bdnf exon IV promoter or dissociation of the methyl-CpG-binding protein (MeCP2) and its corepressors (e.g. MecP2-histone deacetylase-mSin3A complex) from the $B d n f$ exon IV promoter [44-46].

Previous studies have shown that the regulation of BDNF at the mRNA level may affect the brain function. Two $B d n f$ mRNA transcripts that facilitate different subcellular localizations have been identified in the murine brain [47]. One transcript containing a short 3' untranslated region (3' UTR) is localized in the soma of hippocampal neurons, while the other transcript containing a long 3' UTR is distributed in the dendrites. Inducing a mutation in the long 3' UTR in mice leads to expression of a truncated version of the transcript and impairs the dendritic targeting of $B d n f$ mRNA, such that BDNF expression is shifted from dendrites to the soma. This results in deficits in the pruning of dendritic spines and selective impairment of long-term potentiation (LTP) at dendritic synapses [47]. In addition to the transcript species selectivity, $B D N F$ mRNAs also display activitydependent dendritic localization in vitro, with transcripts I and IV selectively affecting proximal dendrites and transcripts II and VI selectively affecting distal dendrites. It has also been demonstrated that the dendritic targeting of short 3' UTR can be induced by both depolarization and NT3, via binding to cytoplasmatic polyadenylation element-binding proteins (CPEB)-1, CPEB-2, embryonic lethal abnormal vision-like proteins (ELAV)-2 and ELAV4, while the inducible dendritic targeting of long 3' UTR requires ELAV-1, ELAV-3, ELAV-4 and Fragile X mental retardation syndrome-related (FXR) proteins [48-50]. This suggests that specific $B D N F$ variants may selectively respond to different extracellular stimuli in order to modulate neuronal development and synaptic plasticity.

It is important to note that there are remarkable differences in the regulatory mechanisms of rodent and human $B D N F$ genes. As shown in Fig. 1b, the human BDNF gene contains 11 exons and 9 promoters [51]. The expression of the human $B D N F$ gene in particular brain regions is also highly regulated at the transcription level. For example, it has been found that the amygdala has relatively high expression of $B D N F$ transcripts containing exons I, IV and VI. On the other hand, the BDNF exon II transcript is relatively upregulated in the cerebellum, while higher expression of exon IXabcd transcripts is found in 
the striatum, thalamus and globus pallidus. In humans, the promoters upstream of Exons I-VIII control regional and cell-type-specific expression, and the promoter upstream of Exon IX regulates activity-dependent BDNF expression. Exons $\mathrm{Vh}$ and VIIIh are human-specific and are not found in rodents. Exon Vh has an upstream sequence and a separate promoter, while exon VIIIh has no independent promoter to control its expression. Thus, various BDNF transcripts can be generated by using alternative promoters and splicing mechanisms, and some of these mechanisms differ substantially for rodent and human $B D N F$ genes.

Transcription of noncoding natural antisense RNAs from the anti-BDNF gene to the $B D N F$ gene locus showed that BDNF and anti-BDNF transcripts form dsRNA duplexes in the human brain [51]. This indicates that the anti-BDNF transcripts play a crucial role in regulating BDNF expression. The possible roles of anti-BDNF may include regulating $B D N F$ pre-mRNA splicing and inhibition of $B D N F$ transcription or $B D N F$ translation. The transcription of $B D N F$ mRNA can also be regulated by $\mathrm{Ca}^{2+}$ influx because $\mathrm{Ca}^{2+}$ can initiate the binding of CREB and calcium-responsive transcription factor (CaRF) to the BDNF promoters [52]. Moreover, many other regulators such as basic helix-loop-helix B2 and NF- $\mathrm{kB}$ have been identified to bind to $B D N F$ promoters $[53,54]$. The multiple promoters in the $B D N F$ gene mediate complex transcription mechanisms. How the different BDNF mRNA variants then respond to intracellular processes and extracellular environments will lead to the diversity of BDNF neuronal distribution and biological functions.

The full-length BDNF protein has 247 amino acids and is encoded by the BDNF gene on human chromosome11p13. As a secreted protein, BDNF is initially synthesized in the endoplasmic reticulum as a precursor protein, called pre-pro-BDNF, which is cleaved into the pro-BDNF isoform $(\sim 32 \mathrm{kDa})$ when translocated to the Golgi apparatus. There are three fates of pro-BDNF: (1) intracellular cleavage by furin or convertases followed by release of mature BDNF (mBDNF) $(\sim 14 \mathrm{kDa})$; (2) secretion as pro-BDNF and extracellular cleavage by metalloproteinases 2 (MMP2), MMP9 and plasmin; (3) secretion as pro-BDNF without modification [55-58]. The cleavage conversion of pro-BDNF is controlled by tissue plasminogen activator (tPA) [59]. BDNF functions are subsequently initiated by binding to one of its receptors, such as TrkB and p75 neurotrophin receptor $\left(\mathrm{p} 75^{\mathrm{NTR}}\right)$ [60]. Notably, the balance of pro-BDNF and mBDNF is important for synaptic plasticity. Pro-BDNF binds specifically to $\mathrm{p} 75^{\mathrm{NTR}}$ to regulate cell death and long-term depression (LTD) [26, 61-63], while mBDNF binds more readily to TrkB to promote cell survival and
LTP [64, 65]. As a co-receptor, sortilin is also involved in pro-BDNF-induced apoptosis [66, 67]. The binding region of pro-BDNF-sortilin interaction is located within amino acid residues 71-100 [68]. Therefore, the distinct binding affinities of the BDNF isoforms to various receptors are closely correlated with their action on synaptic plasticity. As a portion of pro-BDNF, BDNF pro-peptide is generated through $\mathrm{N}$-terminal cleavage of pro-BDNF. The BDNF pro-peptide is localized at presynaptic termini to enhance hippocampal LTD $[26,69]$ and regulate dendritic spine morphology [70]. Therefore, the mBDNF, pro-BDNF and BDNF pro-peptide all modulate synaptic functions in the brain.

BDNF serves many important functions in the adult brain and has been shown to play a critical role in supporting neuronal survival and differentiation [71], enhancing synaptic transmission [72] and synaptic plasticity [73], and promoting memory processes [71, 74]. The neurotrophic functions of BDNF are primarily mediated by the TrkB receptor [75]. BDNF and TrkB are present at both presynaptic and postsynaptic sites in neurons. Presynaptic BDNF promotes neurotransmitter release (e.g. glutamate and GABA) via the TrkBMAP kinase-synapsin signaling cascade [76]. It has been reported that myosin VI (Myo6) and Myo6-binding protein (GIPC1) can form a complex to engage TrkB, which may be necessary for the BDNF-TrkB-mediated presynaptic function and synaptic plasticity [75]. Postsynaptic BDNF signaling contributes to enhancing the function of various ion channels, such as NMDAR, as well as calcium, sodium and potassium channels [77, 78]. Once activated, the synaptic effects of BDNF signaling occur within seconds [79]. Maintaining the functional regulation of the BDNF/TrkB system is vital to healthy ageing, as the loss of BDNF signaling in the adult brain has been associated with impaired learning and memory [80], declining cognition [81], and abnormal mood-related behavior [82].

\section{Distribution of BDNF}

BDNF mRNA is distributed throughout the central nervous system (CNS), including the cortical, hippocampal, nigral, amygdala and thalamic regions [83-85]. The highest level of BDNF mRNA is found in the hippocampus [86]. Hippocampal BDNF expression is primarily localized to the CA2, the medial portion of CA1, and the nuclei of granule cells in the dentate gyrus and the pyramidal cell layer [87]. In addition, BDNF is highly produced and expressed in the entorhinal cortex, a key brain area for learning and memory and a major relay between the cortex and hippocampus. It has been found that BDNF produced in the entorhinal cortex is actively transported to the hippocampus [88]. The mRNA expression 
of BDNF has also been detected in the granule cell layer of the cerebellum [86]. Notably, although BDNF mRNA expression is lacking in certain regions of the brain (e.g., the adult rodent striatum), substantial amounts of BDNF protein can be found in these regions because axons can anterogradely transport BDNF mRNA to the terminals of BDNF-expressing neurons $[85,86]$. Thus, factors regulating the neuronal circuitry between brain regions that contain BDNF-producing neurons (i.e., the entorhinal cortex) and regions that lack BDNF-producing neurons (i.e., the hippocampus) play a critical role in governing BDNF trafficking in the brain. Another important source of BDNF in the body is platelet cells [89]. Peripheral BDNF is stored in blood platelets and synthesized by vascular cells, epithelial cells, muscle cells, leukocytes and macrophages [90, 91]. Pro-BDNF was found in human blood samples with a molar ratio (of pro-BDNF to BDNF) of 1:5 in platelets and 10:1 in plasma. Platelet activation was also found to selectively release BDNF, but not pro-BDNF [92]. Recently, BDNF was also found to promote platelet activation, aggregation and secretion by activating a truncated form of the TrkB receptor [93]. However, assessments of BDNF levels in platelets have not been fully examined in AD patients. Questions about the role of pro-BDNF in platelet function and how the platelet ratio of pro-BDNF/BDNF related to neuronal levels remain unanswered.

\section{Methods of BDNF detection}

Several commonly used techniques and novel approaches have been reported for detecting BDNF levels [94]. BDNF gene expression is commonly measured by reverse-transcription polymerase chain reaction (RT-PCR) or quantitative real-time PCR (qPCR) [95]. While this technique is very sensitive, different cell types have unique transcriptomes and thus may possess distinct regulatory mechanisms. More recently, single-cell transcriptomic analysis has attracted great interest as a means to provide more accurate information on how individual cells respond to signals or when they acquire abnormal phenotypes [96-98]. In previous research, the expression profile of $\mathrm{BDNF} / \mathrm{TrkB}$ has been studied in various cell types and diseases by combining single-cell transcriptome analysis with overexpression, knockout, or knockdown of TrkB [99-102]. These studies clarified whether the protective mechanism of BDNF on neuronal survival or neurogenesis is mediated via TrkB; and the targets and effects of BDNF anterogradely transported from the cortex to other regions of the brain (such as striatum). Recently, a qRT-PCR protocol with HEX (hexachloro-fluorescein) and FAM (6-carboxyfluorescein) to detect the products of Val66- and Met66-coding BDNF allele has been developed for detection of BDNF Val66Met polymorphism [103].

Levels of the BDNF protein in brain tissues, blood, CSF and saliva can also be detected by sandwich enzymelinked immunosorbent assay (ELISA) [104]. There are four different types of commercial ELISA kits available for BDNF [105], including (1) kits designed to recognize pro-BDNF or mBDNF selectively; (2) antibodies against the carboxy-terminal of mBDNF; (3) monoclonal antibodies against mBDNF; and (4) monoclonal antibodies against recombinant mBDNF. The first class of ELISA kits are highly selective for each target, although the sensitivity to pro-BDNF in these kits is $0.5 \mathrm{ng} / \mathrm{ml}$, much lower than mBDNF $(5-8 \mathrm{pg} / \mathrm{ml})$. Thus, it is not easy to achieve accurate detection of pro-BDNF in body fluids using this method. The last three routinely used kits recognize both pro-BDNF and mBDNF. Given the divergent biological functions of pro-BDNF and mBDNF, highly sensitive ELISA kits must be developed to differentiate between the BDNF isoforms. Notably, Bockaj and colleagues recently demonstrated a fast and reliable method for point-of-care quantification of circulating BDNF levels that could potentially function as a diagnostic tool [106]. Briefly, they developed a device (EndoChip) capable of detecting BDNF using only small amounts of blood collected through a finger prick. The device is a polymerbased chip with nanopores and a wrinkled gold film (electrode/sensing layer). An increase in BDNF concentration $(0.1-2.0 \mathrm{ng} / \mathrm{ml})$ causes remarkable differences in redox current. Alternatively, the levels of BDNF in brain tissues, cell lysates and media of cultures have been measured by immunoprecipitation/western blot analysis, which can clearly distinguish between pro-BDNF and mBDNF [107, 108]. A reliable measurement of low levels of endogenous pro-BDNF can also be obtained by designing monoclonal antibodies specific for the pro-domain [109].

Techniques such as confocal microscopy are used to visualize the expression, secretion, and trafficking of BDNF. As a practical example, Sindbis viral infection of hippocampal neurons has previously been used to enable cultured neurons to selectively express constructs containing either valine BDNF (valBDNF) or methionine BDNF (metBDNF), followed by GFP [110]. Visualizing valBDNF-GFP or metBDNF-GFP fluorescence via confocal microscopy could then be used to identify the effects of these single nucleotide polymorphisms (SNP) on the expression, distribution, intracellular trafficking and activity-dependent secretion of BDNF in living neurons. While confocal microscopy provides excellent spatial resolution, it is not well suited for investigating real-time dynamic processes. As an alternative, lentivirus encoding BDNF-pHluorin, a reporter composed of fulllength (pro)BDNF and a pH-sensitive form of GFP, has 
also been used to investigate dynamic biological events such as the secretion of BDNF in primary cortical neurons [111, 112]. As a drawback, it is difficult to detect the reporter gene in intracellular vesicles because of the low $\mathrm{pH}$ in the lumen. Deacidification causes a rapid enhancement in fluorescence during exocytosis, which then decays because the cargo diffuses into the extracellular medium [111]. To address this, the spatiotemporal dynamics of BDNF exocytosis can be monitored using total internal reflection fluorescence time-lapse microscopy. A $B d n f$-Luciferase transgenic mouse model was also generated for high-throughput screening of candidate agents that activate endogenous BDNF expression in cultured primary cortical neurons [113, 114]. Taken together, the recent advances in these methods may help to examine further the transcription, translation, expression, secretion, transportation, biological function and therapeutic potential of BDNF in AD.

\section{The role of BDNF in AD Animal studies}

Different animal models are used to dissect many of the molecular and cellular mechanisms that drive the pathogenesis of AD. Currently, the most popular approaches employ various transgenic rodent models that exhibit amyloid and tau pathologies, such as Tg2576 [115], APP and presenilin 1 (APP/PS1) [116], Tau/APP [117], J20 [118], $3 \times \mathrm{Tg}$ [119] and $5 \times$ FAD [120] transgenic mice, as well as McGill-R-Thy1-APP [121] transgenic rats. Similarly, these transgenic models have been previously used to investigate how the expression and regulation of BDNF are altered in the context of AD-like pathologies, and how intervention strategies or therapeutic agents that enhance BDNF could serve as a potential treatment for $\mathrm{AD}[117,122,123]$. For example, previous studies have shown that APP/PS1 transgenic mice that express the mutated variant of human APP and PSEN1 genes linked to familial AD, namely, the Swedish APP KM670/671NL mutation (APPswe) and PSEN1 L166P mutation, exhibit memory deficits and impaired hippocampal neurogenesis in adulthood [124]. Facilitating social interaction by housing APP/PS1 mice with wild-type mice reverses the deficits in memory and neurogenesis, an effect that can be mimicked by overexpressing BDNF or blocked by ablating it. Gene delivery or overexpression of BDNF has also been shown to enhance hippocampal LTP and inhibit the effect of $A \beta$ and tau on cell loss $[88,125,126]$. Furthermore, BDNF treatment decreases the generation of toxic $A \beta$ by promoting the $\alpha$-secretase processing of APP in transgenic APP/PS1 mice, suggesting it may be able to modulate the amyloidogenic pathway directly [127].
In loss-of-function experiments, triple transgenic APP/ PS1/BDNF ${ }^{+/-}$mice exhibited an earlier onset of learning deficits and accelerated impairment in a two-way active avoidance task compared with APP/PS1 or $\mathrm{BDNF}^{+/-}$ mice [128]. However, no change in plaque density was observed between APP/PS1 and APP/PS1/BDNF ${ }^{+/-}$ mice [128]. Similarly, by crossing $\mathrm{BDNF}^{+/-}$mice with APPdE9 mice (bearing APPswe and PSEN1 $\triangle$ E9 mutations), researchers found that while the haploinsufficiency-induced decrease of BDNF impaired learning and memory, it did not alter amyloid pathology [129]. Aged triple transgenic mice $(3 \times \mathrm{Tg}$, bearing APPswe, MAPT P301L, and PSEN1 M146V mutations) have widespread $\mathrm{A} \beta$ plaques and neurofibrillary tangles [119]. Knockdown of $\mathrm{BDNF}$ in the aged $3 \times \mathrm{Tg} / \mathrm{BDNF}^{+/-}$mice led to a significant reduction of BDNF levels, but this did not appear to exacerbate $A \beta$ and tau pathology [130]. These results suggest that chronically reduced expression of $B D N F$ does not affect $A \beta$ and tau pathologies. On the other hand, Wang et al. reported that deprivation of BDNF/ TrkB indeed contributes to AD-like pathologies in wildtype mice [28]. Several possible causes may contribute to these conflicting results. First, there may be inherent differences in the animal models themselves. For example, compensatory processes may have occurred to respond to the chronically depleted levels of BDNF in the transgenic models. Second, decreased BDNF expression may reduce APP expression [131]. Third, there may be a dose-sensitivity window whereby the degree of BDNF knockdown could have a differing effect on $A \beta$ or tau pathologies. Lastly, BDNF may target the cellular and molecular pathologies downstream of $A \beta$ accumulation when exerting its therapeutic effects.

\section{Clinical investigations}

The first report on BDNF from studies in a clinical population came from Phillips and colleagues who found that BDNF mRNA was reduced in postmortem hippocampal samples obtained from $A D$ patients, suggesting that BDNF may have contributed to the progressive atrophy of neurons in AD [132]. Similar reductions in BDNF mRNA levels have been found in samples from the parietal cortex and entorhinal cortex of $\mathrm{AD}$ patients [133, 134]. Other reports have suggested that the decreased BDNF protein in the hippocampus, temporal cortex, and CSF in $\mathrm{AD}$ may correlate with the degeneration of specific neuronal populations, such as the basal forebrain cholinergic system [135-137]. Reduced levels of both pro-BDNF and mBDNF also occur early in the progression of AD [36]. However, it should be noted that although decreased BDNF levels in brain tissues have been associated with $\mathrm{AD}$ progression, there have been conflicting reports on whether BDNF levels are reduced in the CSF of $\mathrm{AD}$ 
patients. These conflicting results may be caused by a few different factors. First, most clinical studies have analyzed total BDNF concentrations by ELISA, which cannot reliably differentiate pro-BDNF from mBDNF. Second, the lower threshold for detection must be increased as there is a low baseline level of CSF BDNF [138]. Third, CSF BDNF levels also decrease during healthy aging, suggesting this may only serve as a prognostic biomarker for younger individuals with an elevated risk of developing AD [137]. These limitations should be addressed before $\mathrm{BDNF}$ is used as a promising biomarker for AD diagnosis in the clinical setting.

Efforts to determine whether plasma BDNF levels can serve as a blood-based biomarker in $\mathrm{AD}$ have received increasing attention over the past decade [139-141]. Blood sample collection is minimally invasive and far more suitable for detecting and monitoring AD pathologies in healthcare settings than existing methods that require CSF or PET analyses. However, previous studies on plasma BDNF levels in AD patients have conflicting results. While some studies reported that the peripheral BDNF levels in AD patients were decreased [138, 142-144], others found no difference or even enhanced BDNF concentrations in AD patients [145-147]. Many meta-analyses have been performed to systemically analyze the change of peripheral BDNF during the development and progression of AD. It has been reported that patients with $\mathrm{AD}$ have significantly lower peripheral blood BDNF levels than healthy controls [148]. A higher serum BDNF level has also been linked to a reduced risk of dementia [149]. When compared with the age- and sex-matched healthy controls, blood BDNF levels initially increase during the early stages of $\mathrm{AD}$ and then reduce in patients with moderate or severe AD [150]. The initial increase in blood BDNF levels could be caused by compensatory repair mechanisms that arise during the early stages of $\mathrm{AD}$. Then, as the severity of the disease progresses (such as Mini-Mental State Examination [MMSE] score $<20$ ), these compensatory mechanisms may begin to fail, resulting in decreased peripheral blood BDNF levels. The association between serum BDNF and AD progression has been linked to the rate of cognitive decline. Decreased serum BDNF levels are specifically associated with fast cognitive decline in $\mathrm{AD}$ patients (that is, a lower MMSE score $>4$ per year), rather than slow cognitive decline [140]. The association also occurs between the serum pro-BDNF levels and the hippocampal pro-BDNF levels, which are related to the hippocampal pTau expressions [151].

The evidence from clinical investigations suggests that BDNF could act as a biomarker and therapeutic target in $\mathrm{AD}$. However, several key questions remain to be answered. First, how do factors associated with altered peripheral BDNF levels and AD risk (i.e., age, lifestyle, and comorbid physical conditions) modulate plasma BDNF levels as the disease progresses? Answers to these questions could provide insights into the diagnostic value of peripheral BDNF and open up the door for personalized therapeutic strategies. Second, what factors must be considered when measuring plasma BDNF concentrations? For example, BDNF concentration in serum is over 100-fold higher than plasma concentrations due to the degranulation of platelets during the clotting process [90, 91, 152]. BDNF levels in the peripheral blood are also known to be regulated by other cells such as mononuclear and epithelial cells [153], and these regulatory mechanisms may be altered under certain conditions that could obscure any findings. Third, would the diagnostic validity of plasma BDNF levels be improved when combined with other blood-based biomarkers? Some researchers proposed composite biomarkers (i.e., serine/ threonine kinase, DYRK1A, BDNF, and homocysteine) to identify AD at an early stage [154].

\section{Genetic evidence}

Certain BDNF gene polymorphisms have a significant impact on hippocampal function and memory. The dbSNP: rs6265 SNP in the human BDNF gene is a common functional nucleotide polymorphism that leads to a methionine (Met) substitution for valine (Val) at codon 66 (Val66Met, G196A) [155]. The substitution of Val by Met modulates both the intracellular trafficking of proBDNF and the secretion of mBDNF [110, 156]. Further insight into this mechanism comes from studies demonstrating that the Val66Met SNP impairs the dendritic trafficking of BDNF mRNA by disrupting interaction of BDNF with translin [157] and disturbing the intracellular sorting and secretion of BDNF by blocking its interaction with sortilin [158].

Several lines of evidence have shown that the BDNF Met $_{66}$ allele exacerbates $A \beta$-dependent $A D$ pathogenesis and adversely impacts hippocampal function and human episodic memory [110, 159-162]. Since the $B D N F$ Val66Met has no relationship with the rates of change in cognitive decline among healthy adults with low $A \beta$, it has been proposed that high $A \beta$ levels coupled with Met $_{66}$ carriage may be used as prognostic markers in the preclinical stage of AD [163]. Further support comes from studies showing that the $B D N F$ Val66Met polymorphism decreases the hippocampal-medial prefrontal connectivity, increases the vulnerability of the memory network to $A \beta$, and worsens cognitive decline [164]. Among the elderly with normal cognition, those who carry BDNF Val66Met will experience faster cognitive decline and greater hippocampal atrophy [165]. APOE is a risk factor for late-onset 
AD. MCI patients carrying both the $A P O E \varepsilon 4$ and $B D N F$ Met alleles exhibit more obvious memory deficits, though no significant changes in brain structure are observed [165]. Moreover, the BDNF Met $_{66}$ allele is associated with increased CSF concentrations of total tau and increased pTau concentrations in mutation carriers [159].

Many findings suggest that the $B D N F \mathrm{Met}_{66}$ allele may exacerbate $\mathrm{AD}$-related pathologies. However, studies examining this relationship more closely suggest that this association may depend on the severity of the disease and the sex of the individual. It has been reported that the $\mathrm{Met}_{66}$ allele increased AD risk in females but not in males, suggesting that BDNF may be a sex-specific risk factor for AD [166-168]. Additionally, the transition from healthy cognition to cognitive impairment in $\mathrm{AD}$ can be characterized as a progression from subjective cognitive decline (SCD) during the preclinical stages to mild cognitive impairment (MCI) during prodromal stages, and then to dementia during the clinical stages of the disease. The Val66Met polymorphism increases the risk of progressing from $\mathrm{SCD}$ to $\mathrm{MCI}$, and from $\mathrm{MCI}$ to $\mathrm{AD}$, exclusively in women. The Met allele also diminishes the transition time from SCD to MCI [169]. Therefore, the influence of Val66Met polymorphism on $\mathrm{AD}$ varies by both sex and disease severity (or stage of the disease). Furthermore, the reduced levels of BDNF protein in the temporal cortex of $\mathrm{AD}$ patients are suggested to have no association with BDNF polymorphisms [135]. Genomewide association studies of AD have similarly shown that the $B D N F$ Val66Met is not a risk factor for $\mathrm{AD}$ [170]. These findings suggest that the BDNF Val66Met polymorphism may interact with events downstream of $A D$ pathogenesis, accelerating the progression of dementia in a subset of patients.

Ultimately, there are conflicting results regarding the association between the BDNF Met $_{66}$ allele and ADrelated risk and pathologies. Differences in these findings may arise because the targeted phenotypes of these studies are different, and the BDNF gene mainly manifests in the early stages of $\mathrm{AD}$. Other factors may influence the role of $B D N F$ Val66Met polymorphism in $\mathrm{AD}$, including ethnicity, age and sex. The BDNF Val66Met has linkage disequilibrium with other BDNF polymorphisms, such as C270T (rs2030324) and G712A, which may affect their interactions and downstream phenotypes, and participate in the occurrence and development of $\mathrm{AD}[171$, 172]. Altogether, though the current studies do not identify that mutations in the BDNF gene are a risk factor for $\mathrm{AD}$, substantial evidence supports the notion that BDNF may be a potential target for $\mathrm{AD}$ therapy. The association between BDNF Val66Met polymorphism and AD risk should be further examined in future studies.

\section{Potential mechanisms underlying BDNF's effect on AD}

Neuronal protective effects

Neurotrophins such as BDNF play an essential role in maintaining a functional nervous system in both healthy and diseased states. Under physiological conditions, the processing from pro-BDNF to mBDNF is important for neuronal development, neuronal survival, and synaptic plasticity. The mBDNF and its receptor, TrkB, are widely expressed in the developing and adult mammalian brains [173, 174]. The pathways associated with changes in neuronal excitability are triggered by the binding of $\mathrm{mBDNF}$ to TrkB, indicating that TrkB activation is crucial for controlling the survival, morphogenesis, and plasticity of neurons [175]. Moreover, mBDNF/TrkB elicits many other downstream intracellular signaling pathways, such as mitogen-activated protein kinase/extracellular signalregulated protein kinase (MAPK/ERK), PI3K, and phospholipase $\mathrm{C}_{\gamma}$ /protein kinase $\mathrm{C}\left(\mathrm{PLC}_{\gamma} / \mathrm{PKC}\right)[175-$ 177]. These signaling pathways are associated with activation of the transcription factor CREB that mediates the transcription of genes essential for synaptic plasticity [175]. For example, the BDNF/TrkB signaling-mediated hippocampal LTP is dependent on the recruitment of $\mathrm{PLC}_{\gamma}$, followed by phosphorylation of calcium/calmodulin kinase IV (CaMKIV) and CREB [176]. In turn, the expression of BDNF is modulated partially by the phosphorylation of CREB in a $\mathrm{Ca}^{2+}$-dependent manner [178]. Additionally, there is a $\mathrm{Ca}^{2+}$ response element (CRE) in the BDNF gene to mediate BDNF transcription. In postsynaptic neurons, $\mathrm{Ca}^{2+}$ influx promotes phosphorylation of CREB through binding to CRE, resulting in the activation of BDNF transcription [178]. BDNF transcription in these neurons is at least partially CREB-dependent, as mutation of CRE or blockade of CREB function leads to a massive loss of BDNF transcription [178].

Under pathological conditions such as AD, BDNF is involved in $A \beta$ accumulation, tau phosphorylation, neuroinflammatory response and apoptosis (Fig. 2). As discussed previously, AD-related deficits in memory processes are associated with reduced BDNF levels at the synapses. Specifically, $A \beta$ has been shown to impair the processing of BDNF in both an activity-dependent and an activity-independent manner. While $A \beta$ reduces the activity-dependent BDNF transcription by impairing CREB phosphorylation, $A \beta$-stimulated reductions in basal BDNF levels are associated with a decrease of CREB transcription [179]. This may be because that CREB phosphorylation alone is not sufficient to cause BDNF induction. CREB family member works cooperatively with other transcription factors, such as CaRF [52] 


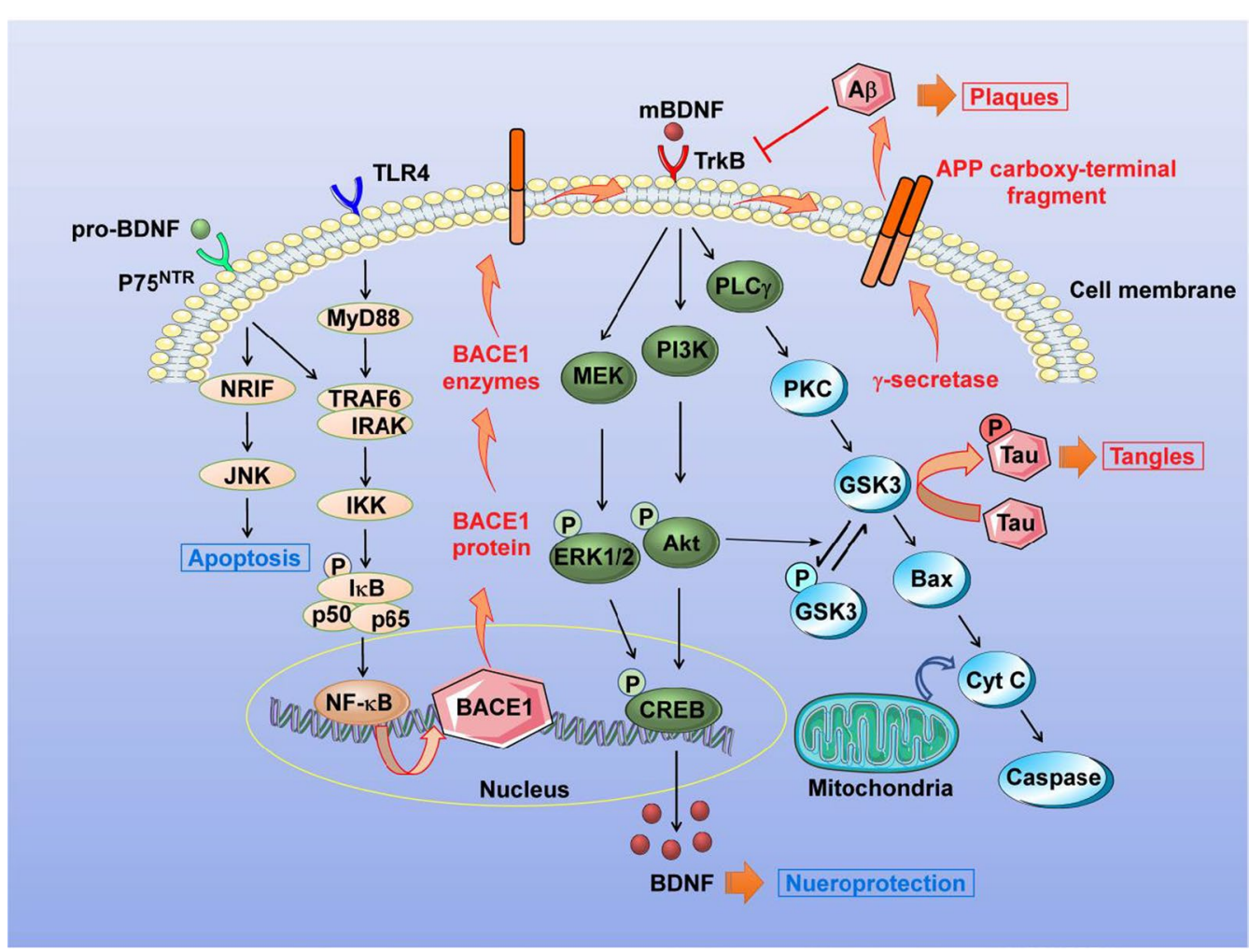

Fig. 2 BDNF-related signaling pathways in AD. The pathways related to neuronal excitability are triggered by the interaction between BDNF and TrkB, inducing its dimerization and autophosphorylation of tyrosine residues in the cytoplasmic kinase domain. MEK, PI3K and PLCY signaling pathways are activated to phosphorylate the transcription factor CREB that mediates transcription of genes essential for synaptic plasticity. GSK3 becomes inactive after phosphorylation, resulting in synthesis of glycogen in the liver cells. When GSK3 remains in its active form, it hyper-phosphorylates tau protein in nerve cells, resulting in the microtubule destabilization and neurofibrillary tangle formation and finally leads to AD. GSK3 also induces the overexpression of Bax to mediate apoptotic injury. Additionally, interaction between pro-BDNF and p75 $5^{\mathrm{NTR}}$ induces apoptosis through the JNK cascade. The activated NF-KB promotes the expression of $\beta$-secretase 1 (BACE1) gene, followed by the overexpression of BACE1 protein and enhanced BACE1 enzyme activity. AB is generated from APP by two enzymes: $\beta$-secretase (BACE1 is the major one) cuts APP first to produce a C-terminal fragments (CTFs), including C89 and C99. C99 is a membrane bound product. Then $\gamma$-secretase (including presenilin, nicastrin, $\mathrm{APH}-1$ and PEN-2) cleaves $\mathrm{C} 99$ at a position inside the cell membrane to generate the mature A $\beta$ peptide. In turn, $A \beta$ inhibits the expression of TrkB, leading to neurodegeneration. BDNF: brain-derived neurotrophic factor, $\mathrm{p} 75^{\mathrm{NTR}}$ : $\mathrm{p75}$ neurotrophin receptor, TrkB: tropomyosin receptor kinase B, AB: amyloid $\beta$, APP: amyloid $\beta$ precursor protein, BACE1: $\beta$-secretase 1; NRIF: NT receptor interacting factor, JNK: $c$-Jun N-terminal kinase, TRAF6: TNF receptor associated factor 6, IRAK: Interleukin-1 receptor-associated kinase, IKK: inhibitor of nuclear factor kappa-B kinase, IKB: inhibitor of NF-KB, NF-KB: nuclear factor-KB, TLR4: Toll-like receptor 4, MyD88; Myeloid differentiation primary response gene 88, TNF-a: tumor necrosis factor-a, MEK: mitogen-activated protein kinase kinase, ERK1/2: extracellular signal-regulated protein kinase 1/2, CREB: CAMP-response element binding protein, PI3K: phosphoinositide 3-kinase, Akt: protein kinase B, PLCY: phospholipase $C_{\gamma^{\prime}}$ PKC: protein kinase C, GSK3 3 : glycogen synthase kinase-3ß, Cyt C: cytocheome C

and myocyte enhancer factor 2 (MEF2) family members [180], to mediate BDNF transcription. Further knowledge will be needed to characterize the mechanisms in depth.

\section{Inhibition of tau phosphorylation}

NFTs formed by hyperphosphorylated microtubuleassociated protein tau are one of the neuropathological hallmarks of $\mathrm{AD}$. In primary neurons and $\mathrm{AD}$ animal models, the overexpression or hyperphosphorylation of tau decreases BDNF expression, and in turn, BDNF regulates the expression, phosphorylation and distribution of tau [181, 182]. Overexpression of human tau in hTau (heterozygous mouse tau-knockout) and 8c-het (homozygous mouse tau-knockout) transgenic mice dramatically reduces the BDNF level [181]. Overexpression of A $\beta$ in APP23 mice results in a reduction of BDNF mRNA, while APP23 $\times$ Tau-knockout mice show rescued BDNF levels and have no significant difference from the non-transgenic group [181]. These results indicate that overexpression of tau is responsible for BDNF downregulation, and knockout of tau may rescue BDNF levels. 
To clarify the interaction between BDNF and tau, Xiang et al. demonstrated that BDNF depletion promotes tau proteolytic cleavage by provoking $\delta$-secretase activation [183]. The subsequently generated tau N368 fragment binding to the TrkB receptor C-terminal tail, a site of PLC- $\gamma 1$ binding, antagonizes BDNF/TrkB neurotrophic signaling and induces neuronal cell death. Furthermore, deprivation of $\mathrm{BDNF} / \operatorname{Trk} \mathrm{B}$ promotes phosphorylation of the Janus kinase 2/signal transducer and activator of transcription 3 (JAK2/STAT3) pathway and activation of CCAAT/enhancer-binding protein $\beta /$ asparagine endopeptidase $(C / E B P \beta / A E P)$, resulting in the expression of $\delta$-secretase [28]. In the Tau-P301L transgenic zebrafish model, significant down-regulation of BDNF is observed, which occurs in a TrkB receptor-independent manner at as early as $48 \mathrm{~h}$ after the Tau-P301L zebrafish embryos are fertilized [184]. BDNF knockdown leads to defective axonal development and neuronal cell death, which can be rescued by exogenous BDNF treatment. In TauP301L larvae, however, supplementation of exogenous BDNF repairs primary axonal growth and motility, but it does not prevent neuronal apoptosis. Treatment with a TrkB agonist, 7,8-dihydroxyflavone, completely rescues the locomotor phenotype of Tau-P301L larvae. Accordingly, reduction of BDNF is an early consequence of tauinduced neurotoxicity, and that the BDNF/TrkB signaling is necessary to protect against the tau-induced neurodegenerative effects. Furthermore, long-term treatment strategies targeting BDNF or TrkB may provide additional protection against neuronal loss and cell death. The pro-BDNF is also associated with the occurrence and development of AD. First, the pro-BDNF level in AD cortices is lower than that in healthy controls, which is consistent with the report from Peng et al. [36]. Second, the reduced expression of hippocampal TrkB receptors is linked to higher $\mathrm{p}$-tau levels. Third, higher serum levels of pro-BDNF are correlated with lower pro-BDNF and higher p-tau in the hippocampus [151]. Thus, the total BDNF, mBDNF, pro-BDNF and TrkB receptors are closely associated with tau pathology, and more extensive studies are required to better understand the mechanisms linking BDNF/TrkB signaling to tau pathology, including the role of each BDNF isoform in different diseases and in various tissue specificities.

GSK3 is a key molecule linking BDNF to tau. As shown in Fig. 2, the effect of BDNF on GSK3 activity has been evaluated in the Akt and PKC signaling pathways. After BDNF binds to TrkB, the downstream PI3K is activated, followed by phosphorylation of Akt, which further phosphorylates GSK3 $\alpha$ and GSK3 $\beta$ to inactivate the GSK3 proteins [185]. In addition, GSK3 phosphorylation is PKC-dependent. Inhibition of GSK3 increases BDNF mRNA and protein levels in cultured cortical neurons
[186]. The biological activity of tau is modulated by its degree of phosphorylation. GSK3 $\beta$ acts as a critical kinase for tau protein phosphorylation [187]. It has been reported that the full-length GSK3 $\beta(47 \mathrm{kDa})$ is significantly decreased, and truncation of GSK3 $\beta(41 \mathrm{kDa})$ is markedly increased in the AD human brain when compared with healthy control cases [188]. The GSK3 $\beta$ truncation is positively correlated with the site-specific phosphorylation of tau (including Ser199, Thr202, Thr205, Thr212, Thr217, and Ser396). The mechanism is that excitotoxic conditions lead to a $\mathrm{Ca}^{2+}$-induced overactivation of calpain I, which cleaves GSK3 $\beta$ at Ser381Ser382, resulting in enhanced kinase activity and the subsequent phosphorylation of tau proteins [188]. These results indicate that increasing GSK3 $\beta$ expression will decrease BDNF mRNA levels, and that enhancing GSK3 $\beta$ enzyme activity will promote tau phosphorylation. However, some conflicting results question the efficacy of BDNF as a mediator of tau phosphorylation. In taumutant P301L transgenic mice, the BDNF gene delivery attenuates cognitive deficits, promotes synaptic degeneration, but has no effect on tau hyperphosphorylation or the activity of tau-related enzymes, including GSK3 $\beta$ and phosphatase PP2A [189]. Inherent differences between the types of experimental models may partially account for the contradictory findings. Phosphorylated tau may quickly respond to BDNF supplementation in vitro. However, in vivo BDNF treatment is a long-term process. Further studies are required to examine the mechanism of BDNF on tauopathies in humans and animal models.

\section{Reduction of $A \beta$ generation}

$A \beta$ is generated from proteolytic cleavage of APP through the amyloidogenic pathway [190-193]. Under physiological conditions, APP is predominantly cleaved via the non-amyloidogenic pathway, which occurs by $\alpha$-secretase cleavage to generate the soluble $\alpha \mathrm{APP}$ fragment (sAPP $\alpha)$ and the membrane-anchored C-terminal fragment (CTF) C83. C83 is then cleaved by $\gamma$-secretase, resulting in the release of the nontoxic P3 $\alpha$ fragment and CTF $\gamma$ [194197]. APP can also be cleaved by $\beta$-secretase (BACE1) at the Glu11 site or by $\theta$-secretase (BACE2) to produce $\mathrm{C} 89$ and $C 80$, respectively, precluding $A \beta$ generation [193, 198-200]. Alternatively, APP undergoes amyloidogenic cleavage by BACE1 at the Asp1 site to release sAPP $\beta$ and C99. Next, $\gamma$-secretase cleaves the C99 to release toxic $\mathrm{A} \beta_{1-40}$ or $\mathrm{A} \beta_{1-42}$ [201].

Experimental studies suggest that $A \beta$ deposition is closely associated with the loss of BDNF. Intracerebroventricular injection of $A \beta_{1-42}$ oligomers downregulates BDNF mRNA and protein expression [202]. The $A \beta$ oligomers impair the axonal BDNF retrograde trafficking, thereby adversely impacting BDNF signaling and 
synaptic function [203]. Oligomeric $A \beta_{1-42}$ stimulation also significantly reduces the overall expression of $B D N F$ by specifically downregulating BDNF transcripts IV and $\mathrm{V}$ [204]. In turn, the interruption of BDNF signaling triggers hippocampal amyloidogenesis by promoting the accumulation of PS1 N-terminal catalytic subunits, APP $\mathrm{C}$-terminal fragments, and abnormal aggregation of $\mathrm{A} \beta$ [205]. Moreover, full-length TrkB modulates APP levels by increasing APP transcription [206]. In turn, BDNF can regulate the surface expression of full-length TrkB in a time-dependent manner. This effect was first demonstrated in hippocampal and neuronal cultures, where the level of TrkB on the plasma membrane was found to initially increase following treatment with BDNF (within seconds) and then decrease following prolonged treatment (minutes to hours) [207].

The BDNF/TrkB signaling can directly modulate APP processing. For example, retinoic acid increases the expression of TrkB in neuronal cultures [208]. Combining retinoic acid treatment with BDNF shifts APP processing to $\alpha$-secretase, promoting the release of sAPP. Similarly, treating APP/PS1 mice with BDNF decreases the generation of toxic $A \beta$ by promoting the $\alpha$-secretase processing of APP [127]. By transfecting SH-SY5Y cells with GSTAPP in the presence of YFP-tagged TrkB wild-type or kinase death mutant (K572R), and then treating the cells with BDNF, Xia et al. found that BDNF induced TrkB to phosphorylate APP Y687 residue and APP trafficking to trans-Golgi network, resulting in the decrease of APP exposure to $\delta$-secretase cleavage. Thus, $\delta$-secretase cleaves TrkB, leading to the reduction of p-APP Y687 and alteration of APP trafficking [209]. Moreover, they reported that both TrkB (N365 and N486/489 residues) and APP can be cleaved by $\delta$-secretase in AD brains, resulting in the mitigation of TrkB signaling and the reduction of p-APP Y687. Therefore, both BDNF/TrkB pathway and $\delta$-secretase may be potential targets for $A D$ treatment [210]. The Sortilin Related Receptor 1 (SORL1/ SORLA) and its SNP are highly associated with the occurrence and development of late-onset $\mathrm{AD}$ and have been shown to affect the metabolism, trafficking, and processing of APP [211-213]. BDNF activates the transcription of Sorla via the ERK pathway, thereby diminishing the production of $A \beta$ [214]. On the other hand, Sorl1-knockout mice exhibit lower levels of BDNF and fewer deposits of $A \beta$ in the brain [215]. SORL1 inhibits the degradation of APP by $\gamma$-secretase, resulting in the reduction of toxic $A \beta$. Moreover, the expression of BDNF is decreased via the SORL1-NMDAR-CREB-BDNF signaling pathway [216]. These findings suggest that the beneficial effects of BDNF on APP processing are at least partly dependent on SORL1. However, in human pluripotent stem cells, depletion of SORL1 contributes to AD by selectively impairing the neuronal endosomal trafficking of APP, which is independent of APP processing [211]. This discovery seems to echo the sentiment that risk factors for late-onset $\mathrm{AD}$ may be characterized moreso by deficits in trafficking and clearance than production and processing.

It is worthwhile to mention that another neurotrophin, nerve growth factor (NGF), has been shown to regulate APP processing via an independent set of receptors (TrkA and $p 75^{\mathrm{NTR}}$ ) and sortilin [217]. Advanced $\mathrm{A} \beta$-amyloidosis is characterized by the impaired metabolism of NGF and a concomitant loss of cholinergic synapses and neuronal phenotype in the basal forebrain of McGill-R-Thy1-APP transgenic rats [218]. This suggests that deficits in NGF metabolic signaling may contribute to the high vulnerability of cholinergic neurons in AD. There is also a difference in BDNF and NGF signaling to regulate APP processing. The APP-TrkA binding sites encompass both $\alpha$ - and $\beta$-secretase cleavage sites. When NGF binds to TrkA, it may drive APP metabolism in a manner that promotes processing via the non-amyloidogenic pathway [219]. The phosphorylation of APP at Threonine 668 (T668) increases the gene expression of BACE1 [220]. NGF blocks the T668 phosphorylation of APP and promotes the normal metabolism through TrkA signaling [221, 222]. NGF promotes the binding of TrkA to APP, thereby hindering the interaction between APP and BACE1. The NGF/TrkA/APP pathway is linked to the Tyr kinase signaling adaptor SH2containing sequence $C$ [221]. NGF binding with TrkA can mediate the phospholipase $\mathrm{C}-\gamma$ (PLC- $\gamma$ ) [223], ERK [224], and PI3K/Akt signaling pathways [225]. TrkA and p $75^{\text {NTR }}$ receptors share the same binding site in the APP juxta-membrane domain [226]. APP (597-695) is necessary for the interplay between APP and $\mathrm{p} 75^{\mathrm{NTR}}$ [226]. The binding of sortilin to TrkA promotes TrkA anterograde axonal transport, strengthens neurotrophic factor signal transduction, and interacts with APP to affect its metabolism [227].

NGF is essential for the survival of cholinergic neurons, and it is a potential therapeutic target for AD. Results of a phase $1 / 2$ clinical trial demonstrated that while delivering adeno-associated virus (AAV)-NGF into the cholinergic neurons of the nucleus basalis of Meynert of AD patients is safe, it has no benefit on cognitive improvement [228]. However, a follow-up analysis on the autopsied brains of three trial participants revealed that NGF failed to reach the cholinergic neurons in any of the injections. Therefore, further studies are needed to determine the clinical efficacy of NGF gene therapy [228]. Tuszynski et al. also reported that the $B D N F$ gene therapy might be better than NFG in AD treatment [229]. BDNF is widely expressed in the cortex and is more potent than NGF to 
rebuild neural circuits, ameliorate cell loss and improve neuronal function in AD. Additionally, targeted delivery of the $B D N F$ gene into the entorhinal cortex or hippocampus may be more effective for $\mathrm{AD}$ treatment [230].

\section{Interaction with inflammatory factors}

Lipopolysaccharide (LPS) is an endotoxin from the outer membrane of Gram-negative bacteria. Direct injection of LPS into the brain or periphery is a popular method used to study and induce inflammation that activates both the neuroimmune and neuroendocrine systems [231]. Administration of either pro-inflammatory cytokines or LPS leads to a remarkable decrease in BDNF gene expression [232]. The neuroinflammation- and LPS-induced memory deficits have been attributed to the activation of TLR4/NF-kB signaling and inhibition of CREB/BDNF expression in $A D$ models [233]. Inflammation significantly decreases BDNF transcription. A single intraperitoneal injection of $E$. coli has been shown to profoundly reduce the expression of different $B D N F$ transcripts in the hippocampus of aged rodents [234]. More specifically, aged rats exhibit a loss of the exon IV-specific transcript in CA1, exon II- and VI-specific transcripts in CA3, and exon I- and II-specific transcripts in the dentate gyrus [234]. These effects may be mediated by $\mathrm{C} /$ $\mathrm{EBP} \beta$, an inflammatory cytokine-activated transcription factor, which has been shown to bind to the BDNF promoter and repress its transcription [235]. In turn, BDNF deficiency has also been shown to promote C/EBP $\beta$ activation by stimulating the JAK2/STAT3 signaling pathway, indicating that these mechanisms may be coupled together [28]. Importantly, triggering this cascade either via $B D N F$ depletion or $C / E B P \beta$ activation could accelerate $A \beta$ and tau pathology in $3 \times \mathrm{Tg}$ mice, suggesting that $\mathrm{BDNF} / \mathrm{TrkB}$ reduction and $\mathrm{C} / \mathrm{EBP} \beta$ activation may work cooperatively to drive $\mathrm{AD}$ pathogenesis. Although BDNF links inflammation and neuroplasticity, the systemic inflammatory response affects not only BDNF but also NGF and neurotrophin-3 (NT-3) [232]. More evidence is needed to determine how inflammation specifically alters the transcription of $B D N F$ and the underlying mechanisms.

Our previous studies have confirmed that the expression of NF- $\kappa B$ is increased in the brains of AD patients, and that NF- $\mathrm{KB}$ signaling up-regulates human BACE1 gene transcription to facilitate $\beta$-secretase cleavage and $A \beta$ generation (Fig. 2) [15]. Furthermore, we have shown that the GSK3 $\beta$-mediated BACE1 gene expression is dependent on NF- $\mathrm{kB}$ signaling, and that inhibition of GSK3 $\beta$ can decrease BACE1 expression and reduce Alzheimer-associated phenotypes [236]. The sAPP $\beta$ has also been shown to activate NF- $\mathrm{KB}$, resulting in the production of inflammatory cytokines (i.e., IL-6) in microglial cells and hippocampal neurons [237]. Collectively, these data suggest that the NF- $\mathrm{kB}$-mediated $\mathrm{A} \beta$ production and neuroinflammation may be potential targets for $\mathrm{AD}$ treatment. To that end, a few key points regarding the interaction between BDNF and NF- $\mathrm{KB}$ in AD should be kept in mind. First, since the $B D N F$ gene contains binding sites for activated NF- $\mathrm{kB}$ in the $5^{\prime}$ flanking region of exon IV, NF-kB plays an important role in BDNF-induced neuroprotection $[40,238]$. Specifically, activated NF- $\kappa B$ can translocate into the nucleus, where it binds to the promoters on transcripts I, III and IV of the $B d n f$ gene to initiate BDNF transcription [53, 238-240]. Second, exogenous BDNF promotes the TrkB-mediated NF- $\mathrm{kB}$ activation, which is beneficial for neuronal survival [238]. BDNF treatment has been shown to dose-dependently increase the mRNA and protein expression of Bcl-xL in the rat hippocampus through phosphorylation of NF- $\mathrm{KB}$ at the Ser529 site and the activation of casein kinase II [241]. Alternatively, blocking NF- $\mathrm{kB}$ activation suppresses BDNF-induced late-phase LTP [242]. The crosstalk between BDNF and NF- $\mathrm{kB}$ is critical for neuroprotection. However, chronic NF- $k B$ activation will lead to neuroinflammation, followed by neurodegeneration and cognitive impairment. Further examination of the neuroprotective concentrations of BDNF and the period of NF- $\mathrm{kB}$ activation is warranted. These findings would provide key insights into the clinal relevance of BDNFtargeting therapies in AD.

\section{BDNF-targeting strategies for AD modification}

Numerous studies have suggested that therapeutically increasing BDNF levels in brain regions important for memory and cognition may lead to improved clinical outcomes of AD patients [183, 243]. However, the delivery route of exogenous BDNF is limited due to its short plasma half-life and the limited diffusion across the blood-brain barrier (BBB) [244-246]. As a result, many intervention strategies have sought to restore BDNF level and signaling endogenously. These therapies target BDNF either by directly promoting its endogenous production (i.e., via $B D N F$ gene therapy) or indirectly enhancing BDNF signaling and secretion in the brain (i.e., via exercise). In the following section, we further discuss the current therapeutic approaches to targeting BDNF in the treatment of AD (Fig. 3). Several review papers have already presented a comprehensive overview and analysis of the outcome of clinical trials involving various BDNF-targeting pharmacological treatments in neurodegenerative diseases [247-249]. Therefore, we specifically focus on providing novel insights into the molecular mechanisms underlying current BDNF-targeting therapeutic strategies in AD. We will explain how recent preclinical and clinical research findings have inspired new 


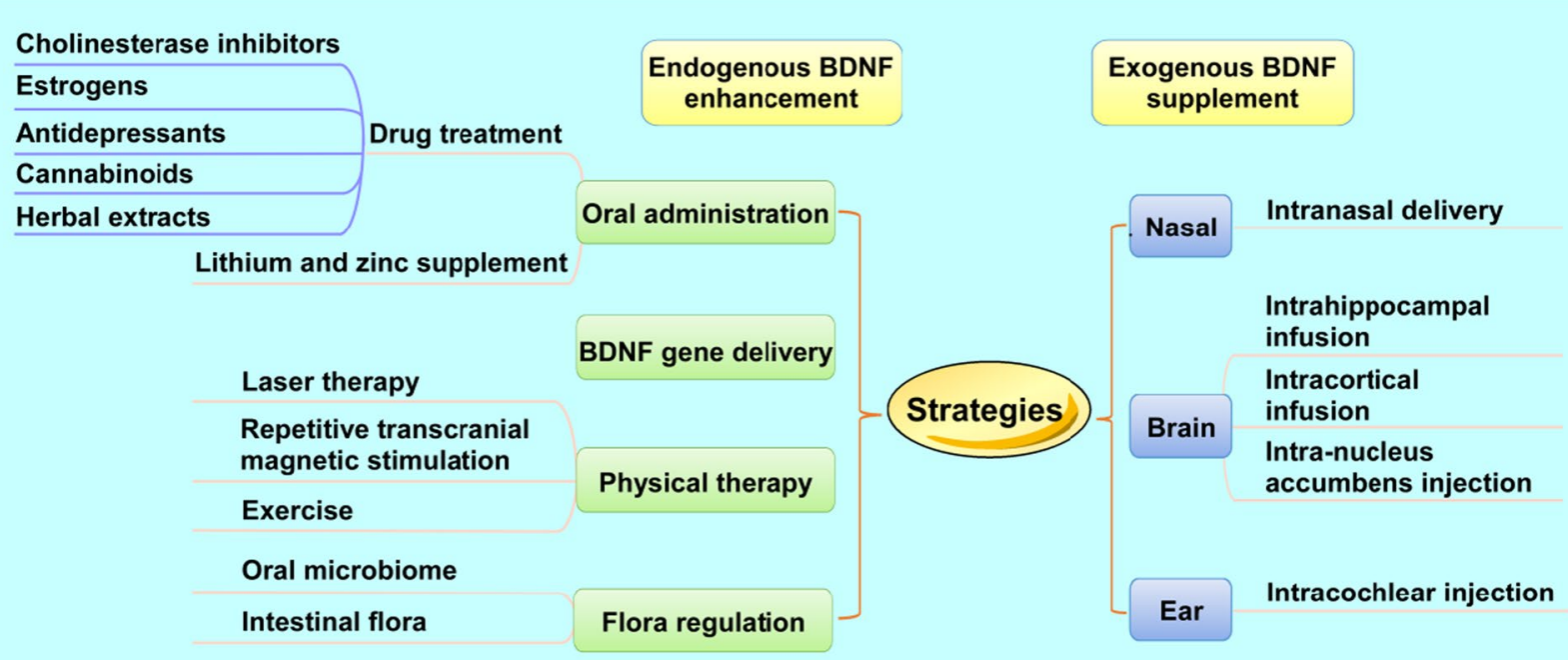

Fig. 3 Strategies to improve BDNF levels in the brain. The current therapeutic approaches to enhancing BDNF concentration include endogenous BDNF enhancement and exogenous BDNF supplement. The former one aims to induce endogenous BDNF production or secretion. The latter one attempts to release BDNF in situ or further transport it into target brain regions

approaches to administering or modulating BDNF signaling, and the potential of BDNF as a diagnostic biomarker of or a therapeutic agent for AD.

\section{Improvement of endogenous BDNF production Drug treatment}

Currently, the FDA-approved drugs for AD include acetylcholinesterase inhibitors (AChEIs), an NMDAR antagonist, and the IgG1 anti-A $\beta$ monoclonal antibody (aducanumab). Approved AChEIs-including donepezil, galantamine, and rivastigmine, and the approved NMDAR antagonist (memantine) are symptomatic treatments that do not treat the underlying pathological cause of AD. Thus, aducanumab is the first and only diseasemodifying drug licensed for AD [6]. Most (if not all) of the drugs approved for $\mathrm{AD}$ treatment are known to influence the level of BDNF. In the following section, we will discuss molecular mechanisms underlying the association between BDNF signaling and drugs that have been approved for the treatment of AD.

\section{AChEIs}

A pathological hallmark of $\mathrm{AD}$ is that the cholinergic neurons of the basal forebrain are the first to fall prey to neurodegeneration [250]. AChEIs such as donepezil enhance cholinergic transmission and have been approved for the treatment of $\mathrm{AD}$ on the basis that they were found to delay the progression of cognitive decline in clinical trials. Notably, experimental studies have also shown that AChEI administration enhances the cholinergic tone in cholinergic neurons of the basal forebrain in mice, and that these effects are mediated by the activation of Trk receptors [251]. Similarly, BDNF promotes the survival and differentiation of cholinergic neurons in the same region of the rat brain [252]. These findings suggest that AChEI administration may have some neuroprotective effects in $A D$, which is conferred by the activation of neurotrophic signaling. In support, clinical studies have shown that the AChEI donepezil increases the level of CNS BDNF in AD patients [208].

As the neuroprotective effects of AChEIs are transient at best, a more provocative question is what mechanism governs their regulation of neurotrophin signaling. One possible explanation comes from studies on the effect of AChEIs in other neurodegenerative conditions. Administration of donepezil has been found to protect against vascular dementia by inhibiting the nuclear translocation of histone deacetylase 6 (HDAC6) and the binding of HDAC6 to BDNF promoter IV, which enhances $B D N F$ expression [253]. HDAC6 is upregulated in the cortex and hippocampus of AD patients [254, 255]. The consequences of HDAC6-BDNF binding have previously been studied in the context of other risk factors for AD. For example, ApoE4 has been shown to promote the nuclear translocation of HDACs in human neurons, resulting in decreased BDNF expression [255]. Specifically, ApoE4 has been found to induce HDAC6 to bind to $B D N F$ promoter IV, thereby inhibiting the expression of BDNF. Therefore, these findings suggest that inhibiting the HDAC6-BDNF binding in the cortex could increase BDNF levels and exert neuroprotective effects in AD. Another key question is what BDNF signaling pathways do AChEIs activate. Previous experimental studies have 
shown that administration of donepezil or galantamine in mice enhances the production of BDNF, thereby suppressing neuronal apoptosis via the activation of PI3K/ Akt and ERK pathways and phosphorylation of CREB [256]. However, it is worth re-stating that the neuroprotective effects of AChEIs do not prevent the progression of AD. Therefore, although these studies suggest that AChEIs can exert neuroprotective effects via enhancing endogenous BDNF levels, more investigations are required.

\section{Antidepressants}

Depressive symptoms are common in patients with cognitive impairment. The overall prevalence of depression in $\mathrm{AD}$ patients is up to $50 \%$ [257-259]. A largescale longitudinal study has found that the depressive symptoms in $\mathrm{AD}$ patients reflect prodromal features of dementia, and dementia is not likely a consequence of long-term depression [260]. This suggests that the pathological mechanisms may differ from those of depressive symptoms in adulthood-that is, in adults without dementia. Despite these differences, antidepressants are still the only treatment option available for the depressive symptoms in dementia[261]. In general, the effect of antidepressants on BDNF expression is not well understood. Several studies suggest that antidepressants like the selective serotonin reuptake inhibitor (SSRI) fluoxetine increase BDNF levels and are dependent on normal TrkB signaling to elicit their behavioral effects $[262,263]$. This implies that the therapeutic efficacy of SSRIs may be dependent upon activation of the BDNF/TrkB pathways. However, other studies have reported that certain SSRIs (i.e., fluoxetine, paroxetine, and sertraline) regulate the expression of BDNF mRNA in a dose- and time-dependent manner, such that the acute treatment downregulates BDNF expression, whereas chronic treatment upregulates it $[264,265]$. One possible explanation for this effect is that the bi-phasic shifts in BDNF regulation may be caused by differences in the expression pattern of individual BDNF exons. For example, $4 \mathrm{~h}$ after systemic injection of paroxetine, the expression of $B D N F$ exon IV was found to be selectively downregulated in the rat hippocampus [266]. In rats, neuronal activity has been shown to induce $B D N F$ exon IV expression as an immediate-early gene response, meaning $B D N F$ exon IV mRNA levels can exhibit fast and transient changes, whereas $B D N F$ exon I levels exhibit slower responses [266, 267]. Moreover, the therapeutic effects of paroxetine therapy are associated with polymorphism of the $B D N F$ gene, whereby carriers of the A allele of BDNF G196A polymorphism respond better to the paroxetine therapy in AD-related depression [268]. These findings support the notion that the ability of SSRIs to alleviate depression-related symptoms may be mechanistically linked to the BDNF/TrkB signaling. Nonetheless, although antidepressant drugs are a primary therapeutic approach currently used for the treatment of depression in AD patients, several systematic meta-analyses have suggested that SSRIs fair no better than a placebo in their ability to alleviate depressive symptoms in AD [269-272]. Additional high-quality randomized controlled trials with different drug types, dosages, and treatment periods should be conducted to confirm the effectiveness and safety of antidepressants in AD patients.

\section{Estrogens}

Estrogen and its receptor-mediated signaling pathways play vital roles in brain function. Both estrogen and BDNF have been shown to exert highly potent effects in the hippocampus, and thus have been explored as potential pathological mediatory and therapeutic targets in psychiatric conditions characterized by memory loss [273-275]. Estradiol $\left(\mathrm{E}_{2}\right)$ and BDNF have also been shown to help regulate many of the same biological functions, including modulating the activity of NMDARs (especially the $\mathrm{NR}_{2 \mathrm{~B}}$ subunit), promoting neurogenesis in the dentate gyrus, and facilitating the formation of memories [276, 277]. It has been reported that estrogen receptor $\alpha(E R \alpha)$ and BDNF are colocalized in CA3 subregion of the developing hippocampus [278, 279]. LPS-induced sickness behavior in mice shows that the role of BDNF in the response to neuroinflammatory challenge occurs in a sex-dependent manner [280]. Notably, LTP was found to produce an elevated inflammatory response in the cortex and hippocampus of wild-type males, as well as in $\mathrm{BDNF}^{+/-}$males. Alternatively, the elevated inflammatory response was found to occur only in $\mathrm{BDNF}^{+/-}$females (not in wild-type females) and only in the hippocampus. These results either suggest that the BDNF/TrkB signaling may be significantly more sensitive to inflammatory insults in the female hippocampus, or that the basal levels of BDNF are significantly higher in the hippocampus of females than males.

Inherent differences in the role of BDNF as an inflammatory mediator between males and females may arise because the $B D N F$ gene contains a sequence homologous to the estrogen response element [281], and the estrogen ligand-receptor complexes can bind to this sequence and rapidly increase BDNF transcription. Additionally, the aromatization of testosterone in male mice leads to high levels of $E_{2}$ in the brain [282]. As a result, the expression of BDNF can still be regulated through estrogen-mediated mechanisms in male mice [280]. However, the effects of exogenous $E_{2}$ treatment on various types of memory, and the estrogen-receptor pathways that are activated, have been shown to differ significantly in the hippocampus of male and female rodents [283]. Thus, these differences may be more related to the inherent differences in 
the expression of estrogen-receptors and downstream signaling pathways between males and females than to $\mathrm{E}_{2}$. In agreement, BDNF may act as a signaling molecule downstream of $E_{2}$ to mediate its structural and electrophysiological effects [284]. $E_{2}$ and BDNF have been shown to share several signal transduction pathways and transcription factors, such as AKT, ERK, MAPK, PI3K, $\mathrm{Src} / \mathrm{Fyn}, \mathrm{Ca}^{2+} /$ calmodulin-dependent protein kinase II (CaMKII) and CREB [285-288]. 17ß-estradiol administration induces the phosphorylation of $\operatorname{TrkB}$ and the expression of mature BDNF. However, $17 \beta$-estradiol activates hippocampal TrkB signaling independently of enhanced mBDNF [289]. Although many studies have highlighted the benefits of estrogen replacement therapy (ERT) among AD patients [290-293], the impact of ERT on the risk of cognitive decline remains highly contentious [294, 295].

\section{Cannabinoids}

Since the 1990s, the endocannabinoid system has received increasing interest due to its neuroprotective effect, and there is considerable evidence suggesting that targeting the cannabinoid system might be an effective strategy to protect against AD [296-298]. Cannabinoid type 1 (CB1) receptors primarily localize at nerve terminals and regulate excitatory and inhibitory neurotransmission [299]. In kainic acid (KA)induced excitotoxicity, inactivation of $\mathrm{CB} 1$ receptors can decrease the KA-induced BDNF mRNA levels, indicating that $\mathrm{CB} 1$ receptor-mediated neuroprotection may be, at least partially, dependent on BDNF expression [300]. The CB1 receptor is the main molecular target of endocannabinoids and phytocannabinoids, such as $\Delta^{9}$-tetrahydrocannabinol, extracted from the Cannabis sativa plant [301]. To better understand CB1/ BDNF interaction, healthy volunteers were intravenously injected with $\Delta^{9}$-tetrahydrocannabinol, which increased serum BDNF levels [302]. One possible explanation is that the $\mathrm{CB} 1$ receptor-mediated BDNF expression relies on the activation of the $B D N F$ gene promoter IV via the PI3K/Akt/mTORC1/BDNF pathway, which is capable of enabling rapid responses to promote BDNF production [303]. A major drawback of using $\Delta^{9}$-tetrahydrocannabinol as a therapeutic agent in $\mathrm{AD}$ is that it has been shown to produce deficits in cognitive behaviors that are impaired in $\mathrm{AD}$, such as learning and memory [304]. However, overexpressing BDNF in these regions protects against the cognitive deficits induced by adolescent cannabis exposure in mice [304]. In turn, BDNF-TrkB-CB1R interactions promote the release of endocannabinoids at cortical excitatory synapses [305]. Endogenous BDNF also plays a crucial role in cannabinoid-induced neurogenesis in the subventricular zone and hippocampal dentate gyrus [306]. Although cannabinoids have demonstrated the potential to offer multifaceted protection against $\mathrm{AD}$, further studies are warranted to determine whether chronic administration of cannabinoids can be considered a safe, effective, and low-cost therapy for AD.

\section{Herbal extracts}

Herbal extracts have been proposed as an alternative medicine to delay the progression of $\mathrm{AD}$, and some extracts have been shown to work through regulating BDNF. For example, resveratrol (3, 5, 4'-trihydroxytrans-stilbene) treatment ameliorates oxidative stress and cognitive deficits in a rat model of vascular dementia by increasing hippocampal BDNF expression [307]. Chronic administration of curcumin, the main active ingredient in turmeric, alleviates $\mathrm{AD}$-associated cognitive impairments via upregulating BDNF/ERK and Akt/GSK3 $\beta$ signaling in the hippocampus [308-311]. However, as the low bioavailability of curcumin limits its effect in humans, some modified curcumin formulations are being studied. Huperzine $\mathrm{A}$ is a novel lycopodium alkaloid extracted from the Chinese herb Huperzia serrata (Qian Ceng Ta). It belongs to the class of non-competitive AChEIs, and has an antagonistic effect on NMDARs [312]. Huperzine A improves oxidative glutamate toxicity by activating the BDNF/TrkB-dependent PI3K/Akt/mTOR signaling pathway [313]. Moreover, oral administration of huperzine A remarkably alleviates the neuronal damage and memory deficits by increasing the expression and levels of BDNF, which it accomplishes by phosphorylating the MAPK/ERK pathway [314]. However, in a recent phase II clinical trial in individuals with AD, huperzine A $(200 \mu \mathrm{g})$ failed to demonstrate clinical efficacy [315]. Other herbs, such as Ginkgo biloba, Panax ginseng, Rehmannia glutinosa Libosch., Polygala tenuifolia Willd, Salvia miltiorrhizae Bunge, and Ficus erecta Thunb. leaves, have also been investigated for therapeutic efficacy in AD and are considered as potential agents that could endogenously increase BDNF [316-323]. However, clinical evidence supporting the beneficial effect of herbal extracts on BDNF is still lacking.

\section{Lithium and zinc}

Lithium or zinc supplementation has been proposed as a novel $\mathrm{AD}$ therapeutic strategy due to their modulatory effects on multiple targets, including inflammation, autophagy, oxidative stress and mitochondrial dysfunction [324-327]. Notably, lithium treatment in $\mathrm{AD}$ patients has been shown to increase BDNF serum values $(\sim 30 \%)$ and mitigate cognitive impairment [328]. However, a negative correlation between lithium in drinking water and changes of AD mortality has been reported [329]. It should be noted that limitations in the experimental design may have caused these conflicting 
results. While using "microdoses" of lithium in mild cognitive impairment has yielded encouraging results, prolonged exposure and high doses of lithium treatment induce toxicity [330, 331]. For example, De-Paula et al. stimulated primary cortical and hippocampal neurons with therapeutic $(2 \mathrm{mM})$ and subtherapeutic (0.02 and $0.2 \mathrm{mM}$ ) dosages of lithium [332]. They found that administering low subtherapeutic doses of lithium $(0.02 \mathrm{mM})$ had a more extensive and robust effect on enhancing neuronal BDNF in different brain regions than the higher doses typically considered to be therapeutic. Interestingly, the role of lithium on BBB integrity in rats is dependent on their state of mental health. Whereas lithium treatment repairs the stress-induced BBB hyperpermeability in the hippocampus, it has the opposite effect in normal controls [333]. This suggests that lithium may interact with BDNF signaling pathways in a context-dependent manner.

Experimental research has shown that zinc interacts with multiple AD-related pathologies, some of which are directly mediated by BDNF. Zinc activates GPR39 metabotropic receptors in the CNS [334, 335]. GPR39 knockout mice display decreased CREB and BDNF levels in the hippocampus, but not in the frontal cortex [336]. This suggests that the expression of BDNF and CREB can only be modulated by zinc in certain brain regions. In zinc transporter-3 knockout mice, deficits in learning and memory were observed at 6 months of age, accompanied by decreased levels of TrkB, NMDAR2b, $\alpha$-amino-3-hydroxy-5-methyl-4-isoxazolepropionic acid receptor (AMPAR)2a, BDNF, and pro-BDNF [337]. Oral supplementation with zinc has been found to reduce $A \beta$ and tau pathology in the hippocampus, ameliorate mitochondrial dysfunction, reduce inflammation, inhibit oxidative stress, and increase BDNF concentration [338-343]. Importantly, zinc gluconate solution can cross the BBB to biosynthesize fluorescent zinc oxide nanoclusters, enabling high spatiotemporal bioimaging [344]. Therefore, zinc supplementation has the potential to play a dual role in AD treatment, neuroprotection and bioimaging, with the latter function being beneficial for evaluating its own efficacy. Results from nuclear magnetic resonance spectroscopy, light scattering, and cryo-electron microscopy indicate that $\mathrm{Zn}^{2+}$ binding to the BDNF Met66 prodomain and Val66 prodomain result in different conformational and macroscopic structures [345]. The substitution of Met66 results in a higher affinity of prodomain to $\mathrm{Zn}^{2+}$, owing to the His40-mediated stabilization of its multimeric structure. Moreover, the molecular mechanism of zinc deficiency-induced cognitive impairment is associated with hippocampal BDNF DNA methylation [346]. In brief, this suggests that the upregulation of BDNF may contribute to the neuroprotective effects of lithium or zinc in AD treatment.

\section{BDNF gene delivery}

The primary obstacle for $B D N F$ gene delivery is the selection and optimization of vehicles. Gene-delivery vehicles are mainly divided into two categories: synthetic carriers and recombinant viruses. The former includes polymers and liposomes, and the latter includes AAV, poxvirus, retrovirus, adenovirus, lentivirus and herpes simplex virus [347, 348]. Each delivery vector has its advantages and disadvantages. Polymer-based vectors used for $B D N F$ gene delivery include nanoparticles and hydrogels, among others [349]. Liposomes, which are natural biodegradable lipid bilayers, have great advantage of being similar to natural cell membranes. These nonviral carriers are based on the electrostatic interactions of cationic compounds that spontaneously complex with the BDNF plasmid. Polymer-based vectors exhibit a number of desirable traits, including ease of manufacturing, good safety and stability, low immunogenicity, and simple methods to incorporate target ligands [350, 351]. Unfortunately, the transfection efficiency of polymers as genedelivery vectors is several orders of magnitude lower than that of recombinant viruses. Thus, using a recombinant virus is still the primary means for $B D N F$ gene delivery [352, 353]. On the downside, viral vectors can induce inflammation and immune responses. Although the systemic immune response induced by systemic injection of viral vectors can be considered harmful in clinical trials, gene therapy of the brain is considered a relatively safe intervention strategy $[354,355]$.

$B D N F$ gene delivery exerts protective effects against $A \beta$ - and tau-related pathologies in AD. However, this treatment has no direct action on $\mathrm{A} \beta$ deposition and tau hyperphosphorylation. Treating J20 APP transgenic mice with Lenti-BDNF gene delivery for 5 months alleviated learning and memory deficits, ameliorated synaptic degeneration, and reduced atrophy [126]. However, this BDNF treatment did not change amyloid plaque density. Similarly, P301L mutant tau transgenic mice receiving recombinant human $B D N F$ gene using an AAV8 vector (AAV-BDNF) showed higher BDNF levels in the brain and improved memory deficits, although the AAV-BDNF gene delivery had no direct effect on tau protein, GSK3 $\beta$, and phosphatase PP2A [189]. On the other hand, BDNF supplementation indeed did successfully alleviate tauopathy-induced memory impairments by inhibiting neuron loss, synaptic degeneration, and impaired neurogenesis [189].

FDA-approved clinical trials of gene therapies have previously applied the AAV delivery strategy because it can target specific neurons in the brain regions, allowing 
widespread and stable expression of proteins with the safety of long-term treatment [356-358]. MR-guided infusion of AAV2-BDNF has been used to accurately and consistently target BDNF into the non-human primate entorhinal cortex [230]. Moreover, real-time MR imaging of AAV in the primate brain has been applied to accurately target intracranial structures and monitor the vector distribution in real-time during injection, thereby ensuring accurate targeting and spread of the vector [359]. Mutant AAVs have also been studied intensively. Delivery of BDNF using the tyrosine triple mutant AAV (tm-scAAV2) showed that the RNA expression of BDNF was about 300 times higher than that of the AAV group, and produced significantly higher proteins [360]. These methods enable more effective clinical translation to alleviate neuronal loss and prevent neuronal dysfunction in AD. In February 2021, a first-in-human Phase I clinical trial was launched to assess the safety and efficacy of modified AAV2-BDNF in the treatment of patients with AD or MCI [361]. The modified method for delivering BDNF will be more conducive for the delivery and distribution of BDNF into the entorhinal cortex and hippocampus.

Another approach for extended delivery of BDNF is the use of cell-based vectors, such as neural stem cells (NSCs), mesenchymal stem cells (MSCs), Schwann cells, CD4 $\mathrm{T}$ cells, and fibroblasts [362-365]. Direct BDNF gene delivery using MSC can overcome BBB blocking [366]. In previous research, BDNF-transduced bone marrow stromal cells (BMSCs) were transplanted by intravenous injection into irradiated female SJL/J mice for 8 weeks, resulting in a dramatic delay of experimental autoimmune encephalomyelitis onset and a reduction in overall severity [367]. On the other hand, these BDNF-producing cells only allow prolonged delivery of BDNF. Unfortunately, this method is difficult to be controlled precisely because the delivered BDNF dosages are dependent on cell survival and the stability of transfection. Another concern is that bone marrow-derived cells can migrate and reside in various nonhematopoietic tissues, therefore producing undesired effects. Thus, encapsulation of these BDNF-producing cells has been proposed to achieve continuous and local release. Encapsulated BDNF-producing fibroblasts in alginate-poly$L$-ornithine survived for at least one month after being transplanted into the site of cervical spinal cord injury in rats without immunosuppression [363]. Transfection of $B D N F$ gene recombinant MSCs via the adhesive peptide PPFLMLLKGSTR-modified scaffold improved cell survival and BDNF expression [368]. Alginate-based compositions have also been used to transport NSCs-BDNF and BMSCs-BDNF, maintaining long-term survival and proliferation of cells, as well as controlled release of
BDNF [362]. However, when delivering the $B D N F$ gene to APP transgenic mice after "disease onset", no protection against neuronal death was found following a 1.5-month therapeutic period [88]. This suggests that $B D N F$ gene delivery might not be a suitable therapeutic strategy for $\mathrm{AD}$ at all stages of the disease. As such, both early and long-term treatments may be required.

\section{Physical interventions}

Numerous physical interventions have been used to slow down the progression of $\mathrm{AD}$, such as laser therapy, repetitive transcranial magnetic stimulation (rTMS) and exercise [369-372]. Low-level laser treatment has been shown to alleviate $A \beta$-induced neuronal loss and dendritic atrophy by enhancing BDNF via ERK/CREB pathway activation [32]. In clinical trials, laser therapy has been successfully applied to treat prostate cancer, lung cancer, and acute pain [373-375]. However, it has not been translated well to AD patients. Novel approaches and more clinical studies are needed to evaluate the efficacy of laser therapy for Alzheimer's patients. rTMS is a non-invasive therapy for cognitive dysfunction in $\mathrm{AD}$ that acts by regulating neuronal excitability [376]. Different frequencies of rTMS target different brain regions, making it theoretically possible to improve cognitive deficits that are highly localized to a particular brain region [377]. Additionally, the cognitive benefits of rTMS have been associated with the induction of hippocampal BDNF expression. Low-frequency $(1 \mathrm{~Hz})$ rTMS increased hippocampal BDNF and NMDAR expression, and rescued deficits in LTP and spatial memory in an $A \beta_{1-42}$-induced toxicity rat model [378]. While this approach seems promising, changes in BDNF expression following rTMS treatment are difficult to detect in human brain tissues. The role of transcranial direct current stimulation (tDCS) in memory improvement has also been investigated as a possible intervention strategy that could promote the BDNF signaling pathway $[379,380]$. Mice subjected to tDCS stimulation exhibit enhanced acetylation at $B d n f$ promoter I that persists for one week, suggesting that remodeling of $B d n f$ may mediate the long-lasting effects of $\mathrm{tDCS}$ treatment. The action of $\mathrm{tDCS}$ varies in $\mathrm{Val} / \mathrm{Val}$ and Met/Met carriers [381]. Compared with $\mathrm{BDNF}^{\mathrm{Val} / \mathrm{Val}}$ mice, $\mathrm{BDNF}^{\mathrm{Met} / \mathrm{Met}}$ show decreased levels of $B D N F$ exon IV- and VI-specific transcripts, higher trimethyl-histoneH3-Lys27 binding to BDNF exon V, VI and VIII promoters, and impaired trafficking of BDNF VI transcript to CA1 and CA3 regions. Moreover, tDCS promotes synaptic plasticity via activity-dependent BDNF secretion [382].

Physical exercise, especially aerobic exercise, is beneficial for improving cognitive function. Studies have attributed many of the therapeutic benefits of exercise in $\mathrm{AD}$ 
to its effect on BDNF levels [383, 384]. Exercise increased the levels of pCREB, CaMKIV and BDNF in the CA1 and dentate gyrus of rats with intracerebroventricular infusion of $250 \mathrm{pmol} /$ day $\mathrm{A} \beta_{1-42}$ peptides for two weeks [385]. Four weeks of cardiovascular exercise in mice led to a remarkable increase in BDNF mRNA and protein levels, accompanied by an improved synaptic load in the dentate gyrus region [386]. Moreover, six months of voluntary physical exercise in $5 \times$ FAD mice rescued cognitive deficits by increasing astrocytic BDNF in the hippocampus [387]. Astrocyte-released BDNF plays a vital role in modifying the morphology and density of dendritic spines through a truncated form of the TrkB (TrkB T1) receptor [388]. The TrkB T1 receptor specifically localizes at $\mathrm{GFAP}^{+}$astrocytes to increase the number of $\mathrm{GFAP}^{+}$ astrocytes and improve $A \beta$ plaque-associated astrocytic morphology via the BDNF/TrkB signaling pathway [386]. A ten-week treadmill training program in APP/PS1 mice also restored hippocampal memory and dendritic arbor in the $\mathrm{CA} 1$ and $\mathrm{CA} 3$ regions via $\mathrm{BDNF} / \mathrm{TrkB}$ signaling pathways [389]. For obvious reasons, these results cannot be directly translated to humans. Exercise protocols used in animal studies are significantly different from those used in humans, and how exercise enhances BDNF levels during $\mathrm{AD}$ is still unknown. A meta-analysis by da Costa Daniele et al. found that exercise indeed promotes neurogenesis and reduces cerebral $\mathrm{A} \beta$ deposition in both healthy and dementia models [390]. However, evidence on exercise-induced inflammation, oxidative stress, metabolism and insulin sensitivity was scarce. Few studies have compared the beneficial effects among acute exercise, chronic exercise and high-intensity training in $\mathrm{AD}$. It has been demonstrated that aerobic exercise training is associated with increased polyunsaturated free fatty acids, decreased phospholipids, sphingolipids and ceramides, and alterations of gut microbiome metabolites-among which, approximate $30 \%$ of these metabolites are correlated with altered BDNF levels [391]. Thus, more direct evidence should be obtained to confirm how to use exercise to prevent or treat $\mathrm{AD}$.

\section{Regulation of microbiota}

A growing body of evidence has suggested that dysregulation of the human microbiome may contribute to the pathogenesis of AD. Poor dental status (i.e., loss of teeth) has been considered an early sign of $\mathrm{AD}$, and irregular tooth brushing is a high risk factor for dementia [392, 393]. P. gingivalis, T. forsythia, and T. denticola have been implicated as the main pathogens responsible for triggering inflammatory responses, and are associated with the pathogenesis of AD [394]. Gut microbial diversity is altered in AD patients [395]. Compared with healthy controls, AD individuals' microbiome show a lower abundance of Firmicutes and Actinobacteria, and a higher abundance of Bacteroidetes at the phylum level. Researchers have also identified 13 genera as potential CSF biomarkers of AD pathology. Among these, increased levels of Dialister and SMB53 are associated with less AD pathology. The abundance of Bacteroides, Turicibacter and SMB53 (family Clostridiaceae) is closely linked with CSF chitinase-3-like protein 1 in AD patients, supporting that the change of intestinal bacterial abundance may be correlated with glial activation in AD.

The BDNF level is closely related to the composition of gut microbiota. Compared to mice with normal gut microbiota, germ-free mice show lower mRNA and protein concentration of BDNF in the hippocampus, amygdala and cortex [396-398]. After transferring fecal microbiota, the levels of cognitive behavior, inflammatory mediators, microglia activity, and BDNF in recipient mice are similar to those of donor mice [399]. This mechanism is associated with the activation of AKT-GSK3 $\beta$ / $\beta$-catenin pathways. These results suggest that the CNS BDNF levels can be significantly disturbed due to the absence of gut microbiota and restored by microbiota transplantation. Furthermore, probiotic supplements are beneficial for up-regulating BDNF levels. VSL\#3 is a probiotic mixture composed of $8 \mathrm{Gram}$-positive bacterial strains. In aged (20-22 months) male rats, VSL\#3 treatment increases the abundance of Actinobacteria and Bacteroidetes, suppresses microglial activation, and enhances BDNF levels [400]. How might gut microbiota regulate BDNF levels? Some neurochemicals such as neurotransmitters, butyrate, short-chain fatty acids, and secondary bile acids, can be synthesized and recognized by gut microbiota [396, 401-406]. Accordingly, gut microbiota may influence CNS BDNF function by modulating the activity of these neurochemicals.

\section{Exogenous administration of BDNF}

Intravenous injection of BDNF is limited by its short plasma half-life (as short as $0.92 \mathrm{~min}$ ) and poor BBB permeability [244]. Thus, it is a challenge to evaluate the local distribution and action of BDNF in targeted brain regions. As shown in Table 1, some precise local delivery methods have been proposed, including intrahippocampal [407], intra-cortical [408-411], intranucleus accumbens [412], intranasal [413, 414], and intra-cochlear [415] infusions. Preclinical studies have shown that the brain-specific delivery of BDNF is beneficial for promoting the expression of BDNF receptors, inducing lasting potentiation of synaptic transmission, and increasing neurogenesis and ectopic granule cells $[416,417]$. However, exogenous BDNF delivery is hard to apply in clinical settings because most direct delivery methods of BDNF are highly invasive, and treatment 
Table 1 Local delivery routes of exogenous BDNF

\begin{tabular}{|c|c|c|c|c|c|}
\hline Delivery route & Model & Targeted brain region & BDNF delivery vehicle & Results & References \\
\hline \multirow[t]{4}{*}{ Intrahippocampal infusion } & Rats & Hippocampus & BDNF-containing PBS & $\begin{array}{l}\text { Improves lasting potentiation } \\
\text { of synaptic function in the } \\
\text { dentate gyrus }\end{array}$ & [416] \\
\hline & & DG & BDNF (no detailed information) & $\begin{array}{l}\text { Increases neurogenesis of DG; } \\
\text { most new neurons appear to } \\
\text { become granule cells }\end{array}$ & {$[417]$} \\
\hline & & VHPC & BDNF dissolved in PBS & $\begin{array}{l}\text { Increases excitability in infral- } \\
\text { imbic targets and supports } \\
\text { extinction memories }\end{array}$ & [411] \\
\hline & & CA1 & BDNF-containing sterile saline & $\begin{array}{l}\text { Reverses the impairments in } \\
\text { memory persistence; gener- } \\
\text { ates persistent LTM storage via } \\
\text { activation of ERK }\end{array}$ & [407] \\
\hline \multirow[t]{3}{*}{ Intracortical infusion } & Rats & dmPFC & BDNF-containing PBS & $\begin{array}{l}\text { Alleviates cocaine-induced } \\
\text { decrease in basal extracellular } \\
\text { glutamate; reduces cocaine- } \\
\text { mediated increase in extracel- } \\
\text { lular glutamate with the NAc }\end{array}$ & {$[408]$} \\
\hline & & & & $\begin{array}{l}\text { Inhibits cocaine-induced phos- } \\
\text { phorylation of ERK and CREB }\end{array}$ & [409] \\
\hline & Mice & vmPFC & $\begin{array}{l}\text { BDNF reconstituted in } 0.9 \% \\
\text { saline }\end{array}$ & $\begin{array}{l}\text { Rescues paradoxical reversal } \\
\text { learning enhancement } \\
\text { induced by stress or prefrontal } \\
\text { cortical damage }\end{array}$ & [410] \\
\hline $\begin{array}{l}\text { Intra-nucleus accumbens } \\
\text { injection }\end{array}$ & Rats & Nucleus accumbens & BDNF dissolved in saline & $\begin{array}{l}\text { Suppresses dopamine release } \\
\text { and dopamine-related behav- } \\
\text { iors induced by methampheta- } \\
\text { mine }\end{array}$ & {$[412]$} \\
\hline \multirow[t]{3}{*}{ Intranasal delivery } & Rats & Nasal cavity & $\begin{array}{l}{ }^{125} \text {-BDNF dissolved in sterile } \\
\text { PBS }\end{array}$ & $\begin{array}{l}\text { Intranasal delivery of } 70 \mu \mathrm{g} \\
\left.{ }^{125} \mid\right] \text {-radiolabeled BDNF results } \\
\text { in } 1.6-25.1 \mathrm{ng} / \mathrm{ml} \text { within } \\
25 \mathrm{~min} \text { in brain parenchyma }\end{array}$ & [418] \\
\hline & & & $\begin{array}{l}\text { BDNF reconstituted in sterile } \\
\text { PBS }\end{array}$ & $\begin{array}{l}\text { Alleviates cerebral local inflam- } \\
\text { mation induced by ischemia/ } \\
\text { reperfusion }\end{array}$ & [414] \\
\hline & & & BDNF-containing saline & $\begin{array}{l}\text { Improves visual depth percep- } \\
\text { tion in amblyopic rats }\end{array}$ & [413] \\
\hline \multirow[t]{2}{*}{ Intracochlear infusion } & Cats & Cochlear & $\begin{array}{l}\text { BDNF-containing sterile artifi- } \\
\text { cial perilymph }\end{array}$ & $\begin{array}{l}\text { Increases the total volume } \\
\text { of cochlear nucleus to exert } \\
\text { neurotrophic effects }\end{array}$ & [407] \\
\hline & Guinea pigs & & $\begin{array}{l}\text { BDNF-containing saline with } \\
\text { BSA (1\%) }\end{array}$ & $\begin{array}{l}\text { Enhanced survival of spiral } \\
\text { ganglion cells }\end{array}$ & {$[450]$} \\
\hline
\end{tabular}

$B B B$ blood-brain barrier, $B D N F$ brain-derived neurotrophic factor, $C R E B$ CAMP-response element binding protein, $E R K$ extracellular regulated protein kinases, $S A$ selfadministration, TrkB tyrosine kinase receptor type B, DG dentate gyrus, vHPC ventral hippocampus, LTM g long-term memory, dmPFC dorsomedial prefrontal cortex, $N A c$ nucleus accumbens, vmPFC ventromedial prefrontal cortex, $B S A$ bovine serum albumin

duration and dosing times are ambiguous. Moreover, BDNF is unstable and easy to degrade in a biological medium. Intranasal delivery of $70 \mu \mathrm{g}\left[{ }^{125} \mathrm{I}\right]$-radiolabeled BDNF results in delivery of $1.6-25.1 \mathrm{ng} / \mathrm{ml}$ of BDNF within $25 \mathrm{~min}$ in brain parenchyma, and this value increases further by $60 \mathrm{~min}$ [418]. In addition to reaching the CNS directly, this concentration of BDNF is sufficient to activate the PI3K/Akt pathway. Thus, a great deal of evidence supports the clinical potential of using intranasal delivery of BDNF because (1) there is a large surface area for drug absorption through the nasal mucosa, (2) intranasal delivery bypasses the $\mathrm{BBB},(3)$ the needle-free and easy self-administration improves patients' compliance, (4) it enables both rapid and direct CNS delivery of BDNF with high bioavailability by avoiding first-pass hepatic clearance, (5) it causes minimal systemic exposure, (6) a small dosage can be used, avoiding adverse effects, and (7) no drug modification is required. The dosage of intranasal protein is minimal, whereas the administration period is prolonged. Intranasal delivery of BDNF (42 pmol, $1 \mu \mathrm{M}$ )-PBS solution (bilateral, administered once every 
two days for a total of seven doses over 14 days) significantly improves the memory performance [419]. In contrast, a higher BDNF dosage $(10 \mu \mathrm{M})$ does not lead to further improvements, indicating this method has a ceiling effect.

Although several reviews and meta-analyses have revealed that the intranasal delivery route is safe and effective $[420,421]$, there are still some limitations to a carrier-free delivery of BDNF. First, intranasal BDNF delivery can also enter nasal-associated lymphatics and deep cervical lymph nodes [422]. Thus, the effects of intranasal BDNF on the nasal mucosa and the undesired immune response should be examined. Second, simply delivering BDNF in solution is challenging to retain in the nasal cavity due to the fast diffusion from the administered sites and rapid clearance by the mucociliary clearance system [423]. Third, compared with the amount of BDNF applied in the nasal cavity, the amount of BDNF reaching the CNS is small (generally below 1\%) [424]. Fourth, some nasal cytochrome P450/proteases may degrade BDNF. Finally, the pharmacokinetic profile of intranasal BDNF must be characterized. Thus, many other carrier-based approaches have been studied for effective nose-to-brain administration of BDNF.

Nanoencapsulation technologies have been widely utilized to solve the limitations of carrier-free delivery of macromolecular drugs. Table 2 summarizes some polymeric nanoparticles used for BDNF delivery. The polymeric nanoparticles are solid colloidal particles in which BDNF can be dissolved, entrapped, encapsulated, or chemically bound to the polymer matrix $[425,426]$. PEGylation of BDNF can enhance the diffusion of BDNF in the brain tissue and spinal cord [427, 428]. PEG-based BDNF nano-system, mediated by electrostatic coupling and hydrogen bonding, is beneficial for stabilizing BDNF, protecting against the nonspecific binding with serum proteins, and activating TrkB as well as other downstream signaling pathways [429-431]. Compared with native BDNF, intranasal administration of the nano-BDNF complex can enhance BDNF levels in the hippocampus and brainstem regions by regulating the viscosity and permeability of nasal mucosa [429]. PLGA nanoparticles help to protect drugs from enzymatic degradation and prolong the half-life $[432,433]$. To enable sustained local release of BDNF, PLGA microparticles are further patterned with hydrogels $[434,435]$. The short-range electrostatic interactions between PLGA and BDNF protein make BDNF adsorb to the surface of nanoparticles rather than encapsulate within the nanoparticles. Meanwhile, the amphiphilic hydrogel polymers enhance the interaction between BDNF and PLGA nanoparticles, resulting in a sustained release for at least 28 days. Therefore, the release profile of BDNF can be regulated by modifying the components of nano-formulations [436].

As derivatives of extracellular matrix (ECM) components, natural biopolymers are advocated to deliver macromolecular drugs and can be adjusted for intranasal drug administration [437]. Collagens are the most abundant proteins to maintain the structural integrity of ECM. BDNF fused with a collagen-binding domain (CBD-BDNF) can specifically bind to collagen [438-440]. Chitosan has similar structural characteristics as glycosaminoglycan, which is the main component of the ECM [441]. As shown in Table 3, collagen and chitosan scaffolds used for BDNF delivery are generally produced on a macroscopic scale. However, native ECM is located in the nanofibrous network structure. To develop biomimetic scaffolds, a collagen-chitosan complex has been made to prepare nanoscale scaffolds [442]. However, no nanoparticles based on collagen or chitosan have been reported for BDNF delivery. Alginate, naturally occurring linear unbranched polysaccharides extracted from brown algae cell walls, has been considered as an ideal biodegradable polymer for continuous delivery of proteins [443]. This is because alginate can be crosslinked by adding divalent cation to the aqueous solution. During the gelation process, proteins can then be incorporated into alginate matrices [444]. As a bioadhesive polymer, alginate can specifically facilitate the delivery to mucosal tissues [445]. Another natural polysaccharide, agarose, is derived from red algae [446]. Upon cooling hot agarose solution in water, a physical crosslinked three-dimensional gel network can be obtained via $\mathrm{H}$-bonding and hydrophobic interactions [447]. Interestingly, proteins such as BDNF exhibit various degrees of $\mathrm{H}$-bonding and hydrophobic interactions [448]. Therefore, agarose has been used as a good coupling partner for loading and delivering BDNF without inflammatory or immunological responses. As shown in Table 3, the alginate- and agarose-based hydrogel system used for BDNF delivery is characterized by sustained release of BDNF, protects neuronal functions and minimizes inflammatory damage. Thus, alginate and agarose hydrogel scaffolds have been used for BDNFproducing cell transplants [362, 366, 449]. In vivo, these encapsulated BDNF-producing cells can release bioactive BDNF, which persists in the injured site over one month and promotes host axon growth. Accordingly, the intranasal delivery and biodegradable nanocarriers may help the development of AD therapy by targeting BDNF. To improve the availability of exogenous BDNF therapy, important questions should be answered concerning the noninvasive transport routes, the therapeutic doses of BDNF, and the safety and clinical efficacy of administering $\mathrm{BDNF}$ to $\mathrm{AD}$ patients. 


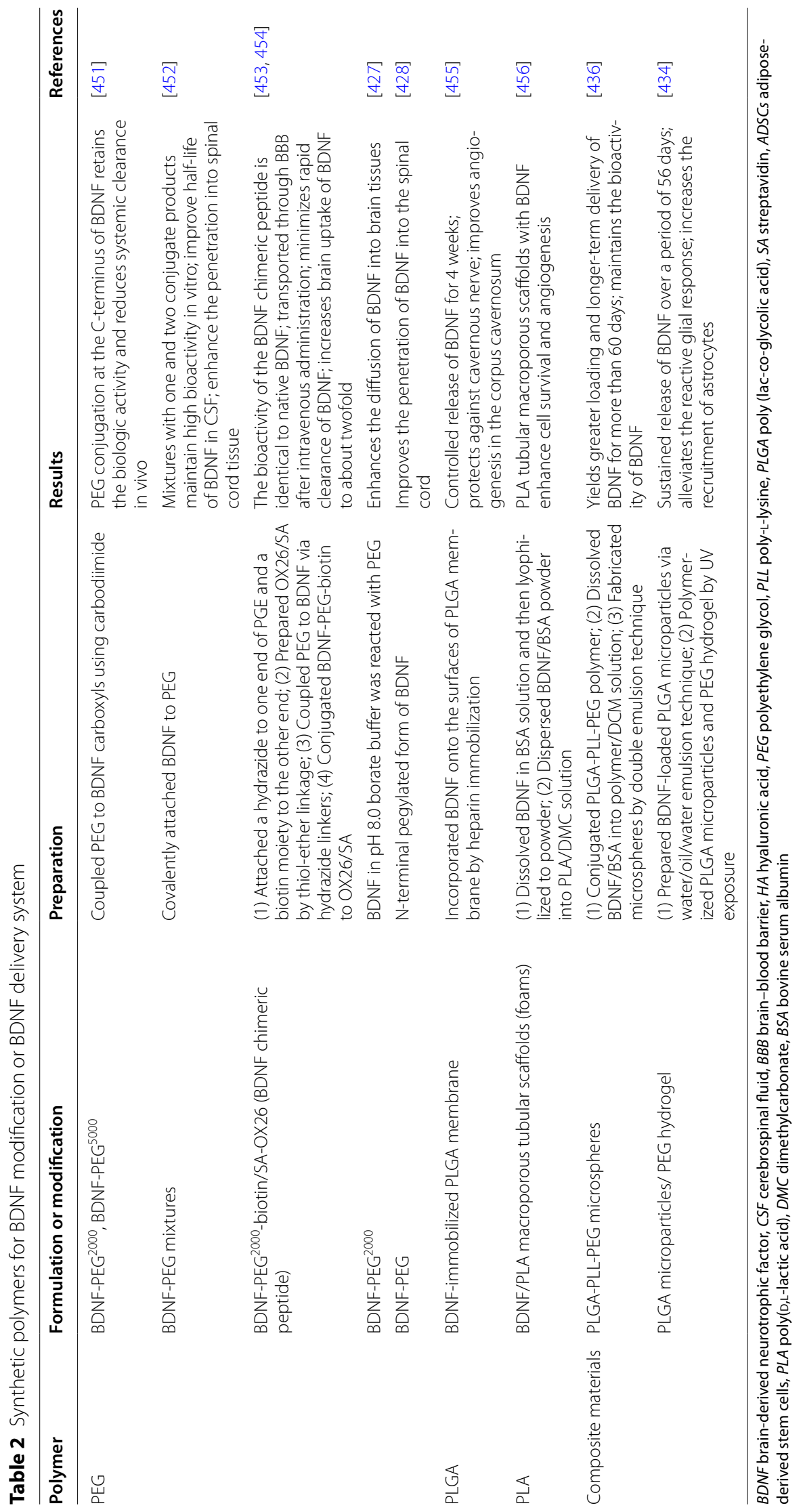




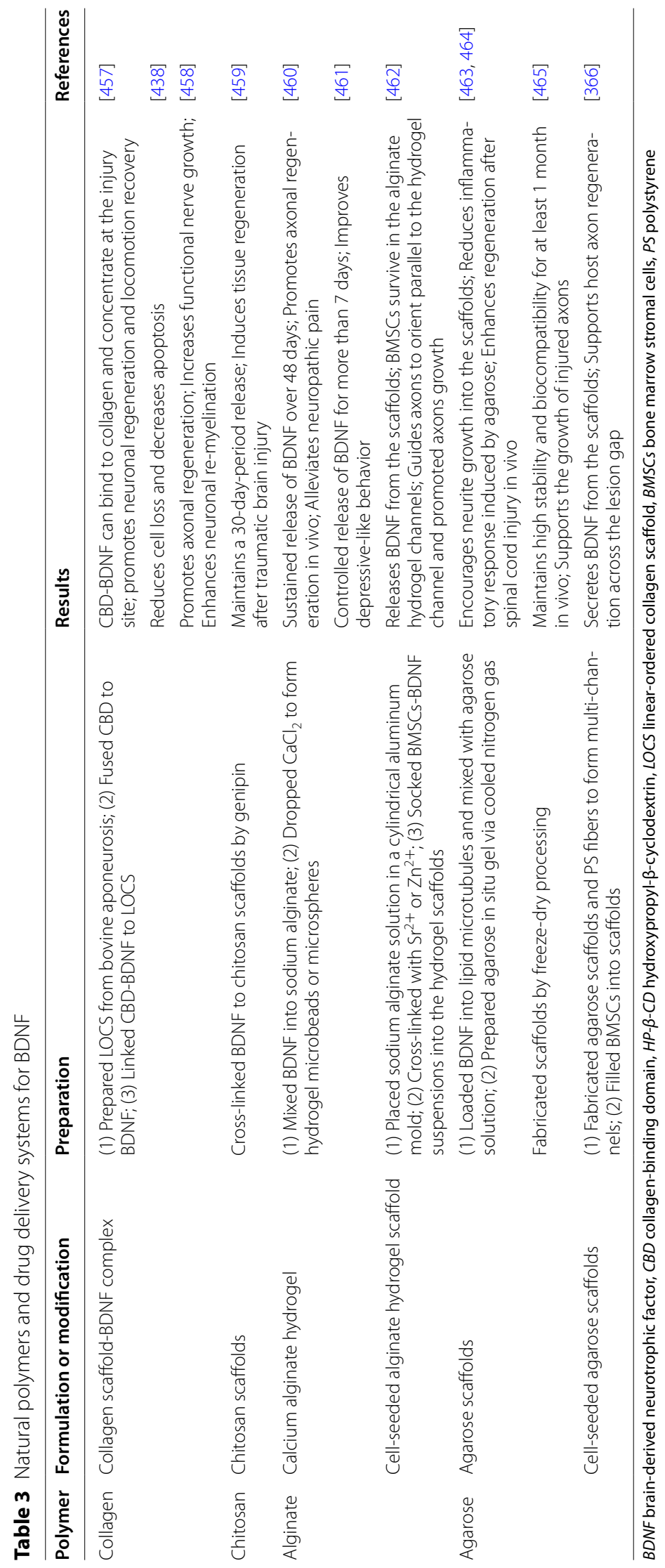




\section{Conclusion}

BDNF is a key neurotrophic molecule that has been shown to enhance synaptic plasticity and improve learning and memory. Disruption of BDNF has been found in different stages of AD. In this review, we discuss the effect of BDNF on AD-related pathologies, including $A \beta$ accumulation, tau phosphorylation, neuroinflammation, neuronal apoptosis, and cognitive decline. BDNF/TrkB and the downstream cell signaling pathways, including PI3K/Akt, ERK/CREB, and PKC/ GSK3, are further discussed for their effects on AD. Although some data reported that BDNF did not affect $\mathrm{AD}$, higher BDNF levels indeed reduced the risk of AD. Most AD drugs currently used in clinical (e.g. donepezil, galantamine, rivastigmine and tacrine) and many therapeutic agents under development increase BDNF biosynthesis. Therefore, even though BDNF is not the primary molecular target of these drugs, we should not lose sight that BDNF is implicated in the mechanism of cognitive improvement. Many strategies have also been reported to support the possibility that exogenous BDNF supplementation would be an alternative option to improve cognitive function in AD. Biodegradable nanocarriers combined with intranasal delivery of BDNF to avoid invasive administration and improve brain-targeted distribution may provide novel promising approaches for AD therapy.

BDNF plays several vital roles in most neural cells and peripheral systems. In addition to $\mathrm{AD}$, it is also involved in several metabolic syndromes, including atherosclerosis, hypertension, hyperglycemia, type 2 diabetes mellitus, and many other neuropsychiatric diseases such as depression, Parkinson's disease and Huntington's disease. More in-depth studies are needed to understand the role of different isoforms of BDNF, and the relationship between peripheral and brain BDNF under pathological conditions.

\begin{abstract}
Abbreviations
AD: Alzheimer's disease; A $\beta$ : Amyloid $\beta$; APP: Amyloid $\beta$ precursor protein; BDNF: Brain-derived neurotrophic factor; NMDAR: N-methyl-D aspartate receptor; p75 NTR: P75 neurotrophin receptor; TrkB: Tropomyosin receptor kinase B; JNK: C-Jun N-terminal kinase; JAK2: Janus kinase 2; STAT3: Signal transducer and activator 3; IRAK: Interleukin-1 receptor-associated kinase; NFKB: Nuclear factor-KB; TLR4: Toll-like receptor 4; MyD88: Myeloid differentiation primary response gene 88; TNF-a: Tumor necrosis factor-a; IL-6: Interleukin-6; MEK: Mitogen-activated protein kinase kinase; ERK1/2: Extracellular signalregulated protein kinase 1/2; CREB: CAMP-response element binding protein; (C/EBP) B: CCAAT/enhancer binding protein $\beta$; PI3K: Phosphoinositide 3-kinase; Akt: Protein kinase B; PLC : Phospholipase $C_{\gamma} ;$ GSK3 $\beta$ : Glycogen synthase kinase-3ß; Cyt C: Cytocheome C.
\end{abstract}

Acknowledgements

W.S. was the holder of the Tier 1 Canada Research Chair in Alzheimer's Disease.
Authors' contributions

$L G, Y Z$ and WS wrote the manuscript. All authors read and approved the final manuscript

\section{Funding}

This work was supported by National Natural Science Foundation of China (81903824) (L.G.).

\section{Availability of data and materials}

Available upon request.

\section{Declarations}

Ethics approval and consent to participate

Not applicable.

\section{Consent for publication}

Not applicable.

\section{Competing interests}

The authors declare that they have no competing interests.

\section{Author details}

1Shandong Collaborative Innovation Center for Diagnosis, Treatment and Behavioral Interventions of Mental Disorders, Institute of Mental Health, College of Pharmacy, Jining Medical University, Jining 272067, Shandong, China. ${ }^{2}$ Townsend Family Laboratories, Department of Psychiatry, The University of British Columbia, 2255 Wesbrook Mall, Vancouver, BC V6T 1Z3, Canada. ${ }^{3}$ National Clinical Research Center for Geriatric Disorders, Xuanwu Hospital, Capital Medical University, Beijing 100053, China. ${ }^{4}$ Institute of Aging, Key Laboratory of Alzheimer's Disease of Zhejiang Province, School of Mental Health and The Affiliated Kangning Hospital, Wenzhou Medical University, Wenzhou 325000, Zhejiang, China. ${ }^{5}$ Oujiang Laboratory (Zhejiang Lab for Regenerative Medicine, Vision and Brain Health), Wenzhou 325001, Zhejiang, China.

Received: 10 September 2021 Accepted: 1 January 2022

Published online: 28 January 2022

\section{References}

1. Alzheimer A. Uber eine eigenartige Erkrankung der Hirnrinde. Zentralbl Nervenh Psych. 1907;18:177-9.

2. Liao X, Cai F, Sun Z, Zhang Y, Wang J, Jiao B, et al. Identification of Alzheimer's disease-associated rare coding variants in the ECE2 gene. JCI Insight. 2020;5(4):e135119.

3. Zeng J, Chen L, Wang Z, Chen Q, Fan Z, Jiang H, et al. Marginal vitamin A deficiency facilitates Alzheimer's pathogenesis. Acta Neuropathol. 2017;133(6):967-82.

4. Zhang Y, Dong Z, Song W. NLRP3 inflammasome as a novel therapeutic target for Alzheimer's disease. Signal Transduct Target Ther. 2020;5(1):37.

5. Cummings J, Lee G, Ritter A, Sabbagh M, Zhong K. Alzheimer's disease drug development pipeline: 2020. Alzheimers Dement (N Y). 2020;6(1):e12050.

6. Cavazzoni P. FDA's decision to approve new treatment for Alzheimer's disease. U.S. Food and Drug Administration; 2021.

7. Fillit $\mathrm{H}$, Green A. Aducanumab and the FDA-where are we now? Nat Rev Neurol. 2021;17(3):129-30.

8. Alexander GC, Emerson S, Kesselheim AS. Evaluation of aducanumab for Alzheimer disease: scientific evidence and regulatory review involving efficacy, safety, and futility. JAMA. 2021;325(17):1717-8.

9. Zhang Y, Song W. Islet amyloid polypeptide: another key molecule in Alzheimer's pathogenesis? Prog Neurobiol. 2017;153:100-20.

10. Qing H, He G, Ly PT, Fox CJ, Staufenbiel M, Cai F, et al. Valproic acid inhibits Abeta production, neuritic plaque formation, and behavioral deficits in Alzheimer's disease mouse models. J Exp Med. 2008;205(12):2781-9.

11. Sun X, He G, Qing H, Zhou W, Dobie F, Cai F, et al. Hypoxia facilitates Alzheimer's disease pathogenesis by up-regulating BACE1 gene expression. Proc Natl Acad Sci USA. 2006;103(49):18727-32. 
12. Liu F, Zhang Y, Liang Z, Sun Q, Liu H, Zhao J, et al. Cleavage of potassium channel Kv2.1 by BACE2 reduces neuronal apoptosis. Mol Psychiatry. 2018;23(7):1542-54

13. Yun Y, Zhang Y, Zhang C, Huang L, Tan S, Wang P, et al. Regulator of calcineurin 1 is a novel RNA-binding protein to regulate neuronal apoptosis. Mol Psychiatry. 2019;26:1361-75.

14. Zhang $X$, Song $W$. The role of APP and BACE1 trafficking in APP processing and amyloid-beta generation. Alzheimers Res Ther. 2013;5(5):46.

15. Chen $\mathrm{CH}$, Zhou W, Liu S, Deng Y, Cai F, Tone M, et al. Increased NFkappaB signalling up-regulates BACE1 expression and its therapeutic potential in Alzheimer's disease. Int J Neuropsychopharmacol. 2012;15(1):77-90.

16. Zhang S, Zhao J, Zhang Y, Zhang Y, Cai F, Wang L, et al. Upregulation of MIF as a defense mechanism and a biomarker of Alzheimer's disease. Alzheimers Res Ther. 2019;11(1):54

17. Bartus RT, Dean RL, Beer B, Lippa AS. The cholinergic hypothesis of geriatric memory dysfunction. Science. 1982;217(4558):408.

18. Kosik KS, Joachim CL, Selkoe DJ. Microtubule-associated protein Tau (Tau) is a major antigenic component of paired helical filaments in Alzheimer-disease. Proc Natl Acad Sci USA. 1986:83(11):4044-8.

19. Grundke-lqbal I, lqbal K, Tung YC, Quinlan M, Wisniewski HM, Binder LI. Abnormal phosphorylation of the microtubule-associated protein tau (tau) in Alzheimer cytoskeletal pathology. Proc Natl Acad Sci USA. 1986;83(13):4913-7.

20. Maragos WF, Greenamyre JT, Penney JB, Young AB. Glutamate dysfunction in Alzheimer's disease: an hypothesis. Trend Neurosci. 1987;10(2):65-8.

21. Hardy JA, Higgins GA. Alzheimer's disease-the amyloid cascade hypothesis. Science. 1992;256(5054):184

22. Hardy J, Selkoe DJ. The amyloid hypothesis of Alzheimer's disease: progress and problems on the road to therapeutics. Science. 2002;297(5580):353-6.

23. Aisen PS, Davis KL. Inflammatory mechanisms in Alzheimer's disease: implications for therapy. Am J Psychiatry. 1994;151 (8):1105-13.

24. Swerdlow RH, Khan SM. A "mitochondrial cascade hypothesis" for sporadic Alzheimer's disease. Med Hypotheses. 2004;63(1):8-20.

25. Edelmann E, Cepeda-Prado E, Franck M, Lichtenecker P, Brigadski T, Leßmann $V$. Theta burst firing recruits BDNF release and signaling in postsynaptic CA1 neurons in spike-timing-dependent LTP. Neuron. 2015;86(4):1041-54

26. Mizui T, Ishikawa Y, Kumanogoh H, Lume M, Matsumoto T, Hara T, et al. BDNF pro-peptide actions facilitate hippocampal LTD and are altered by the common BDNF polymorphism Val66Met. Proc Natl Acad Sci U S A. 2015;112(23):E3067-74

27. Schinder AF, Poo M. The neurotrophin hypothesis for synaptic plasticity. Trend Neurosci. 2000;23(12):639-45

28. Wang Z-H, Xiang J, Liu X, Yu SP, Manfredsson FP, Sandoval IM, et al. Deficiency in BDNF/TrkB neurotrophic activity stimulates $\delta$-secretase by upregulating C/EBPß in Alzheimer's disease. Cell Rep. 2019;28(3):655669.e655.

29. Elliott E, Atlas R, Lange A, Ginzburg I. Brain-derived neurotrophic factor induces a rapid dephosphorylation of tau protein through a PI-3 Kinase signalling mechanism. Eur J Neurosci. 2005;22(5):1081-9.

30. Avila J, Lucas JJ, Perez M, Hernandez F. Role of Tau protein in both physiological and pathological conditions. Physiol Rev. 2004;84:361-84.

31. Tanqueiro SR, Ramalho RM, Rodrigues TM, Lopes LV, Sebastiao AM, Diogenes MJ. Inhibition of NMDA receptors prevents the loss of BDNF function induced by amyloid beta. Front Pharmacol. 2018:9:237.

32. Meng C, He Z, Xing D. Low-level laser therapy rescues dendrite atrophy via upregulating BDNF expression: implications for Alzheimer's disease. J Neurosci. 2013;33(33):13505.

33. Guo CC, Jiao CH, Gao ZM. Silencing of LncRNA BDNF-AS attenuates Abeta25-35-induced neurotoxicity in PC12 cells by suppressing cel apoptosis and oxidative stress. Neurol Res. 2018;40:1-10.

34. Galic MA, Riazi K, Pittman QJ. Cytokines and brain excitability. Front Neuroendocrinol. 2012:33(1):116-25

35. Di Filippo M, Chiasserini D, Gardoni F, Viviani B, Tozzi A, Giampa C, et al. Effects of central and peripheral inflammation on hippocampal synaptic plasticity. Neurobi Dis. 2013;52:229-36.

36. Peng S, Wuu J, Mufson EJ, Fahnestock M. Precursor form of brainderived neurotrophic factor and mature brain-derived neurotrophic factor are decreased in the pre-clinical stages of Alzheimer's disease. J Neurochem. 2005;93(6):1412-21.

37. Ng TKS, Ho CSH, Tam WWS, Kua EH, Ho RC. Decreased serum brainderived neurotrophic factor (BDNF) levels in patients with Alzheimer's disease (AD): a systematic review and meta-analysis. Int J Mol Sci. 2019;20(2):257.

38. Forlenza OV, Diniz BS, Teixeira AL, Radanovic M, Talib LL, Rocha NP, et al. Lower cerebrospinal fluid concentration of brain-derived neurotrophic factor predicts progression from mild cognitive impairment to Alzheimer's disease. Neuromol Med. 2015;17(3):326-32.

39. Weinstein G, Beiser AS, Choi SH, Preis SR, Chen TC, Vorgas D, et al. Serum brain-derived neurotrophic factor and the risk for dementia: the Framingham Heart Study. JAMA Neurol. 2014;71(1):55-61.

40. Aid T, Kazantseva A, Piirsoo M, Palm K, Timmusk T. Mouse and rat BDNF gene structure and expression revisited. J Neurosci Res. 2007:85(3):525-35.

41. Karpova NN. Role of BDNF epigenetics in activity-dependent neuronal plasticity. Neuropharmacology. 2014;76 Pt C:709-18.

42. Maynard KR, Hill JL, Calcaterra NE, Palko ME, Kardian A, Paredes D, et al. Functional role of BDNF production from unique promoters in aggression and serotonin signaling. Neuropsychopharmacology. 2015:41:1943.

43. Martinowich $\mathrm{K}$, Hattori D, Wu H, Fouse S, He F, Hu Y, et al. DNA methylation-related chromatin remodeling in activity-dependent BDNF gene regulation. Science. 2003;302(5646):890-3.

44. Kim JW, Autry AE, Na ES, Adachi M, Bjorkholm C, Kavalali ET, et al. Sustained effects of rapidly acting antidepressants require BDNFdependent MeCP2 phosphorylation. Nat Neurosci. 2021;24(8):1100-9.

45. Johnson S, Liston C. MeCP2 for sustained antidepressant effects. Nat Neurosci. 2021;24(8):1047-8.

46. Li H, Shang J, Zhang C, Lu R, Chen J, Zhou X. Repetitive transcranial magnetic stimulation alleviates neurological deficits after cerebral ischemia through interaction between RACK1 and BDNF exon IV by the phosphorylation-dependent factor MeCP2. Neurotherapeutics. 2020;17(2):651-63.

47. An JJ, Gharami K, Liao G-Y, Woo NH, Lau AG, Vanevski F, et al. Distinct role of long 3' UTR BDNF mRNA in spine morphology and synaptic plasticity in hippocampal neurons. Cell. 2008;134(1):175-87.

48. Baj G, Leone E, Chao MV, Tongiorgi E. Spatial segregation of BDNF transcripts enables BDNF to differentially shape distinct dendritic compartments. Proc Natl Acad Sci U S A. 2011;108(40):16813-8.

49. Oe S, Yoneda Y. Cytoplasmic polyadenylation element-like sequences are involved in dendritic targeting of BDNF mRNA in hippocampal neurons. FEBS Lett. 2010;584(15):3424-30.

50. Vicario A, Colliva A, Ratti A, Davidovic L, Baj G, Gricman $Ł$, et al. Dendritic targeting of short and long $3^{\prime}$ UTR BDNF mRNA is regulated by BDNF or NT-3 and distinct sets of RNA-binding proteins. Front Mol Neurosci. 2015:8:62.

51. Pruunsild P, Kazantseva A, Aid T, Palm K, Timmusk T. Dissecting the human BDNF locus: bidirectional transcription, complex splicing, and multiple promoters. Genomics. 2007;90(3):397-406.

52. Tao X, West AE, Chen WG, Corfas G, Greenberg ME. A calcium-responsive transcription factor, carf, that regulates neuronal activity-dependent expression of BDNF. Neuron. 2002;33(3):383-95.

53. Jiang $X$, Tian F, Du Y, Copeland NG, Jenkins NA, Tessarollo L, et al. BHLHB2 controls Bdnf promoter 4 activity and neuronal excitability. J Neurosci. 2008;28(5):1118-30

54. Kairisalo M, Korhonen L, Sepp M, Pruunsild P, Kukkonen JP, Kivinen J, et al. NF-kB-dependent regulation of brain-derived neurotrophic factor in hippocampal neurons by X-linked inhibitor of apoptosis protein. Eur J Neurosci. 2009;30(6):958-66

55. Dieni S, Matsumoto T, Dekkers M, Rauskolb S, Ionescu MS, Deogracias $\mathrm{R}$, et al. BDNF and its pro-peptide are stored in presynaptic dense core vesicles in brain neurons. J Cell Biol. 2012;196(6):775-88.

56. Mowla SJ, Farhadi HF, Pareek S, Atwal JK, Morris SJ, Seidah NG, et al. Biosynthesis and post-translational processing of the precursor to brain-derived neurotrophic factor. J Biol Chem. 2001;276(16):12660-6.

57. Mizoguchi H, Nakade J, Tachibana M, Ibi D, Someya E, Koike H, et al. Matrix metalloproteinase-9 contributes to kindled seizure development in pentylenetetrazole-treated mice by converting pro-BDNF to mature BDNF in the hippocampus. J Neurosci. 2011;31(36):12963-71. 
58. Vafadari B, Salamian A, Kaczmarek L. MMP-9 in translation: from molecule to brain physiology, pathology, and therapy. J Neurochem. 2016:139:91-114.

59. Pang PT, Teng HK, Zaitsev E, Woo NT, Sakata K, Zhen S, et al. Cleavage of proBDNF by tPA/Plasmin is essential for long-term hippocampal plasticity. Science. 2004;306(5695):487.

60. Motamedi S, Karimi I, Jafari F. The interrelationship of metabolic syndrome and neurodegenerative diseases with focus on brain-derived neurotrophic factor (BDNF): kill two birds with one stone. Metab Brain Dis. 2017;32(3):651-65.

61. Woo NH, Teng HK, Siao CJ, Chiaruttini C, Pang PT, Milner TA, et al. Activation of p75NTR by proBDNF facilitates hippocampal long-term depression. Nat Neurosci. 2005:8(8):1069-77.

62. Rosch H, Schweigreiter R, Bonhoeffer T, Barde YA, Korte M. The neurotrophin receptor p75NTR modulates long-term depression and regulates the expression of AMPA receptor subunits in the hippocampus. Proc Natl Acad Sci U S A. 2005;102(20):7362-7.

63. Koshimizu H, Kiyosue K, Hara T, Hazama S, Suzuki S, Uegaki K, et al. Multiple functions of precursor BDNF to CNS neurons: negative regulation of neurite growth, spine formation and cell survival. Mol Brain. 2009;2(1):27.

64. Fayard B, Loeffler S, Weis J, Vögelin E, Krüttgen A. The secreted brainderived neurotrophic factor precursor pro-BDNF binds to TrkB and p75NTR but not to TrkA or TrkC. J Neurosci Res. 2005;80(1):18-28.

65. Xu B, Gottschalk W, Chow A, Wilson Rl, Schnell E, Zang K, et al. The role of brain-derived neurotrophic factor receptors in the mature hippocampus: modulation of long-term potentiation through a presynaptic mechanism involving TrkB. J Neurosci. 2000;20(18):6888.

66. Lee R, Kermani P, Teng KK, Hempstead BL. Regulation of cell survival by secreted proneurotrophins. Science. 2001;294(5548):1945-8.

67. Teng HK, Teng KK, Lee R, Wright S, Tevar S, Almeida RD, et al. ProBDNF induces neuronal apoptosis via activation of a receptor complex of p75NTR and sortilin. J Neurosci. 2005;25(22):5455-63.

68. Ho IHT, Liu X, Zou Y, Liu T, Hu W, Chan H, et al. A novel peptide interfering with probdnf-sortilin interaction alleviates chronic inflammatory pain. Theranostics. 2019;9(6):1651-65.

69. Mizui T, Ohira K, Kojima M. BDNF pro-peptide: a novel synaptic modulator generated as an N-terminal fragment from the BDNF precursor by proteolytic processing. Neural Regen Res. 2017;12(7):1024.

70. Guo J, Ji Y, Ding Y, Jiang W, Sun Y, Lu B, et al. BDNF pro-peptide regulates dendritic spines via caspase-3. Cell Death Dis. 2016;7:e2264.

71. Ghosh A, Carnahan J, Greenberg ME. Requirement for BDNF in activity-dependent survival of cortical neurons. Science. 1994;263(5153):1618-23.

72. Patterson SL, Abel T, Deuel TAS, Martin KC, Rose JC, Kandel ER. Recombinant BDNF rescues deficits in basal synaptic transmission and hippocampal LTP in BDNF knockout mice. Neuron. 1996;16(6):1137-45.

73. Baker-Herman TL, Fuller DD, Bavis RW, Zabka AG, Golder FJ, Doperalski $N J$, et al. BDNF is necessary and sufficient for spinal respiratory plasticity following intermittent hypoxia. Nat Neurosci. 2004;7(1):48-55.

74. Levine ES, Crozier RA, Black IB, Plummer MR. Brain-derived neurotrophic factor modulates hippocampal synaptic transmission by increasing. Proc Natl Acad Sci USA. 1998:95(17):10235.

75. Yano H, Ninan I, Zhang H, Milner TA, Arancio O, Chao MV. BDNF-mediated neurotransmission relies upon a myosin VI motor complex. Nat Neurosci. 2006;9(8):1009-18.

76. Jovanovic JN, Czernik AJ, Fienberg AA, Greengard P, Sihra TS. Synapsins as mediators of BDNF-enhanced neurotransmitter release. Nat Neurosci. 2000;3(4):323-9.

77. Kovalchuk Y, Hanse E, Kafitz KW, Konnerth A. Postsynaptic induction of BDNF-mediated long-term potentiation. Science. 2002;295(5560):1729-34.

78. Manabe T. Does BDNF have pre- or postsynaptic targets? Science. 2002:295(5560):1651.

79. Vaz SH, Jorgensen TN, Cristovao-Ferreira S, Duflot S, Ribeiro JA, Gether $U$, et al. Brain-derived neurotrophic factor (BDNF) enhances GABA transport by modulating the trafficking of GABA transporter-1 (GAT-1) from the plasma membrane of rat cortical astrocytes. J Biol Chem. 2011;286(47):40464-76
80. Heldt SA, Stanek L, Chhatwal JP, Ressler KJ. Hippocampus-specific deletion of BDNF in adult mice impairs spatial memory and extinction of aversive memories. Mol Psychiatry. 2007;12(7):656-70.

81. Gray J, Yeo GS, Cox JJ, Morton J, Adlam AL, Keogh JM, et al. Hyperphagia, severe obesity, impaired cognitive function, and hyperactivity associated with functional loss of one copy of the brain-derived neurotrophic factor (BDNF) gene. Diabetes. 2006;55(12):3366-71.

82. Adachi M, Barrot M, Autry AE, Theobald D, Monteggia LM. Selective loss of brain-derived neurotrophic factor in the dentate gyrus attenuates antidepressant efficacy. Biol Psychiatry. 2008;63(7):642-9.

83. Ernfors $\mathrm{P}$, Wetmore $\mathrm{C}$, Olson $\mathrm{L}$, Persson $\mathrm{H}$. Identification of cells in rat brain and peripheral tissues expressing mRNA for members of the nerve growth factor family. Neuron. 1990;5(4):511-26.

84. Ceccatelli S, Ernfors P, Villar MJ, Persson H, Hökfelt T. Expanded distribution of mRNA for nerve growth factor, brain-derived neurotrophic factor, and neurotrophin 3 in the rat brain after colchicine treatment. Proc Natl Acad Sci U S A. 1991;88(22):10352

85. Conner JM, Lauterborn JC, Yan Q Gall CM, Varon S. Distribution of brain-derived neurotrophic factor (BDNF) protein and mRNA in the normal adult rat CNS: evidence for anterograde axonal transport. J Neurosci. 1997;17(7):2295-313.

86. Hofer M, Pagliusi SR, Hohn A, Leibrock J, Barde YA. Regional distribution of brain-derived neurotrophic factor mRNA in the adult mouse brain. EMBO J. 1990;9(8):2459-64.

87. Katoh-Semba R, Takeuchi IK, Semba R, Kato K. Distribution of brainderived neurotrophic factor in rats and its changes with development in the brain. J Neurochem. 1997:69(1):34-42.

88. Nagahara AH, Merrill DA, Coppola G, Tsukada S, Schroeder BE, Shaked $G M$, et al. Neuroprotective effects of brain-derived neurotrophic factor in rodent and primate models of Alzheimer's disease. Nat Med. 2009;15(3):331-7.

89. Yamamoto H, Gurney ME. Human platelets contain brain-derived neurotrophic factor. J Neurosci. 1990;10(11):3469-78.

90. Fujimura H, Altar CA, Chen R, Nakamura T, Nakahashi T, Kambayashi $J$, et al. Brain-derived neurotrophic factor is stored in human platelets and released by agonist stimulation. Thromb Haemost. 2002;87(04):728-34.

91. Watanabe K, Hashimoto E, Ukai W, Ishii T, Yoshinaga T, Ono T, et al. Effect of antidepressants on brain-derived neurotrophic factor (BDNF) release from platelets in the rats. Prog Neuropsychopharmacol Biol Psychiatry. 2010;34(8):1450-4.

92. Le Blanc J, Fleury S, Boukhatem I, Bélanger J-C, Welman M, Lordkipanidzé $M$. Platelets selectively regulate the release of BDNF, but not that of its precursor protein, proBDNF. Front Immunol. 2020;11:575607-575607.

93. Boukhatem I, Fleury S, Welman M, Le Blanc J, Thys C, Freson K, et al. The brain-derived neurotrophic factor prompts platelet aggregation and secretion. Blood Adv. 2021;5(18):3568-80.

94. Donegà S, Tongiorgi E. Detecting BDNF protein forms by ELISA, western blot, and immunofluorescence. In: Duarte C, Tongiorgi E, editors. BrainDerived Neurotrophic Factor (BDNF). Neuromethods, vol 143. Humana, New York, NY. 2018. p. 89-103.

95. Reinhart V, Bove SE, Volfson D, Lewis DA, Kleiman RJ, Lanz TA. Evaluation of TrkB and BDNF transcripts in prefrontal cortex, hippocampus, and striatum from subjects with schizophrenia, bipolar disorder, and major depressive disorder. Neurobiol Dis. 2015;77:220-7.

96. Tang F, Barbacioru C, Wang Y, Nordman E, Lee C, Xu N, et al. mRNASeq whole-transcriptome analysis of a single cell. Nat Methods. 2009;6(5):377-82.

97. Tang F, Lao K, Surani MA. Development and applications of single-cell transcriptome analysis. Nat Methods. 2011;8(4):S6-11.

98. Mathys H, Davila-Velderrain J, Peng Z, Gao F, Mohammadi S, Young JZ, et al. Single-cell transcriptomic analysis of Alzheimer's disease. Nature. 2019;570(7761):332-7.

99. Bai X, Yilin C, Qi X, Cai D. Single-cell analysis for BDNF and TrkB receptors in cardiac microvascular endothelial cells. Bio-Med Mater Eng. 2014;24:2257-64

100. Unterwald EM, Page ME, Brown TB, Miller JS, Ruiz M, Pescatore KA, et al. Behavioral and transcriptome alterations in male and female mice with postnatal deletion of TrkB in dorsal striatal medium spiny neurons. Mol Neurodegen. 2013;8(1):47. 
101. Bochukova EG, Lawler K, Croizier S, Keogh JM, Patel N, Strohbehn $\mathrm{G}$, et al. A transcriptomic signature of the hypothalamic response to fasting and BDNF deficiency in Prader-Willi syndrome. Cell Rep. 2018;22(13):3401-8

102. Bhattarai P, Cosacak MI, Mashkaryan V, Demir S, Popova SD, Govindarajan N, et al. Neuron-glia interaction through Serotonin-BDNF-NGFR axis enables regenerative neurogenesis in Alzheimer's model of adult zebrafish brain. PLoS Biol. 2020;18(1):e3000585.

103. de Assis GG, Hoffman JR, Gasanov EV. BDNF Val66Met polymorphism, the allele-specific analysis by qRT-PCR-a novel protocol. In J Med Sci. 2020;17(18):3058.

104. Chen ZY, Jing D, Bath KG, leraci A, Khan T, Siao CJ, et al. Genetic variant BDNF (Val66Met) polymorphism alters anxiety-related behavior. Science. 2006:314(5796):140-3.

105. Yoshida T, Ishikawa M, lyo M, Hashimoto K. Serum levels of mature brain-derived neurotrophic factor (BDNF) and its precursor proBDNF in healthy subjects. Open Clin Chem J. 2012;5(1):7-12

106. Bockaj M, Fung B, Tsoulis M, Foster WG, Soleymani L. Method for electrochemical detection of brain derived neurotrophic factor (BDNF) in plasma. Anal Chem. 2018:90(14):8561-6.

107. Chen B, Dowlatshahi D, MacQueen GM, Wang JF, Young LT. Increased hippocampal BDNF immunoreactivity in subjects treated with antidepressant medication. Biol Psychiatry. 2001;50(4):260-5.

108. Yang J. Neuronal release of proBDNF. Nat Neurosci. 2009;12(2):113-5.

109. Mizui T, Hattori K, Ishiwata S, Hidese S, Yoshida S, Kunugi H, et al. Cerebrospinal fluid BDNF pro-peptide levels in major depressive disorder and schizophrenia. J Psychiatric Res. 2019;113:190-8.

110. Egan MF, Kojima M, Callicott JH, Goldberg TE, Kolachana BS, Bertolino A, et al. The BDNF val66met polymorphism affects activity-dependent secretion of BDNF and human memory and hippocampal function. Cell. 2003:112(2):257-69.

111. Shimojo M, Courchet J, Pieraut S, Torabi-Rander N, Sando R, Polleux F, et al. SNAREs controlling vesicular release of BDNF and development of callosal axons. Cell Rep. 2015;11(7):1054-66.

112. Matsuda N, Lu H, Fukata Y, Noritake J, Gao H, Mukherjee S, et al. Differential activity-dependent secretion of brain-derived neurotrophic factor from axon and dendrite. J Neurosci. 2009;29(45):14185-98.

113. Fukuchi M, Tabuchi A, Kuwana Y, Watanabe S, Inoue M, Takasaki I, et al, Neuromodulatory effect of Gas- or Gaq-coupled G-protein-coupled receptor on NMDA receptor selectively activates the NMDA receptor/Ca2+/calcineurin/cAMP response element-binding proteinregulated transcriptional coactivator 1 pathway to effectively induce brain-derived neurotrophic factor expression in neurons. J Neurosci. 2015:35(14):5606-24.

114. Fukuchi M, Okuno Y, Nakayama H, Nakano A, Mori H, Mitazaki S, et al. Screening inducers of neuronal BDNF gene transcription using primary cortical cell cultures from BDNF-luciferase transgenic mice. Sci Rep. 2019;9(1):11833.

115. Hsiao K, Chapman P, Nilsen S, Eckman C, Harigaya Y, Younkin S, et al. Correlative memory deficits, Abeta elevation, and amyloid plaques in transgenic mice. Science. 1996;274(5284):99-102.

116. Radde R, Bolmont T, Kaeser SA, Coomaraswamy J, Lindau D, Stoltze L, et al. Abeta42-driven cerebral amyloidosis in transgenic mice reveals early and robust pathology. EMBO Rep. 2006;7(9):940-6.

117. Lewis J, Dickson DW, Lin WL, Chisholm L, Corral A, Jones G, et al. Enhanced neurofibrillary degeneration in transgenic mice expressing mutant tau and APP. Science. 2001;293(5534):1487-91.

118. Mucke L, Masliah E, Yu G-Q, Mallory M, Rockenstein EM, Tatsuno G, et al. High-level neuronal expression of A $1-42$ in wild-type human amyloid protein precursor transgenic mice: synaptotoxicity without plaque formation. J Neurosci. 2000;20(11):4050.

119. Oddo S, Caccamo A, Shepherd JD, Murphy MP, Golde TE, Kayed R, et al. Triple-transgenic model of Alzheimer's disease with plaques and tangles: intracellular Abeta and synaptic dysfunction. Neuron. 2003;39(3):409-21.

120. Oakley H, Cole SL, Logan S, Maus E, Shao P, Craft J, et al. Intraneuronal beta-amyloid aggregates, neurodegeneration, and neuron loss in transgenic mice with five familial Alzheimer's disease mutations: potential factors in amyloid plaque formation. J Neurosci. 2006;26(40):10129-40.

121. Leon WC, Canneva F, Partridge V, Allard S, Ferretti MT, DeWilde A, et al. A novel transgenic rat model with a full Alzheimer's-like amyloid pathology displays pre-plaque intracellular amyloid-beta-associated cognitive impairment. J Alzheimers Dis. 2010;20(1):113-26.

122. Fu H, Rodriguez GA, Herman M, Emrani S, Nahmani E, Barrett G, et al. Tau pathology induces excitatory neuron loss, grid cell dysfunction, and spatial memory deficits reminiscent of early Alzheimer's disease. Neuron. 2017;93(3):533-541.e535.

123. Abd-Elrahman KS, Hamilton A, Vasefi M, Ferguson SSG. Autophagy is increased following either pharmacological or genetic silencing of mGluR5 signaling in Alzheimer's disease mouse models. Mol Brain. 2018;11(1):19

124. Hsiao YH, Hung HC, Chen SH, Gean PW. Social interaction rescues memory deficit in an animal model of Alzheimer's disease by increasing BDNF-dependent hippocampal neurogenesis. J Neurosci. 2014;34(49):16207-19.

125. Jiao S, Shen L, Zhu C, Bu X, Liu Y, Liu C, et al. Brain-derived neurotrophic factor protects against tau-related neurodegeneration of Alzheimer's disease. Transl Psychiatry. 2016;6(10):e907-e907.

126. Nagahara AH, Mateling $M$, Kovacs I, Wang L, Eggert $S$, Rockenstein $E$, et al. Early BDNF treatment ameliorates cell loss in the entorhinal cortex of APP transgenic mice. J Neurosci. 2013;33(39):15596-602.

127. Nigam SM, Xu S, Kritikou JS, Marosi K, Brodin L, Mattson MP. Exercise and $B D N F$ reduce $A \beta$ production by enhancing a-secretase processing of APP. J Neurochem. 2017;142(2):286-96.

128. Psotta L, Rockahr C, Gruss M, Kirches E, Braun K, Lessmann V, et al. Impact of an additional chronic BDNF reduction on learning performance in an Alzheimer mouse model. Front Behav Neurosci. 2015;9:58.

129. Rantamaki T, Kemppainen S, Autio H, Staven S, Koivisto H, Kojima M, et al. The impact of Bdnf gene deficiency to the memory impairment and brain pathology of APPswe/PS1dE9 mouse model of Alzheimer's disease. PLOS ONE. 2013;8(7):e68722.

130. Castello NA, Green KN, LaFerla FM. Genetic knockdown of brain-derived neurotrophic factor in 3xTg-AD mice does not alter $A \beta$ or tau pathology. PLoS ONE. 2012;7(8):e39566.

131. Ge YW, Lahiri D. Regulation of promoter activity of the APP gene by cytokines and growth factors: implications in Alzheimer's disease. Ann NY Acad Sci. 2002;973(1):463-7.

132. Phillips HS, Hains JM, Armanini M, Laramee GR, Johnson SA, Winslow JW. BDNF mRNA is decreased in the hippocampus of individuals with Alzheimer's disease. Neuron. 1991;7(5):695-702.

133. Garzon D, Yu G, Fahnestock M. A new brain-derived neurotrophic factor transcript and decrease in brain-derived neurotrophic factor transcripts 1, 2 and 3 in Alzheimer's disease parietal cortex. J Neurochem. 2002;82(5):1058-64.

134. Ginsberg SD, Malek-Ahmadi MH, Alldred MJ, Chen Y, Chen K, Chao MV, et al. Brain-derived neurotrophic factor (BDNF) and TrkB hippocampal gene expression are putative predictors of neuritic plaque and neurofibrillary tangle pathology. Neurobi Dis. 2019;132:104540.

135. Lee J, Fukumoto H, Orne J, Klucken J, Raju S, Vanderburg CR, et al. Decreased levels of BDNF protein in Alzheimer temporal cortex are independent of BDNF polymorphisms. Exp Neurol. 2005;194(1):91-6.

136. Hock C, Heese K, Hulette C, Rosenberg C, Otten U. Region-specific neurotrophin imbalances in Alzheimer disease: decreased levels of brainderived neurotrophic factor and increased levels of nerve growth factor in hippocampus and cortical areas. Arch Neurol. 2000;57(6):846-51.

137. Li G, Peskind ER, Millard SP, Chi P, Sokal I, Yu CE, et al. Cerebrospinal fluid concentration of brain-derived neurotrophic factor and cognitive function in non-demented subjects. PLoS ONE. 2009;4(5):e5424.

138. Laske C, Stransky E, Leyhe T, Eschweiler GW, Maetzler W, Wittorf A, et al. BDNF serum and CSF concentrations in Alzheimer's disease, normal pressure hydrocephalus and healthy controls. J Psychiatric Res. 2007;41(5):387-94.

139. Gezen-Ak D, Dursun E, Hanagasi H, Bilgic B, Lohman E, Araz OS, et al BDNF, TNFalpha, HSP90, CFH, and IL-10 serum levels in patients with early or late onset Alzheimer's disease or mild cognitive impairment. J Alzheimers Dis. 2013;37(1):185-95.

140. Laske C, Stellos K, Hoffmann N, Stransky E, Straten G, Eschweiler GW, et al. Higher BDNF serum levels predict slower cognitive decline in Alzheimer's disease patients. Int J Neuropsychopharmacol. 2011;14(3):399-404

141. Fernandes BS, Berk M, Turck CW, Steiner J, Goncalves CA. Decreased peripheral brain-derived neurotrophic factor levels are a biomarker 
of disease activity in major psychiatric disorders: a comparative metaanalysis. Mol Psychiatry. 2014;1 1(7):750-1.

142. Forlenza OV, Diniz BS, Teixeira AL, Ojopi EB, Talib LL, Mendonca VA, et al. Effect of brain-derived neurotrophic factor Val66Met polymorphism and serum levels on the progression of mild cognitive impairment. World J Biol Psychiatry. 2010;11(6):774-80.

143. Yu H, Zhang Z, Shi Y, Bai F, Xie C, Qian Y, et al. Association study of the decreased serum BDNF concentrations in amnestic mild cognitive impairment and the Val66Met polymorphism in Chinese Han. J Clin Psychiatry. 2008;69(7):1104-11.

144. Platenik J, Fisar Z, Buchal R, Jirak R, Kitzlerova E, Zverova M, et al. GSK3beta, CREB, and BDNF in peripheral blood of patients with Alzheimer's disease and depression. Prog Neuropsychopharmacol Biol Psychiatry. 2014;50:83-93.

145. Angelucci F, Spalletta G, di lulio F, Ciaramella A, Salani F, Varsi AE, et al. Alzheimer's disease (AD) and mild cognitive impairment (MCI) patients are characterized by increased BDNF serum levels. Curr Alzheimer Res. 2010;7(1):15-20.

146. Faria MC, Goncalves GS, Rocha NP, Moraes EN, Bicalho MA, Gualberto Cintra MT, et al. Increased plasma levels of BDNF and inflammatory markers in Alzheimer's disease. J Psychiatric Res. 2014;53:166-72.

147. Nettiksimmons J, Simonsick EM, Harris T, Satterfield S, Rosano C, Yaffe K, et al. The associations between serum brain-derived neurotrophic factor, potential confounders, and cognitive decline: a longitudinal study. PLoS ONE. 2014;9(3):e91339.

148. Qin XY, Cao C, Cawley NX, Liu TT, Yuan J, Loh YP, et al. Decreased peripheral brain-derived neurotrophic factor levels in Alzheimer's disease: a meta-analysis study ( $N=7277)$. Mol Psychiatr. 2016;22:312.

149. Weinstein G, Beiser AS, Choi SH, Preis SR, Chen TC, Vorgas D, et al. Serum Brain-derived neurotrophic factor and the risk for dementia the framingham heart study. JAMA Neurol. 2014;71(1):55-61.

150. Kim BY, Lee SH, Graham PL, Angelucci F, Lucia A, Pareja-Galeano H, et al. Peripheral brain-derived neurotrophic factor levels in alzheimer's disease and mild cognitive impairment: a comprehensive systematic review and meta-analysis. Mol Neurobiol. 2017;54(9):7297-311.

151. Bharani KL, Ledreux A, Gilmore A, Carroll SL, Granholm A-C. Serum proBDNF levels correlate with phospho-tau staining in Alzheimer's disease. Neurobiol Aging. 2020;87:49-59.

152. Lommatzsch M, Zingler D, Schuhbaeck K, Schloetcke K, Zingler C, Schuff-Werner $P$, et al. The impact of age, weight and gender on BDNF levels in human platelets and plasma. Neurobiol Aging. 2005;26(1):115-23.

153. Kerschensteiner M, Gallmeier E, Behrens L, Leal VV, Misgeld T, Klinkert WE, et al. Activated human T cells, B cells, and monocytes produce brain-derived neurotrophic factor in vitro and in inflammatory brain lesions: a neuroprotective role of inflammation? J Exp Med. 1999;189(5):865-70

154. Janel N, Alexopoulos P, Badel A, Lamari F, Camproux AC, Lagarde J, et al. Combined assessment of DYRK1A, BDNF and homocysteine levels as diagnostic marker for Alzheimer's disease. Transl Psychiatry. 2017;7(6):e1154-e1154.

155. Cargill M, Altshuler D, Ireland J, Sklar P, Ardlie K, Patil N, et al. Characterization of single-nucleotide polymorphisms in coding regions of human genes. Nat Genet. 1999;22(3):231-8.

156. Rogaeva E, Schmitt-Ulms G. Does BDNF Val66Met contribute to preclinical Alzheimer's disease? Brain. 2016;139(Pt 10):2586-9.

157. Chiaruttini C, Vicario A, Li Z, Baj G, Braiuca P, Wu Y, et al. Dendritic trafficking of BDNF mRNA is mediated by translin and blocked by the G196A (Val66Met) mutation. Proc Natl Acad Sci USA. 2009;106(38):16481-6.

158. Chen $Z Y$, leraci A, Teng H, Dall H, Meng CX, Herrera DG, et al. Sortilin controls intracellular sorting of brain-derived neurotrophic factor to the regulated secretory pathway. J Neurosci. 2005;25(26):6156-66.

159. Lim YY, Hassenstab J, Cruchaga C, Goate A, Fagan AM, Benzinger TL, et al. BDNF Val66Met moderates memory impairment, hippocampal function and tau in preclinical autosomal dominant Alzheimer's disease. Brain. 2016;139(Pt 10):2766-77.

160. Pezawas L, Verchinski BA, Mattay VS, Callicott JH, Kolachana BS, Straub $R E$, et al. The brain-derived neurotrophic factor val66met polymorphism and variation in human cortical morphology. J Neurosci. 2004:24(45):10099-102.
161. Franzmeier N, Ren J, Damm A, Monté-Rubio G, Boada M, Ruiz A, et al. The BDNFVal66Met SNP modulates the association between betaamyloid and hippocampal disconnection in Alzheimer's disease. Mol Psychiatry. 2019;26:614-28.

162. Boots EA, Schultz SA, Clark LR, Racine AM, Darst BF, Koscik RL, et al. BDNF Val66Met predicts cognitive decline in the Wisconsin Registry for Alzheimer's Prevention. Neurology. 2017:88(22):2098-106.

163. Lim YY, Villemagne VL, Laws SM, Ames D, Pietrzak RH, Ellis KA, et al. BDNF Val66Met, Abeta amyloid, and cognitive decline in preclinical Alzheimer's disease. Neurobiol Aging. 2013;34(11):2457-64.

164. Franzmeier N, Ren J, Damm A, Monté-Rubio G, Boada M, Ruiz A, et al. The BDNFVal66Met SNP modulates the association between betaamyloid and hippocampal disconnection in Alzheimer's disease. Mol Psychiatry. 2021;26(2):614-28.

165. Cechova K, Andel R, Angelucci F, Chmatalova Z, Markova H, Laczó J, et al. Impact of APOE and BDNF Val66Met gene polymorphisms on cognitive functions in patients with amnestic mild cognitive impairment. J Alzheimer Dis. 2020;73:247-57.

166. Li GD, Bi R, Zhang DF, Xu M, Luo R, Wang D, et al. Female-specific effect of the BDNF gene on Alzheimer's disease. Neurobiol Aging. 2017;53:192.e111-192.e119.

167. Fukumoto N, Fujii T, Combarros O, Kamboh MI, Tsai SJ, Matsushita S, et al. Sexually dimorphic effect of the Val66Met polymorphism of BDNF on susceptibility to Alzheimer's disease: new data and meta-analysis. Am J Med Genet B Neuropsychiatr Genet. 2010;153B(1):235-42.

168. Lin Y, Cheng S, Xie Z, Zhang D. Association of rs6265 and rs 2030324 polymorphisms in brain-derived neurotrophic factor gene with Alzheimer's disease: a meta-analysis. PLoS ONE. 2014;9(4):e94961.

169. Bessi V, Mazzeo S, Bagnoli S, Padiglioni S, Carraro M, Piaceri I, et al. The implication of BDNF Val66Met polymorphism in progression from subjective cognitive decline to mild cognitive impairment and Alzheimer's disease: a 9-year follow-up study. Eur Arch Psychiatry Clin Neurosci. 2020;270(4):471-82.

170. Lambert J-C, Ibrahim-Verbaas CA, Harold D, Naj AC, Sims R, Bellenguez C, et al. Meta-analysis of 74,046 individuals identifies 11 new susceptibility loci for Alzheimer's disease. Nat Genet. 2013;45(12):1452-8.

171. Lim YY, Villemagne VL, Laws SM, Pietrzak RH, Snyder PJ, Ames D, et al. APOE and BDNF polymorphisms moderate amyloid beta-related cognitive decline in preclinical Alzheimer's disease. Mol Psychiatry. 2015;20(11):1322-8

172. Zdanys KF, Kleiman TG, Zhang H, Ozbay F, MacAvoy MG, Gelernter J, et al. BDNF variants, premorbid educational attainment, and disease characteristics in Alzheimer's disease: an exploratory study. J Alzheimers Dis. 2009;17(4):887-98.

173. Isackson PJ, Towner MD, Huntsman MM. Comparison of mammalian, chicken and Xenopus brain-derived neurotrophic factor coding sequences. FEBS Lett. 1991:285(2):260-4.

174. Kasemeier-Kulesa JC, Morrison JA, Lefcort F, Kulesa PM. TrkB/BDNF signalling patterns the sympathetic nervous system. Nat Commun. 2015;6:8281.

175. Harward SC, Hedrick NG, Hall CE, Parra-Bueno P, Milner TA, Pan E, et al. Autocrine BDNF-TrkB signalling within a single dendritic spine. Nature. 2016:538:99.

176. Minichiello L, Calella AM, Medina DL, Bonhoeffer T, Klein R, Korte M. Mechanism of TrkB-mediated hippocampal long-term potentiation. Neuron. 2002;36(1):121-37.

177. Revest J, Le Roux A, Roullot-Lacarrière V, Kaouane N, Vallée M, Kasanetz F, et al. BDNF-TrkB signaling through Erk1/2 MAPK phosphorylation mediates the enhancement of fear memory induced by glucocorticoids. Mol Psychiatry. 2014;19(9):1001.

178. Tao X, Finkbeiner S, Arnold DB, Shaywitz AJ, Greenberg ME. Ca2+ influx regulates $B D N F$ transcription by a CREB family transcription factordependent mechanism. Neuron. 1998;20(4):709-26.

179. Rosa E, Fahnestock M. CREB expression mediates amyloid beta-induced basal BDNF downregulation. Neurobiol Aging. 2015;36(8):2406-13.

180. Lyons MR, Schwarz CM, West AE. Members of the myocyte enhancer factor 2 transcription factor family differentially regulate Bdnf transcription in response to neuronal depolarization. J Neurosci. 2012;32(37):12780-5. 
181. Rosa E, Mahendram S, Ke YD, Ittner LM, Ginsberg SD, Fahnestock M. Tau downregulates BDNF expression in animal and cellular models of Alzheimer's disease. Neurobiol Aging. 2016;48:135-42.

182. Chen Q, Zhou Z, Zhang L, Xu S, Chen C, Yu Z. The cellular distribution and Ser 262 phosphorylation of Tau protein are regulated by BDNF in vitro. PLoS One. 2014;9(3):e91793.

183. Xiang J, Wang ZH, Ahn EH, Liu X, Yu SP, Manfredsson FP, et al. Deltasecretase-cleaved Tau antagonizes TrkB neurotrophic signalings, mediating Alzheimer's disease pathologies. Proc Natl Acad Sci U S A. 2019;116(18):9094-102.

184. Barbereau C, Yehya A, Silhol M, Cubedo N, Verdier JM, Maurice T, et al. Neuroprotective brain-derived neurotrophic factor signaling in the TAUP301L tauopathy zebrafish model. Pharmacol Res. 2020;158:104865.

185. Ortega F, Perez-Sen R, Morente V, Delicado EG, Miras-Portugal MT. P2X7, NMDA and BDNF receptors converge on GSK3 phosphorylation and cooperate to promote survival in cerebellar granule neurons. Cell Mol Life Sci. 2010;67(10):1723-33.

186. Yasuda S, Liang MH, Marinova Z, Yahyavi A, Chuang DM. The mood stabilizers lithium and valproate selectively activate the promoter IV of brain-derived neurotrophic factor in neurons. Mol Psychiatry. 2009;14(1):51-9.

187. Lucas JJ, Hernandez F, Gomez-Ramos P, Moran MA, Hen R, Avila J. Decreased nuclear beta-catenin, tau hyperphosphorylation and neurodegeneration in GSK-3beta conditional transgenic mice. EMBO J. 2001;20(1-2):27-39

188. Jin N, Yin X, Yu D, Cao M, Gong CX, lqbal K, et al. Truncation and activation of GSK-3beta by calpain l: a molecular mechanism links to tau hyperphosphorylation in Alzheimer's disease. Sci Rep. 2015;5:8187.

189. Jiao SS, Shen LL, Zhu C, Bu XL, Liu YH, Liu CH, et al. Brain-derived neurotrophic factor protects against tau-related neurodegeneration of Alzheimer's disease. Transl Psychiatry. 2016;6(10):e907.

190. Bromley-Brits K, Song W. The role of TMP21 in trafficking and amyloidprecursor protein (APP) processing in Alzheimer's disease. Curr Alzheimer Res. 2012;9(4):411-24.

191. Sun X, Bromley-Brits K, Song W. Regulation of $\beta$-site APP-cleaving enzyme 1 gene expression and its role in Alzheimer's disease. J Neurochem. 2012;120(s1):62-70.

192. Kang J, Lemaire HG, Unterbeck A, Salbaum JM, Masters CL, Grzeschik $\mathrm{KH}$, et al. The precursor of Alzheimer's disease amyloid A4 protein resembles a cell-surface receptor. Nature. 1987:325(6106):733-6.

193. Zhang S, Wang Z, Cai F, Zhang M, Wu Y, Zhang J, et al. BACE1 cleavage site selection critical for amyloidogenesis and Alzheimer's pathogenesis. J Neurosci. 2017;37(29):6915-25.

194. Nunan J, Small DH. Regulation of APP cleavage by alpha-, beta- and gamma-secretases. FEBS Lett. 2000;483(1):6-10

195. Esch FS, Keim PS, Beattie EC, Blacher RW, Culwell AR, OltersdorfT, et al. Cleavage of amyloid beta peptide during constitutive processing of its precursor. Science. 1990;248(4959):1122-4.

196. Song W, Nadeau P, Yuan M, Yang X, Shen J, Yankner BA. Proteolytic release and nuclear translocation of Notch-1 are induced by presenilin-1 and impaired by pathogenic presenilin-1 mutations. Proc Natl Acad Sci U S A. 1999;96(12):6959-63.

197. Zhang Z, Nadeau P, Song W, Donoviel D, Yuan M, Bernstein A, et al. Presenilins are required for gamma-secretase cleavage of beta-APP and transmembrane cleavage of Notch-1. Nat Cell Biol. 2000;2(7):463-5.

198. Sun X, Wang Y, Qing H, Christensen MA, Liu Y, Zhou W, et al. Distinct transcriptional regulation and function of the human BACE2 and BACE1 genes. FASEB J. 2005;19(7):739-49.

199. Deng Y, Wang Z, Wang R, Zhang X, Zhang S, Wu Y, et al. Amyloid-beta protein (Abeta) Glu11 is the major beta-secretase site of beta-site amyloid-beta precursor protein-cleaving enzyme 1(BACE1), and shifting the cleavage site to Abeta Asp1 contributes to Alzheimer pathogenesis. Eur J Neurosci. 2013;37(12):1962-9.

200. Wang Z, Xu Q, Cai F, Liu X, WU Y, Song W. BACE2, a conditional betasecretase, contributes to Alzheimer's disease pathogenesis. JCI Insight. 2019;4(1):e123431.

201. Zhang S, Cai F, Wu Y, Bozorgmehr T, Wang Z, Zhang S, et al. A presenilin-1 mutation causes Alzheimer disease without affecting Notch signaling. Mol Psychiatry. 2020;25(3):603-13.

202. Xia DY, Huang X, Bi CF, Mao LL, Peng LJ, Qian HR. PGC-1alpha or FNDC5 is involved in modulating the effects of Abeta1-42 oligomers on suppressing the expression of BDNF, a beneficial factor for inhibiting neuronal apoptosis, abeta deposition and cognitive decline of APP/PS1 Tg mice. Front Aging Neurosci. 2017;9:65.

203. Poon WW, Blurton-Jones M, Tu CH, Feinberg LM, Chabrier MA, Harris JW, et al. $\beta$-Amyloid impairs axonal BDNF retrograde trafficking. Neurobiol Aging. 2011;32(5):821-33.

204. Garzon DJ, Fahnestock M. Oligomeric amyloid decreases basal levels of brain-derived neurotrophic factor (BDNF) mRNA via specific downregulation of BDNF transcripts IV and V in differentiated human neuroblastoma cells. J Neurosci. 2007;27(10):2628.

205. Matrone C, Ciotti MT, Mercanti D, Marolda R, Calissano P. NGF and BDNF signaling control amyloidogenic route and Abeta production in hippocampal neurons. Proc Natl Acad Sci U S A. 2008;105(35):13139-44.

206. Ruiz-León Y, Pascual A. Brain-derived neurotrophic factor stimulates $\beta$-amyloid gene promoter activity by a Ras-dependent/AP-1-independent mechanism in SH-SY5Y neuroblastoma cells. J Neurochem. 2001;79(2):278-85.

207. Haapasalo A, Sipola I, Larsson K, Akerman KE, Stoilov P, Stamm $S$, et al. Regulation of TRKB surface expression by brain-derived neurotrophic factor and truncated TRKB isoforms. J Biol Chem. 2002;277(45):43160-7.

208. Holback S, Adlerz L, Iverfeldt K. Increased processing of APLP2 and APP with concomitant formation of APP intracellular domains in BDNF and retinoic acid-differentiated human neuroblastoma cells. J Neurochem. 2005;95(4):1059-68.

209. Xia Y, Wang Z-H, Liu P, Edgington-Mitchell L, Liu X, Wang X-C, et al. TrkB receptor cleavage by delta-secretase abolishes its phosphorylation of APP, aggravating Alzheimer's disease pathologies. Mol Psychiatry. 2020;26:1-21

210. Liao J, Chen C, Ahn EH, Liu X, Li H, Edgington-Mitchell LE, et al. Targeting both BDNF/TrkB pathway and delta-secretase for treating Alzheimer's disease. Neuropharmacology. 2021;197:108737.

211. Knupp A, Mishra S, Martinez R, Braggin JE, Szabo M, Kinoshita C, et al. Depletion of the AD risk gene SORL1 selectively impairs neuronal endosomal traffic independent of amyloidogenic APP processing. Cell Rep. 2020;31(9):107719.

212. Sager KL, Wuu J, Leurgans SE, Rees HD, Gearing M, Mufson EJ, et al. Neuronal LR1 1/sorLA expression is reduced in mild cognitive impairment. Ann Neurol. 2007:62(6):640-7.

213. Rogaeva E, Meng Y, Lee JH, Gu Y, Kawarai T, Zou F, et al. The neuronal sortilin-related receptor SORL1 is genetically associated with Alzheimer disease. Nat Genet. 2007;39(2):168-77.

214. Rohe M, Synowitz M, Glass R, Paul SM, Nykjaer A, Willnow TE. Brain-derived neurotrophic factor reduces amyloidogenic processing through control of SORLA gene expression. J Neurosci. 2009;29(49):15472-8.

215. Zhao M, Liu J, He J, Chen X, Feng Y, Wang C, et al. A study of the SORL1 gene in the pathogenesis of late-onset Alzheimer's disease by affecting the expression of BDNF. Research Square; 2021

216. Young JE, Boulanger-Weill J, Williams DA, Woodruff G, Buen F, Revilla AC, et al. Elucidating molecular phenotypes caused by the SORL1 Alzheimer's disease genetic risk factor using human induced pluripotent stem cells. Cell Stem Cell. 2015;16(4):373-85.

217. Mañucat-Tan NB, Saadipour K, Wang Y-J, Bobrovskaya L, Zhou XF. Cellular trafficking of amyloid precursor protein in Amyloidogenesis physiological and pathological significance. Mol Neurobiol. 2019;56(2):812-30

218. Iulita MF, Bistué Millón MB, Pentz R, Aguilar LF, Do Carmo S, Allard $S$, et al. Differential deregulation of NGF and BDNF neurotrophins in a transgenic rat model of Alzheimer's disease. Neurobiol Dis. 2017;108:307-23.

219. Canu N, Amadoro G, Triaca V, Latina V, Sposato V, Corsetti V, et al. The intersection of NGF/TrkA signaling and amyloid precursor protein processing in Alzheimer's disease neuropathology. Int J Mol Sci. 2017;18(6):1319.

220. Von Rotz RC, Kohli BM, Bosset J, Meier M, Suzuki T, Nitsch RM, et al. The APP intracellular domain forms nuclear multiprotein complexes and regulates the transcription of its own precursor. J Cell Sci. 2004;117(19):4435-48. 
221. Triaca V, Sposato V, Bolasco G, Ciotti MT, Pelicci P, Bruni AC, et al. NGF controls APP cleavage by downregulating APP phosphorylation at Thr668: relevance for Alzheimer's disease. Aging Cell. 2016;15(4):661-72.

222. Canu N, Pagano I, La Rosa LR, Pellegrino M, Ciotti MT, Mercanti D, et al. Association of TrkA and APP is promoted by NGF and reduced by cell death-promoting agents. Front Mol Neurosci. 2017;10:15.

223. Stephens RM, Loeb DM, Copeland TD, Pawson T, Greene LA, Kaplan DR. Trk receptors use redundant signal transduction pathways involving SHC and PLC- $\gamma 1$ to mediate NGF responses. Neuron. 1994;12(3):691-705

224. Chen JY, Lin JR, Cimprich KA, Meyer T. A two-dimensional ERK-AKT signaling code for an NGF-triggered cell-fate decision. Mol Cell. 2012:45(2):196-209.

225. Delcroix J-D, Valletta JS, Wu C, Hunt SJ, Kowal AS, Mobley WC. NGF signaling in sensory neurons: evidence that early endosomes carry NGF retrograde signals. Neuron. 2003;39(1):69-84.

226. Triaca V, Ruberti F, Canu N. NGF and the amyloid precursor protein in Alzheimer's disease: from molecular players to neuronal circuits. Adv Exp Med Biol. 2021;1331:145-65.

227. Nykjaer A, Lee $R$, Teng KK, Jansen P, Madsen P, Nielsen MS, et al. Sortilin is essential for proNGF-induced neuronal cell death. Nature. 2004;427(6977):843-8

228. Castle MJ, Baltanás FC, Kovacs I, Nagahara AH, Barba D, Tuszynski MH. Postmortem analysis in a clinical trial of AAV2-NGF gene therapy for Alzheimer's disease identifies a need for improved vector delivery. Hum Gene Ther. 2020;31(7-8):415-22.

229. Nagahara AH, Tuszynski MH. Potential therapeutic uses of BDNF in neurological and psychiatric disorders. Nat Rev Drug Discov. 2011;10(3):209-19.

230. Nagahara AH, Wilson BR, Ivasyk I, Kovacs I, Rawalji S, Bringas JR, et al. MR-guided delivery of AAV2-BDNF into the entorhinal cortex of nonhuman primates. Gene Ther. 2018;25(2):104-14.

231. Oitzl MS, Van Oers H, Schöbitz B, de Kloet ER. Interleukin-1 $\beta$, but not interleukin-6, impairs spatial navigation learning. Brain Res. 1993:613(1):160-3.

232. Guan Z, Fang J. Peripheral immune activation by lipopolysaccharide decreases neurotrophins in the cortex and hippocampus in rats. Brain Behav Immun. 2006;20(1):64-71.

233. Chen TT, Lan TH, Yang FY. Low-intensity pulsed ultrasound attenuates LPS-induced neuroinflammation and memory impairment by modulation of TLR4/NF-KB signaling and CREB/BDNF expression. Cereb Cortex. 2019;29(4):1430-8.

234. Chapman TR, Barrientos RM, Ahrendsen JT, Hoover JM, Maier SF, Patterson SL. Aging and infection reduce expression of specific brainderived neurotrophic factor mRNAs in hippocampus. Neurobiol Aging. 2012;33(4):832.e831-814

235. Ahn EH, Kang SS, Liu X, Cao X, Choi SY, Musazzi L, et al. BDNF and Netrin-1 repression by $C / E B P \beta$ in the gut triggers Parkinson's disease pathologies, associated with constipation and motor dysfunctions. Prog Neurobiol. 2021;198:101905.

236. Ly PT, Wu Y, Zou H, Wang R, Zhou W, Kinoshita A, et al. Inhibition of GSK3beta-mediated BACE1 expression reduces Alzheimer-associated phenotypes. J Clin Invest. 2013;123(1):224-35.

237. Barger SW, Harmon AD. Microglial activation by Alzheimer amyloid precursor protein and modulation by apolipoprotein E. Nature. 1997;388(6645):878-81.

238. Lipsky RH, Xu K, Zhu D, Kelly C, Terhakopian A, Novelli A, et al. Nuclear factor $\mathrm{KB}$ is a critical determinant in N-methyl-d-aspartate receptormediated neuroprotection. J Neurochem. 2001;78(2):254-64.

239. Lipsky RH, Ke Xu, Zhu D, Kelly C, Terhakopian A, Novelli A, et al. Nuclear factor $\mathrm{kB}$ is a critical determinant in N-methyl-d-aspartate receptormediated neuroprotection. J Neurochem. 2001;78:254-64.

240. Lubin FD, Ren Y, Xu X, Anderson AE. Nuclear factor-kB regulates seizure threshold and gene transcription following convulsant stimulation. J Neurochem. 2007;103(4):1381-95.

241. Chao CC, Ma YL, Lee EHY. Brain-derived neurotrophic factor enhances $\mathrm{BCl}-\mathrm{xL}$ expression through protein kinase casein kinase 2-activated and nuclear factor kappa b-mediated pathway in rat hippocampus. Brain Pathol. 2011;21(2):150-62.
242. Zhou LJ, Zhong Y, Ren WJ, Li YY, Zhang T, Liu XG. BDNF induces latephase LTP of C-fiber evoked field potentials in rat spinal dorsal horn. Exp Neurol. 2008;212(2):507-14.

243. Blurton-Jones M, Kitazawa M, Martinez-Coria H, Castello NA, Muller FJ, Loring JF, et al. Neural stem cells improve cognition via BDNF in a transgenic model of Alzheimer disease. Proc Natl Acad Sci USA. 2009;106(32):13594-9.

244. Poduslo JF, Curran GL. Permeability at the blood-brain and blood-nerve barriers of the neurotrophic factors: NGF, CNTF, NT-3. BDNF Mol Brain Res. 1996;36(2):280-6.

245. Zuccato C, Cattaneo E. Brain-derived neurotrophic factor in neurodegenerative diseases. Nat Rev Neurol. 2009;5(6):311-22.

246. Pardridge WM, Kang YS, Buciak JL. Transport of human recombinant brain-derived neurotrophic factor (BDNF) through the rat blood-brain barrier in vivo using vector-mediated peptide drug delivery. Pharm Res. 1994;11(5):738-46.

247. Lu B, Nagappan G, Guan X, Nathan PJ, Wren P. BDNF-based synaptic repair as a disease-modifying strategy for neurodegenerative diseases. Nat Rev Neurosci. 2013;14(6):401-16.

248. Song J-H, Yu J-T, Tan L. Brain-derived neurotrophic factor in Alzheimer's disease: risk, mechanisms, and therapy. Mol Neurobiol. 2015;52(3):1477-93.

249. Caffino L, Mottarlini F, Fumagalli F. Born to protect: Leveraging BDNF against cognitive deficit in Alzheimer's disease. CNS Drugs. 2020;34(3):281-97.

250. Schmitz TW, Spreng RN, Initi AsDN. Basal forebrain degeneration precedes and predicts the cortical spread of Alzheimer's pathology. Nat Commun. 2016;7:13249

251. Autio H, Matlik K, Rantamaki T, Lindemann L, Hoener MC, Chao M et al. Acetylcholinesterase inhibitors rapidly activate Trk neurotrophin receptors in the mouse hippocampus. Neuropharmacology. 2011;61(8):1291-6.

252. Alderson RF, Alterman AL, Barde YA, Lindsay RM. Brain-derived neurotrophic factor increases survival and differentiated functions of rat septal cholinergic neurons in culture. Neuron. 1990;5(3):297-306.

253. Jian W, Zhang Z, Zhan J, Chu S, Peng Y, Zhao M, et al. Donepezil attenuates vascular dementia in rats through increasing BDNF induced by reducing HDAC6 nuclear translocation. Acta Pharmacol Sin. 2020;41(5):588-98.

254. Trzeciakiewicz H, Ajit D, Tseng J-H, Chen Y, Ajit A, Tabassum Z, et al. An HDAC6-dependent surveillance mechanism suppresses taumediated neurodegeneration and cognitive decline. Nat Commun. 2020;11(1):1-18.

255. Sen A, Nelson TJ, Alkon DL. ApoE4 and A $B$ oligomers reduce BDNF expression via HDAC nuclear translocation. J Neurosci. 2015:35(19):7538-51.

256. Liu D, Zhang M, Jiang X, Lei H, Li J, Wang X. Protective effects and the mechanisms of donepezil and galantamine on neuronal injury induced by glucose deprivation/reoxygenation. Acta Pharm Sin. 2017;12:928-35

257. Chi S, Wang C, Jiang T, Zhu X-C, Yu J-T, Tan L. The prevalence of depression in Alzheimer's disease: a systematic review and meta-analysis. Curr Alzheimer Res. 2015;12(2):189-98.

258. Starkstein SE, Jorge R, Mizrahi R, Robinson RG. The construct of minor and major depression in Alzheimer's disease. Am J Psychiatry. 2005;162(11):2086-93.

259. Byers AL, Yaffe K. Depression and risk of developing dementia. Nat Rev Neurol. 2011;7(6):323-31.

260. Singh-Manoux A, Dugravot A, Fournier A, Abell J, Ebmeier K, Kivimäki M et al. Trajectories of depressive symptoms before diagnosis of dementia: a 28-year follow-up study. JAMA Psychiat. 2017;74(7):712-8.

261. Orgeta V, Tabet N, Nilforooshan R, Howard R. Efficacy of antidepressants for depression in Alzheimer's disease: systematic review and metaanalysis. J Alzheimer Dis. 2017;58:725-33.

262. Saarelainen T, Hendolin P, Lucas G, Koponen E, Sairanen M, MacDonald $E$, et al. Activation of the TrkB neurotrophin receptor is induced by antidepressant drugs and is required for antidepressant-induced behavioral effects. J Neurosci. 2003;23(1):349-57.

263. Kohtala S, Theilmann W, Rosenholm M, Penna L, Karabulut G, Uusitalo $\mathrm{S}$, et al. Cortical excitability and activation of TrkB signaling during rebound slow oscillations are critical for rapid antidepressant responses. Mol Neurobiol. 2019:56(6):4163-74. 
264. Kozisek ME, Middlemas D, Bylund DB. Brain-derived neurotrophic factor and its receptor tropomyosin-related kinase $B$ in the mechanism of action of antidepressant therapies. Pharmacol Ther. 2008;117(1):30-51.

265. Coppell AL, Pei Q, Zetterström TSC. Bi-phasic change in BDNF gene expression following antidepressant drug treatment. Neuropharmacology. 2003;44(7):903-10.

266. Khundakar A, Zetterstrom T, editors. Differential expression of BDNF exons in rat brain after systemic administration of paroxetine and tranylcypromine. Nature Publishing Group; 2002.

267. Russo-Neustadt A, Beard R, Huang Y, Cotman C. Physical activity and antidepressant treatment potentiate the expression of specific brain-derived neurotrophic factor transcripts in the rat hippocampus. Neuroscience. 2000:101(2):305-12.

268. Zhang L, Fang Y, Zeng Z, Lian Y, Wei J, Zhu H, et al. BDNF gene polymorphisms are associated with Alzheimer's disease-related depression and antidepressant response. J Alzheimers Dis. 2011;26(3):523-30.

269. Orgeta V, Tabet N, Nilforooshan R, Howard R, Leoutsakos J-M. Efficacy of antidepressants for depression in Alzheimer's disease: systematic review and meta-analysis. J Alzheimers Dis. 2017;58(3):725-33.

270. Wang J, Yu JT, Wang HF, Meng XF, Wang C, Tan CC, et al. Pharmacological treatment of neuropsychiatric symptoms in Alzheimer's disease: a systematic review and meta-analysis. J Neurol Neurosurg Psychiatry. 2015;86(1):101-9.

271. Thompson S, Herrmann N, Rapoport MJ, Lanctôt KL. Efficacy and safety of antidepressants for treatment of depression in Alzheimer's disease: a metaanalysis. Can J Psychiatry. 2007;52(4):248-55.

272. Khoury R, Grossberg GT. Impact of antidepressant use on the trajectory of Alzheimer's disease: evidence, mechanisms, and therapeutic implications. CNS Drugs. 2019;33(1):17-29.

273. Scharfman HE, MacLusky NJ. Estrogen and brain-derived neurotrophic factor (BDNF) in hippocampus: complexity of steroid hormonegrowth factor interactions in the adult CNS. Front Neuroendocrinol. 2006:27(4):415-35.

274. Harte-Hargrove LC, MacLusky NJ, Scharfman HE. Brain-derived neurotrophic factor-estrogen interactions in the hippocampal mossy fiber pathway: Implications for normal brain function and disease. Neuroscience. 2013;239:46-66.

275. Wu YWC, Du X, van den Buuse M, Hill RA. Analyzing the influence of BDNF heterozygosity on spatial memory response to $17 \beta$-estradiol. Transl Psychiatry. 2015;5(1):e498-e498.

276. Lee J, Duan W, Mattson MP. Evidence that brain-derived neurotrophic factor is required for basal neurogenesis and mediates, in part, the enhancement of neurogenesis by dietary restriction in the hippocampus of adult mice. J Neurochem. 2002;82(6):1367-75.

277. Santarelli L, Saxe M, Gross C, Surget A, Battaglia F, Dulawa S, et al. Requirement of hippocampal neurogenesis for the behavioral effects of antidepressants. Science. 2003;301(5634):805-9.

278. Solum DT, Handa RJ. Estrogen regulates the development of brainderived neurotrophic factor mRNA and protein in the rat hippocampus. J Neurosci. 2002;22(7):2650-9.

279. McEwen B, Akama K, Alves S, Brake WG, Bulloch K, Lee S, et al. Tracking the estrogen receptor in neurons: implications for estrogen-induced synapse formation. Proc Natl Acad Sci USA. 2001;98(13):7093-100.

280. Rossetti AC, Paladini MS, Trepci A, Mallien A, Riva MA, Gass P, et al. Differential neuroinflammatory response in male and female mice: a role for BDNF. Front Mol Neurosci. 2019;12:166.

281. Sohrabji F, Miranda R, Toran-Allerand CD. Identification of a putative estrogen response element in the gene encoding brain-derived neurotrophic factor. Proc Natl Acad Sci USA. 1995;92(24):11110-4.

282. Wu MV, Manoli DS, Fraser EJ, Coats JK, Tollkuhn J, Honda S-I, et al. Estrogen masculinizes neural pathways and sex-specific behaviors. Cell. 2009;139(1):61-72.

283. Koss WA, Haertel JM, Philippi SM, Frick KM. Sex differences in the rapid cell signaling mechanisms underlying the memory-enhancing effects of 17 beta-estradiol. Eneuro. 2018;5(5):e0267-e318.

284. Scharfman HE, MacLusky NJ. Similarities between actions of estrogen and BDNF in the hippocampus: coincidence or clue? Trend Neurosci. 2005;28(2):79-85.

285. Bi R, Broutman G, Foy MR, Thompson RF, Baudry M. The tyrosine kinase and mitogen-activated protein kinase pathways mediate multiple effects of estrogen in hippocampus. Proc Natl Acad Sci USA. 2000;97(7):3602-7.

286. Mizuno M, Yamada K, Takei N, Tran MH, He J, Nakajima A, et al. Phosphatidylinositol 3-kinase: a molecule mediating BDNF-dependent spatial memory formation. Mol Psychiatry. 2003;8(2):217-24.

287. Blanquet PR, Mariani J, Derer P. A calcium/calmodulin kinase pathway connects brain-derived neurotrophic factor to the cyclic AMPresponsive transcription factor in the rat hippocampus. Neuroscience. 2003:118(2):477-90

288. Lu Y, Sareddy GR, Wang J, Wang R, Li Y, Dong Y, et al. Neuron-derived estrogen regulates synaptic plasticity and memory. J Neurosci. 2019:39(15):2792-809.

289. Gross KS, Alf RL, Polzin TR, Frick KM. 17ß-estradiol activation of dorsal hippocampal TrkB is independent of increased mature BDNF expression and is required for enhanced memory consolidation in female mice. Psychoneuroendocrinology. 2021;125:105110.

290. Simpkins JW, Green PS, Gridley KE, Singh M, de Fiebre NC, Rajakumar G. Role of estrogen replacement therapy in memory enhancement and the prevention of neuronal loss associated with Alzheimer's disease. Am J Med. 1997:103(3 Supplement 1):19S-25S.

291. Imtiaz B, Tuppurainen M, Rikkonen T, Kivipelto M, Soininen H, Kröger $\mathrm{H}$, et al. Postmenopausal hormone therapy and Alzheimer disease: a prospective cohort study. Neurology. 2017;88(11):1062-8.

292. Zhou C, Wu Q, Wang Z, Wang Q, Liang Y, Liu S. The effect of hormone replacement therapy on cognitive function in female patients with Alzheimer's disease: a meta-analysis. Am J Alzheimer Dis Other Dement. 2020;35:1533317520938585.

293. Song YJ, Li SR, Li XW, Chen X, Wei ZX, Liu QS, et al. The effect of estrogen replacement therapy on Alzheimer's disease and Parkinson's disease in postmenopausal women: a meta-analysis. Front Neurosci. 2020;14:157.

294. Dye RV, Miller KJ, Singer EJ, Levine AJ. Hormone replacement therapy and risk for neurodegenerative diseases. Int J Alzheimer Dis. 2012:2012:258454

295. O'Brien J, Jackson JW, Grodstein F, Blacker D, Weuve J. Postmenopausal hormone therapy is not associated with risk of all-cause dementia and Alzheimer's disease. Epidemiol Rev. 2014;36(1):83-103.

296. Butovsky E, Juknat A, Goncharov I, Elbaz J, Eilam R, Zangen A, et al. In vivo up-regulation of brain-derived neurotrophic factor in specific brain areas by chronic exposure to $\Delta 9$-tetrahydrocannabinol. J Neurochem. 2005:93(4):802-11.

297. Munro S, Thomas KL, Abu-Shaar M. Molecular characterization of a peripheral receptor for cannabinoids. Nature. 1993:365(6441):61-5.

298. Albayram O, Alferink J, Pitsch J, Piyanova A, Neitzert K, Poppensieker K, et al. Role of $\mathrm{CB} 1$ cannabinoid receptors on GABAergic neurons in brain aging. Proc Natl Acad Sci USA. 2011;108(27):11256-61.

299. Aguado T, Romero E, Monory K, Palazuelos J, Sendtner M, Marsicano G, et al. The CB1 cannabinoid receptor mediates excitotoxicity-induced neural progenitor proliferation and neurogenesis. J Biol Chem. 2007:282(33):23892-8.

300. Marsicano G, Goodenough S, Monory K, Hermann H, Eder M, Cannich A, et al. CB1 cannabinoid receptors and on-demand defense against excitotoxicity. Science. 2003;302(5642):84-8.

301. Burston JJ, Wiley JL, Craig AA, Selley DE, Sim-Selley L. Regional enhancement of cannabinoid CB1 receptor desensitization in female adolescent rats following repeated $\triangle 9$-tetrahydrocannabinol exposure. Br J Pharmacol. 2010;161(1):103-12.

302. D'Souza DC, Pittman B, Perry E, Simen A. Preliminary evidence of cannabinoid effects on brain-derived neurotrophic factor (BDNF) levels in humans. Psychopharmacology. 2009;202(4):569-78.

303. Blázquez C, Chiarlone A, Bellocchio L, Resel E, Pruunsild P, García-Rincón $D$, et al. The CB1 cannabinoid receptor signals striatal neuroprotection via a PI3K/Akt/mTORC1/BDNF pathway. Cell Death Differ. 2015;22:1618.

304. Segal-Gavish H, Gazit N, Barhum Y, Ben-Zur T, Taler M, Hornfeld SH, et al. BDNF overexpression prevents cognitive deficit elicited by adolescent cannabis exposure and host susceptibility interaction. Hum Mol Genet. 2017:26(13):2462-71.

305. Yeh ML, Selvam R, Levine ES. BDNF-induced endocannabinoid release modulates neocortical glutamatergic neurotransmission. Synapse. 2017;71(5):e21962. 
306. Ferreira FF, Ribeiro FF, Rodrigues RS, Sebastião AM, Xapelli S. Brainderived neurotrophic factor (BDNF) role in cannabinoid-mediated neurogenesis. Front Cell Neurosci. 2018;12:441.

307. Gocmez S, Şahin TD, Yazir Y, Eraldemir F, Polat S, Utkan T. Resveratrol improves cognitive performance and endothelial function by increasing BDNF expression and preventing oxidative stress during experimental vascular dementia in streptozotocin-induced diabetic rats. Biol Psychiatry. 2018;83(9):S144.

308. Zhang L, Fang Y, Xu Y, Lian Y, Xie N, Wu T, et al. Curcumin improves amyloid $\beta$-peptide (1-42) induced spatial memory deficits through BDNF-ERK signaling pathway. PLoS ONE. 2015;10(6):e0131525.

309. Hoppe JB, Coradini K, Frozza RL, Oliveira CM, Meneghetti AB, Bernardi $A$, et al. Free and nanoencapsulated curcumin suppress $\beta$-amyloid-induced cognitive impairments in rats: involvement of BDNF and Akt/GSK-3ß signaling pathway. Neurobiol Learn Mem. 2013;106:134-44

310. Motaghinejad M, Motevalian M, Fatima S, Hashemi H, Gholami M. Curcumin confers neuroprotection against alcohol-induced hippocampal neurodegeneration via CREB-BDNF pathway in rats. Biomed Pharmacother. 2017;87:721-40.

311. Srivastava P, Dhuriya YK, Gupta R, Shukla RK, Yadav RS, Dwivedi HN, et al. Protective effect of curcumin by modulating BDNF/DARPP32/CREB in arsenic-induced alterations in dopaminergic signaling in rat corpus striatum. Mol Neurobiol. 2018;55(1):445-61.

312. Kozikowski AP, Campiani G, Sun LQ, Wang S, Saxena A, Doctor BP. Identification of a more potent analogue of the naturally occurring alkaloid huperzine. A Predictive molecular modeling of its interaction with AChE. J Am Chem Society. 1996;118(46):11357-62.

313. Mao XY, Zhou HH, Li X, Liu ZQ. Huperzine A alleviates oxidative glutamate toxicity in hippocampal HT22 cells via activating BDNF/ TrkB-dependent PI3K/Akt/mTOR signaling pathway. Cell Mol Neurobiol. 2016;36(6):915-25.

314. Wang ZF, Tang LL, Yan H, Wang YJ, Tang XC. Effects of huperzine A on memory deficits and neurotrophic factors production after transient cerebral ischemia and reperfusion in mice. Pharmacol Biochem Behav. 2006;83(4):603-11.

315. Rafii MS, Walsh S, Little JT, Behan K, Reynolds B, Ward C, et al. A phase II trial of huperzine A in mild to moderate Alzheimer disease. Neurology. 2011;76(16):1389-94.

316. Tchantchou F, Xu Y, Wu Y, Christen Y, Luo Y. EGb 761 enhances adult hippocampal neurogenesis and phosphorylation of CREB in transgenic mouse model of Alzheimer's disease. FASEB J. 2007:21(10):2400-8.

317. Shi Y-Q, Huang T-W, Chen L-M, Pan X-D, Zhang J, Zhu Y-G, et al. Ginsenoside $R g 1$ attenuates amyloid- $\beta$ content, regulates PKA/CREB activity, and improves cognitive performance in SAMP8 mice. J Alzheimer Dis. 2010:19(3):977-89.

318. Yabe T, Tuchida H, Kiyohara H, Takeda T, Yamada H. Induction of NGF synthesis in astrocytes by onjisaponins of Polygala tenuifolia, constituents of kampo (Japanese herbal) medicine. Ninjin-yoei-to Phytomed. 2003;10(2-3):106-14.

319. Yu H, Oh-Hashi K, Tanaka T, Sai A, Inoue M, Hirata Y, et al. Rehmannia glutinosa induces glial cell line-derived neurotrophic factor gene expression in astroglial cells via CPKC and ERK1/2 pathways independently. Pharmacol Res. 2006;54(1):39-45.

320. Zhang Q, Liu X, Yan L, Zhao R, An J, Liu C, et al. Danshen extract (Salvia miltiorrhiza Bunge) attenuate spinal cord injury in a rat model: a metabolomic approach for the mechanism study. Phytomedicine. 2019:62:152966.

321. Sohn E, Kim YJ, Kim JH, Jeong SJ. Ficus erecta Thunb leaves ameliorate cognitive deficit and neuronal damage in a mouse model of amyloid- $\beta$ induced Alzheimer's disease. Front Pharmacol. 2021;12(482):607403.

322. Postu PA, Noumedem JA, Cioanca O, Hancianu M, Mihasan M, Ciorpac $M$, et al. Lactuca capensis reverses memory deficits in A $11-42-$ induced an animal model of Alzheimer's disease. J Cell Mol Med. 2018;22(1):111-22.

323. Bawari S, Tewari D, Argüelles S, Sah AN, Nabavi SF, Xu S, et al. Targeting BDNF signaling by natural products: Novel synaptic repair therapeutics for neurodegeneration and behavior disorders. Pharmacol Res. 2019;148:104458
324. Lei P, Ayton S, Appukuttan AT, Moon S, Duce JA, Volitakis I, et al. Lithium suppression of tau induces brain iron accumulation and neurodegeneration. Mol Psychiatry. 2017;22(3):396-406.

325. Duce JA, Tsatsanis A, Cater MA, James SA, Robb E, Wikhe K, et al. Ironexport ferroxidase activity of $\beta$-amyloid precursor protein is inhibited by zinc in Alzheimer's disease. Cell. 2010;142(6):857-67.

326. Chyan W, Zhang DY, Lippard SJ, Radford RJ. Reaction-based fluorescent sensor for investigating mobile $\mathrm{Zn}^{2+}$ in mitochondria of healthy versus cancerous prostate cells. Proc Natl Acad Sci USA. 2014;111(1):143-8.

327. Fang $W$, Liao $W$, Zheng $Y$, Huang $X$, Weng $X$, Fan $S$, et al. Neurotropin reduces memory impairment and neuroinflammation via BDNF/NF-KB in a transgenic mouse model of Alzheimer's disease. Am J Transl Res. 2019;11(3):1541

328. Leyhe T, Eschweiler GW, Stransky E, Gasser T, Annas P, Basun H, et al. Increase of BDNF serum concentration in lithium treated patients with early Alzheimer's disease. J Alzheimers Dis. 2009;16(3):649-56.

329. Fajardo VA, Fajardo VA, LeBlanc PJ, MacPherson REK. Examining the relationship between trace lithium in drinking water and the rising rates of age-adjusted Alzheimer's disease mortality in Texas. J Alzheimers Dis. 2018:61(1):425-34.

330. Zhao L, Gong N, Liu M, Pan X, Sang S, Sun X, et al. Beneficial synergistic effects of microdose lithium with pyrroloquinoline quinone in an Alzheimer's disease mouse model. Neurobiol Aging. 2014;35(12):2736-45.

331. Nunes MA, Viel TA, Buck HS. Microdose lithium treatment stabilized cognitive impairment in patients with Alzheimer's disease. Curr Alzheimer Res. 2013;10(1):104-7.

332. De-Paula VJ, Gattaz WF, Forlenza OV. Long-term lithium treatment increases intracellular and extracellular brain-derived neurotrophic factor (BDNF) in cortical and hippocampal neurons at subtherapeutic concentrations. Bipolar Disord. 2016;18(8):692-5.

333. Taler M, Aronovich R, Henry Hornfeld S, Dar S, Sasson E, Weizman A, et al. Regulatory effect of lithium on hippocampal blood-brain barrier integrity in a rat model of depressive-like behavior. Bipolar Disord. 2021;23(1):55-65.

334. Chorin E, Vinograd O, Fleidervish I, Gilad D, Herrmann S, Sekler I, et al. Upregulation of KCC2 activity by zinc-mediated neurotransmission via the mZnR/GPR39 receptor. J Neurosci. 2011;31(36):12916-26.

335. Mo F, Tang Y, Du P, Shen Z, Yang J, Cai M, et al. GPR39 protects against corticosterone-induced neuronal injury in hippocampal cells through the CREB-BDNF signaling pathway. J Affect Disord. 2020:272:474-84.

336. Mlyniec K, Budziszewska B, Holst B, Ostachowicz B, Nowak G. GPR39 (zinc receptor) knockout mice exhibit depression-like behavior and CREB/BDNF down-regulation in the hippocampus. Int J Neuropsychopharmacol. 2014;18(3):pyu002.

337. Adlard PA, Parncutt JM, Finkelstein DI, Bush Al. Cognitive loss in zinc transporter-3 knock-out mice: a phenocopy for the synaptic and memory deficits of Alzheimer's disease? J Neurosci. 2010;30(5):1631-6.

338. Corona C, Masciopinto F, Silvestri E, Viscovo AD, Lattanzio R, Sorda RL, et al. Dietary zinc supplementation of 3xTg-AD mice increases BDNF levels and prevents cognitive deficits as well as mitochondrial dysfunction. Cell Death Dis. 2010;1:e91.

339. Wang SM, Lee YC, Ko CY, Lai MD, Lin DY, Pao PC, et al. Increase of zinc finger protein 179 in response to CCAAT/enhancer binding protein delta conferring an antiapoptotic effect in astrocytes of Alzheimer's disease. Mol Neurobiol. 2015;51(1):370-82.

340. Abelein A, Gräslund A, Danielsson J. Zinc as chaperone-mimicking agent for retardation of amyloid $\beta$ peptide fibril formation. Proc Nat Acad Sci USA. 2015;112(17):5407-12.

341. Sensi SL, Granzotto A, Siotto M, Squitti R. Copper and zinc dysregulation in Alzheimer's disease. Trends Pharmacol Sci. 2018;39(12):1049-63.

342. Frazzini V, Granzotto A, Bomba M, Massetti N, Castelli V, d'Aurora M, et al. The pharmacological perturbation of brain zinc impairs BDNF-related signaling and the cognitive performances of young mice. Sci Rep. 2018:8(1):9768

343. Wang L, Yin YL, Liu XZ, Shen P, Zheng YG, Lan XR, et al. Current understanding of metal ions in the pathogenesis of Alzheimer's disease. Transl Neurodegener. 2020;9(1):10.

344. Lai L, Jiang X, Han S, Zhao C, Du T, Rehman FU, et al. In vivo biosynthesized zinc and iron oxide nanoclusters for high spatiotemporal dual-modality bioimaging of Alzheimer's disease. Langmuir 2017:33(36):9018-24. 
345. Wang J, Anastasia A, Bains H, Giza Jl, Clossey DG, Deng J, et al. Zinc induced structural changes in the intrinsically disordered BDNF Met prodomain confer synaptic elimination. Metallomics. 2020;12(8):1208-19

346. Hu YD, Pang W, He CC, Lu H, Liu W, Wang ZY, et al. The cognitive impairment induced by zinc deficiency in rats aged $0 \sim 2$ months related to BDNF DNA methylation changes in the hippocampus. Nutr Neurosci. 2017;20(9):519-25.

347. Moon JJ, Suh H, Bershteyn A, Stephan MT, Liu H, Huang B, et al. Interbilayer-crosslinked multilamellar vesicles as synthetic vaccines for potent humoral and cellular immune responses. Nat Mater. 2011;10(3):243-51.

348. Wang D, Tai PW, Gao G. Adeno-associated virus vector as a platform for gene therapy delivery. Nat Rev Drug Discov. 2019;18(5):358-78.

349. Lopes CDF, Gonçalves NP, Gomes CP, Saraiva MJ, Pêgo AP. BDNF gene delivery mediated by neuron-targeted nanoparticles is neuroprotective in peripheral nerve injury. Biomaterials. 2017:121:83-96.

350. Lin C-Y, Lin Y-C, Huang C-Y, Wu S-R, Chen C-M, Liu H-L. Ultrasoundresponsive neurotrophic factor-loaded microbubble-liposome complex: Preclinical investigation for Parkinson's disease treatment. J Control Release. 2020:321:519-28.

351. Avachat C. In vitro evaluation of cationic liposomal delivery of BDNF expressing plasmid DNA in experimental model of Parkinson's disease. Northeastern University; 2017.

352. Kells AP, Fong DM, Dragunow M, During MJ, Young D, Connor B. AAVMediated gene delivery of BDNF or GDNF is neuroprotective in a model of huntington disease. Mol Ther. 2004;9(5):682-8.

353. Connor B, Sun Y, von Hieber D, Tang SK, Jones KS, Maucksch C. AAV1/2mediated BDNF gene therapy in a transgenic rat model of Huntington's disease. Gene Ther. 2015;23:283.

354. Lowenstein PR, Mandel RJ, Xiong W, Kroeger K, Castro MG. Immune responses to adenovirus and adeno-associated vectors used for gene therapy of brain diseases: the role of immunological synapses in understanding the cell biology of neuroimmune interactions. Curr Gene Ther. 2007;7(5):347-60.

355. Bennett J, Wellman J, Marshall KA, McCague S, Ashtari M, DiStefanoPappas J, et al. Safety and durability of effect of contralateral-eye administration of AAV2 gene therapy in patients with childhood-onset blindness caused by RPE65 mutations: a follow-on phase 1 trial. Lancet. 2016;388(10045):661-72.

356. Shen F, Kuo R, Milon-Camus M, Han Z, Jiang L, Young WL, et al. Intravenous delivery of adeno-associated viral vector serotype 9 mediates effective gene expression in ischemic stroke lesion and brain angiogenic foci. Stroke. 2013;44(1):252-4.

357. Kaspar BK, Vissel B, Bengoechea T, Crone S, Randolph-Moore L, Muller $R$, et al. Adeno-associated virus effectively mediates conditional gene modification in the brain. Proc Natl Acad Sci USA. 2002;99(4):2320-5.

358. FDA. FDA approves novel gene therapy to treat patients with a rare form of inherited vision loss. FDA News Release; 2017 [cited 2017 December 19].

359. Fiandaca MS, Varenika V, Eberling J, McKnight T, Bringas J, Pivirotto $P$, et al. Real-time MR imaging of adeno-associated viral vector delivery to the primate brain. Neuroimage. 2009;47(Suppl 2):T27-35.

360. Shiozawa AL, Igarashi T, Kobayashi M, Nakamoto K, Kameya S, Fujishita $\mathrm{S}$, et al. Tyrosine triple mutated AAV2-BDNF gene therapy in an inner retinal injury model induced by intravitreal injection of $\mathrm{N}$-methyl-Daspartate (NMDA). Mol Vis. 2020;26:409-22.

361. Health USD. First-in-human clinical trial to assess gene therapy for Alzheimer's disease; 2021. https://health.ucsd.edu/news/releases/ Pages/2021-02-18-first-in-human-clinical-trial-to-assess-gene-therapyfor-alzheimers-disease.aspx.

362. Gunther MI, Weidner N, Muller R, Blesch A. Cell-seeded alginate hydrogel scaffolds promote directed linear axonal regeneration in the injured rat spinal cord. Acta Biomater. 2015;27:140-50.

363. Tobias CA, Dhoot NO, Wheatley MA, Tessler A, Murray M, Fischer I. Grafting of encapsulated BDNF-producing fibroblasts into the injured cord without immune suppression in adult rats. J Neurotraum. 2004;18(3):287-301

364. Kurozumi K, Nakamura K, Tamiya T, Kawano Y, Kobune M, Hirai S, et al. BDNF gene-modified mesenchymal stem cells promote functional recovery and reduce infarct size in the rat middle cerebral artery occlusion model. Mol Ther. 2004:9(2):189-97.
365. Eremenko E, Mittal K, Berner O, Kamenetsky N, Nemirovsky A, Elyahu Y, et al. BDNF-producing, amyloid $\beta$-specific CD4 T cells as targeted drugdelivery vehicles in Alzheimer's disease. EBioMedicine. 2019;43:424-34.

366. Gao M, Lu P, Lynam D, Bednark B, Campana WM, Sakamoto J, et al. BDNF gene delivery within and beyond templated agarose multi-channel guidance scaffolds enhances peripheral nerve regeneration. J Neural Eng. 2016;13(6):066011.

367. Makar TK, Bever CT, Singh IS, Royal W, Sahu SN, Sura TP, et al. Brainderived neurotrophic factor gene delivery in an animal model of multiple sclerosis using bone marrow stem cells as a vehicle. J Neuroimmunol. 2009;210(1):40-51.

368. Li LM, Huang LL, Jiang XC, Chen JC, OuYang HW, Gao JQ. Transplantation of BDNF gene recombinant mesenchymal stem cells and adhesive peptide-modified hydrogel scaffold for spinal cord repair. Curr Gene Ther. 2018;18(1):29-39.

369. Rojas JC, Lee J, John JM, Gonzalez-Lima F. Neuroprotective effects of near-infrared light in an in vivo model of mitochondrial optic neuropathy. J Neurosci. 2008:28(50):13511-21.

370. Yulug B, Hanoglu L, Khanmammadov E, Duz OA, Polat B, Hanoglu T, et al. Beyond the therapeutic effect of rTMS in Alzheimer's disease: a possible neuroprotective role of hippocampal BDNF? A minireview. Mini-Rev Med Chem. 2018;18(17):1479-85.

371. Cotelli M, Calabria M, Manenti R, Rosini S, Zanetti O, Cappa SF, et al. Improved language performance in Alzheimer disease following brain stimulation. J Neurol Neurosurg Psychiatry. 2011;82(7):794-7.

372. Ngandu T, Lehtisalo J, Solomon A, Levalahti E, Ahtiluoto S, Antikainen $R$, et al. A 2 year multidomain intervention of diet, exercise, cognitive training, and vascular risk monitoring versus control to prevent cognitive decline in at-risk elderly people (FINGER): a randomised controlled trial. Lancet. 2015;385(9984):2255-63.

373. Raz O, Haider MA, Davidson SRH, Lindner U, Hlasny E, Weersink R, et al. Real-time magnetic resonance imaging-guided focal laser therapy in patients with low-risk prostate cancer. Eur Urol. 2010;58(1):173-7.

374. Bjordal JM, Johnson MI, Iversen V, Aimbire F, Lopes-Martins RAB. Lowlevel laser therapy in acute pain: a systematic review of possible mechanisms of action and clinical effects in randomized placebo-controlled trials. Photomed Laser Surg. 2006;24(2):158-68.

375. Brown SB, Brown EA, Walker I. The present and future role of photodynamic therapy in cancer treatment. Lancet Oncol. 2004;5(8):497-508.

376. Nettekoven C, Volz LJ, Leimbach M, Pool EM, Rehme AK, Eickhoff $\mathrm{SB}$, et al. Inter-individual variability in cortical excitability and motor network connectivity following multiple blocks of rTMS. Neuroimage. 2015;118:209-18

377. Chou Y, Ton That V, Sundman M. A systematic review and meta-analysis of rTMS effects on cognitive enhancement in mild cognitive impairment and Alzheimer's disease. Neurobiol Aging. 2020;86:1-10.

378. Tan T, Xie J, Liu T, Chen X, Zheng X, Tong Z, et al. Low-frequency $(1 \mathrm{~Hz})$ repetitive transcranial magnetic stimulation (rTMS) reverses A $\beta 1-42$ mediated memory deficits in rats. Exp Gerontol. 2013;48(8):786-94.

379. Cocco S, Podda MV, Grassi C. Role of BDNF signaling in memory enhancement induced by transcranial direct current stimulation. Front Neurosci. 2018;12:427.

380. Podda MV, Cocco S, Mastrodonato A, Fusco S, Leone L, Barbati SA, et al. Anodal transcranial direct current stimulation boosts synaptic plasticity and memory in mice via epigenetic regulation of BDNF expression. Sci Rep. 2016;6(1):1-19.

381. Mallei A, Baj G, leraci A, Corna S, Musazzi L, Lee FS, et al. Expression and dendritic trafficking of BDNF-6 splice variant are impaired in knock-in mice carrying human BDNF Val66Met polymorphism. Int J Neuropsychopharmacol. 2015;18(12):pyv069.

382. Fritsch B, Reis J, Martinowich K, Schambra HM, Ji Y, Cohen LG, et al. Direct current stimulation promotes BDNF-dependent synaptic plasticity: potential implications for motor learning. Neuron. 2010:66(2): 198-204

383. Valenzuela PL, Castillo-García A, Morales JS, de la Villa P, Hampel H,

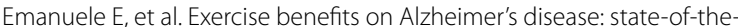
science. Ageing Res Rev. 2020;62:101108.

384. Wang R, Holsinger RMD. Exercise-induced brain-derived neurotrophic factor expression: therapeutic implications for Alzheimer's dementia. Ageing Res Rev. 2018:48:109-21. 
385. Dao AT, Zagaar MA, Levine AT, Alkadhi KA. Comparison of the effect of exercise on late-phase LTP of the dentate gyrus and CA1 of Alzheimer's disease model. Mol Neurobiol. 2016;53(10):6859-68.

386. Fahimi A, Baktir MA, Moghadam S, Mojabi FS, Sumanth K, McNerney $M W$, et al. Physical exercise induces structural alterations in the hippocampal astrocytes: exploring the role of BDNF-TrkB signaling. Brain Struct Funct. 2017:222(4):1797-808.

387. Belaya I, Ivanova M, Sorvari A, llicic M, Loppi S, Koivisto H, et al. Astrocyte remodeling in the beneficial effects of long-term voluntary exercise in Alzheimer's disease. J Neuroinflammation. 2020;17(1):271.

388. de Pins B, Cifuentes-Díaz C, Farah AT, López-Molina L, Montalban E, Sancho-Balsells A, et al. Conditional BDNF delivery from astrocytes rescues memory deficits, spine density, and synaptic properties in the 5XFAD mouse model of Alzheimer disease. J Neurosci. 2019;39(13):2441-58.

389. Lin TW, Shih YH, Chen SJ, Lien CH, Chang CY, Huang TY, et al. Running exercise delays neurodegeneration in amygdala and hippocampus of Alzheimer's disease (APP/PS1) transgenic mice. Neurobiol Learn Mem. 2015;118:189-97.

390. da Costa Daniele TM, de Bruin PFC, de Matos RS, de Bruin GS, Maia Chaves $C$, de Bruin VMS. Exercise effects on brain and behavior in healthy mice, Alzheimer's disease and Parkinson's disease model—a systematic review and meta-analysis. Behav Brain Res. 2020;383:112488.

391. Gaitán JM, Moon HY, Stremlau M, Dubal DB, Cook DB, Okonkwo OC, et al. Effects of aerobic exercise training on systemic biomarkers and cognition in late middle-aged adults at risk for Alzheimer's Disease. Front Endocrino. 2021;12:562.

392. Stewart R, Sabbah W, Tsakos G, D'Aiuto F, Watt RG. Oral health and cognitive function in the Third National Health and Nutrition Examination Survey (NHANES III). Psychosom Med. 2008;70(8):936-41.

393. de Souza RT, Fabri GMC, Nitrini R, Anghinah R, Teixeira MJ, de Siqueira JTT, et al. Oral infections and orofacial pain in Alzheimer's disease: a case-control study. J Alzheimer Dis. 2014;38(4):823-9.

394. Miklossy J. Alzheimer's disease - a neurospirochetosis. Analysis of the evidence following Koch's and Hill's criteria. J Neuroinflammation. 2011:8(1):90.

395. Vogt NM, Kerby RL, Dill-McFarland KA, Harding SJ, Merluzzi AP, Johnson SC, et al. Gut microbiome alterations in Alzheimer's disease. Sci Rep. 2017;7(1):13537.

396. Heijtz RD, Wang S, Anuar F, Qian Y, Björkholm B, Samuelsson A, et al. Normal gut microbiota modulates brain development and behavior. Proc Natl Acad Sci USA. 2011;108(7):3047.

397. Gareau MG, Wine E, Rodrigues DM, Cho JH, Whary MT, Philpott DJ, et al. Bacterial infection causes stress-induced memory dysfunction in mice. Gut. 2011;60(3):307-17.

398. Clarke G, Grenham S, Scully P, Fitzgerald P, Moloney RD, Shanahan F, et al. The microbiome-gut-brain axis during early life regulates the hippocampal serotonergic system in a sex-dependent manner. Mol Psychiatry. 2013;18(6):666-73.

399. Jiang Y, Liu Y, Gao M, Xue M, Wang Z, Liang H. Nicotinamide riboside alleviates alcohol-induced depression-like behaviours in C57BL/6J mice by altering the intestinal microbiota associated with microglial activation and BDNF expression. Food Funct. 2020;11(1):378-91.

400. Distrutti E, O'Reilly J-A, McDonald C, Cipriani S, Renga B, Lynch MA, et al. Modulation of intestinal microbiota by the probiotic VSL\# 3 resets brain gene expression and ameliorates the age-related deficit in LTP. PLOS ONE. 2014;9(9):e106503.

401. Maqsood R, Stone TW. The gut-brain axis, BDNF, NMDA and CNS disorders. Neurochem Res. 2016:41(11):2819-35.

402. Martins-de-Souza D. Proteome and transcriptome analysis suggests oligodendrocyte dysfunction in schizophrenia. J Psychiatric Res. 2010;44(3):149-56.

403. Sun MF, Zhu YL, Zhou ZL, Jia XB, Xu YD, Yang Q, et al. Neuroprotective effects of fecal microbiota transplantation on MPTP-induced Parkinson's disease mice: gut microbiota, glial reaction and TLR4/TNF-a signaling pathway. Brain Behav Immun. 2018;70:48-60.

404. Li Z, Yi C-X, Katiraei S, Kooijman S, Zhou E, Chung CK, et al. Butyrate reduces appetite and activates brown adipose tissue via the gut-brain neural circuit. Gut. 2018;67(7):1269-79.

405. Morrison DJ, Preston T. Formation of short chain fatty acids by the gut microbiota and their impact on human metabolism. Gut Microbes. 2016:7(3):189-200.
406. Sayin SI, Wahlström A, Felin J, Jäntti S, Marschall H-U, Bamberg K, et al. Gut microbiota regulates bile acid metabolism by reducing the levels of tauro-beta-muricholic acid, a naturally occurring FXR antagonist. Cell Metab. 2013;17(2):225-35.

407. Bekinschtein P, Cammarota M, Katche C, Slipczuk L, Rossato Jl, Goldin $A$, et al. BDNF is essential to promote persistence of long-term memory storage. Proc Natl Acad Sci USA. 2008;105(7):2711-6.

408. Berglind WJ, Whitfield TW, LaLumiere RT, Kalivas PW, McGinty JF. A single intra-PFC infusion of BDNF prevents cocaine-induced alterations in extracellular glutamate within the nucleus accumbens. J Neurosci. 2009;29(12):3715

409. Whitfield TW, Shi X, Sun WL, McGinty JF. The suppressive effect of an intra-prefrontal cortical infusion of BDNF on cocaine-seeking is Trk receptor and extracellular signal-regulated protein kinase mitogenactivated protein kinase dependent. J Neurosci. 2011;31(3):834.

410. Graybeal C, Feyder M, Schulman E, Saksida LM, Bussey TJ, Brigman JL, et al. Paradoxical reversal learning enhancement by stress or prefrontal cortical damage: rescue with BDNF. Nat Neurosci. 2011;14:1507.

411. Rosas-Vidal LE, Do-Monte FH, Sotres-Bayon F, Quirk GJ. Hippocampalprefrontal BDNF and memory for fear extinction. Neuropsychopharmacology. 2014;39:2161.

412. Narita M, Aoki K, Takagi M, Yajima Y, Suzuki T. Implication of brainderived neurotrophic factor in the release of dopamine and dopaminerelated behaviors induced by methamphetamine. Neuroscience. 2003;119(3):767-75.

413. Sansevero G, Baroncelli L, Scali M, Sale A. Intranasal BDNF administration promotes visual function recovery in adult amblyopic rats. Neuropharmacology. 2019;145:114-22.

414. Jiang Y, Wei N, Lu T, Zhu J, Xu G, Liu X. Intranasal brain-derived neurotrophic factor protects brain from ischemic insult via modulating local inflammation in rats. Neuroscience. 2011:172:398-405.

415. Kandathil CK, Stakhovskaya O, Leake PA. Effects of brain-derived neurotrophic factor (BDNF) on the cochlear nucleus in cats deafened as neonates. Hearing Res. 2016;342:134-43.

416. Messaoudi E, Bardsen K, Srebro B, Bramham CR. Acute intrahippocampal infusion of BDNF induces lasting potentiation of synaptic transmission in the rat dentate gyrus. J Neurophysiol. 1998;79(1):496-9.

417. Scharfman H, Goodman J, Macleod A, Phani S, Antonelli C, Croll S. Increased neurogenesis and the ectopic granule cells after intrahippocampal BDNF infusion in adult rats. Exp Neurol. 2005;192(2):348-56.

418. Alcala-Barraza SR, Lee MS, Hanson LR, McDonald AA, Frey WH 2nd, McLoon LK. Intranasal delivery of neurotrophic factors BDNF, CNTF, EPO, and NT-4 to the CNS. J Drug Target. 2010;18(3):179-90.

419. Braschi C, Capsoni S, Narducci R, Poli A, Sansevero G, Brandi R, et al. Intranasal delivery of BDNF rescues memory deficits in AD11 mice and reduces brain microgliosis. Aging Clin Exp Res. 2021;33(5):1223-38.

420. Chapman CD, Frey WH 2nd, Craft S, Danielyan L, Hallschmid M, Schioth $H B$, et al. Intranasal treatment of central nervous system dysfunction in humans. Pharm Res. 2013;30(10):2475-84.

421. Shemesh E, Rudich A, Harman-Boehm I, Cukierman-Yaffe T. Effect of intranasal insulin on cognitive function: a systematic review. J Clin Endocrinol Metab. 2012;97(2):366-76.

422. Li M, Li Y, Peng K, Wang Y, Gong T, Zhang Z, et al. Engineering intranasal mRNA vaccines to enhance lymph node trafficking and immune responses. Acta Biomater. 2017;64:237-48.

423. Li X, Du L, Chen X, Ge P, Wang Y, Fu Y, et al. Nasal delivery of analgesic ketorolac tromethamine thermo- and ion-sensitive in situ hydrogels. Int J Pharmaceutics. 2015;489(1):252-60.

424. Frey WH, Liu J, Chen X, Thorne RG, Fawcett JR, Ala TA, et al. Delivery of $125 \mathrm{I}-\mathrm{NGF}$ to the brain via the olfactory route. Drug Deliv. 1997:4(2):87-92.

425. Kandalam S, Sindji L, Delcroix GJR, Violet F, Garric X, André EM, et al. Pharmacologically active microcarriers delivering BDNF within a hydrogel: novel strategy for human bone marrow-derived stem cells neural/neuronal differentiation guidance and therapeutic secretome enhancement. Acta Biomater. 2017:49:167-80.

426. Pakulska MM, Donaghue IE, Obermeyer JM, Tuladhar A, McLaughlin CK, Shendruk TN, et al. Encapsulation-free controlled release: electrostatic adsorption eliminates the need for protein encapsulation in PLGA nanoparticles. Sci Adv. 2016;2(5):e1600519. 
427. Stroh M, Zipfel WR, Williams RM, Ma SC, Webb WW, Saltzman WM. Multiphoton microscopy guides neurotrophin modification with poly(ethylene glycol) to enhance interstitial diffusion. Nat Mater. 2004;3:489.

428. Ankeny DP, McTigue DM, Guan Z, Yan Q, Kinstler O, Stokes BT, et al. Pegylated brain-derived neurotrophic factor shows improved distribution into the spinal cord and stimulates locomotor activity and morphological changes after injury. Exp Neurol. 2001;170(1):85-100.

429. Jiang Y, Fay JM, Poon CD, Vinod N, Zhao Y, Bullock K, et al. Nanoformulation of brain-derived neurotrophic factor with target receptortriggered-release in the central nervous system. Adv Funct Mater. 2018;28(6):1703982

430. Manickavasagam D, Lin L, Oyewumi MO. Nose-to-brain co-delivery of repurposed simvastatin and BDNF synergistically attenuates LPSinduced neuroinflammation. Nanomedicine. 2020;23:102107.

431. Dąbkowska M, Łuczkowska K, Rogińska D, Sobuś A, Wasilewska M, Ulańczyk Z, et al. Novel design of (PEG-ylated)PAMAM-based nanoparticles for sustained delivery of BDNF to neurotoxin-injured differentiated neuroblastoma cells. J Nanobiotechnol. 2020;18(1):120.

432. Tosi G, Vergoni AV, Ruozi B, Bondioli L, Badiali L, Rivasi F, et al. Sialic acid and glycopeptides conjugated PLGA nanoparticles for central nervous system targeting: in vivo pharmacological evidence and biodistribution. J Control Release. 2010;145(1):49-57.

433. Gelperina S, Maksimenko O, Khalansky A, Vanchugova L, Shipulo E, Abbasova K, et al. Drug delivery to the brain using surfactant-coated poly(lactide-co-glycolide) nanoparticles: influence of the formulation parameters. Eur J Pharm Biopharm. 2010;74(2):157-63.

434. Lampe KJ, Kern DS, Mahoney MJ, Bjugstad KB. The administration of BDNF and GDNF to the brain via PLGA microparticles patterned within a degradable PEG-based hydrogel: protein distribution and the glial response. J Biomed Mater Res A. 2011;96A(3):595-607.

435. Pakulska MM, Elliott Donaghue I, Obermeyer JM, Tuladhar A, McLaughlin CK, Shendruk TN, et al. Encapsulation-free controlled release: electrostatic adsorption eliminates the need for protein encapsulation in PLGA nanoparticles. Sci Adv. 2016;2(5):e1600519.

436. Bertram JP, Rauch MF, Chang K, Lavik EB. Using polymer chemistry to modulate the delivery of neurotrophic factors from degradable microspheres: delivery of BDNF. Pharm Res. 2010;27(1):82-91.

437. Aravamudhan A, Ramos DM, Nada AA, Kumbar SG. Chapter 4-Natural polymers: polysaccharides and their derivatives for biomedical applications. In: Kumbar SG, Laurencin CT, Deng M, editors. Natural and synthetic biomedical polymers. Elsevier; 2014. p. 67-89.

438. Guan J, Tong W, Ding W, Du S, Xiao Z, Han Q, et al. Neuronal regeneration and protection by collagen-binding BDNF in the rat middle cerebral artery occlusion model. Biomaterials. 2012;33(5):1386-95.

439. Han Q, Sun W, Lin H, Zhao W, Gao Y, Zhao Y, et al. Linear ordered collagen scaffolds loaded with collagen-binding brain-derived neurotrophic factor improve the recovery of spinal cord injury in rats. Tissue Eng Part A. 2009;15(10):2927-35.

440. Ramalho I, Bergamo E, Lopes A, Medina-Cintrón C, Neiva R, Witek $L$, et al. Periodontal tissue regeneration using brain-derived neurotrophic factor delivered by collagen sponge. Tissue Eng Part A. 2018;25(15-16):1072-83.

441. Muzzarelli R, Baldassarre V, Conti F, Ferrara P, Biagini G, Gazzanelli G, et al. Biological activity of chitosan: ultrastructural study. Biomaterials. 1988;9(3):247-52.

442. Chen ZG, Wang PW, Wei B, Mo XM, Cui FZ. Electrospun collagen-chitosan nanofiber: a biomimetic extracellular matrix for endothelial cell and smooth muscle cell. Acta Biomater. 2010;6(2):372-82.

443. Gombotz WR, Wee S. Protein release from alginate matrices. Adv Drug Deliv Rev. 1998;31(3):267-85.

444. Zhang Z, Zhang R, Zou L, McClements DJ. Protein encapsulation in alginate hydrogel beads: effect of $\mathrm{pH}$ on microgel stability, protein retention and protein release. Food Hydrocolloids. 2016;58:308-15.

445. Gonçalves VSS, Gurikov P, Poejo J, Matias AA, Heinrich S, Duarte CMM, et al. Alginate-based hybrid aerogel microparticles for mucosal drug delivery. Eur J Pharm Biopharm. 2016;107:160-70.

446. Porath J, Axén R, Ernback S. Chemical coupling of proteins to agarose. Nature. 1967;215(5109):1491-2.
447. Liang S, Xu J, Weng L, Dai H, Zhang X, Zhang L. Protein diffusion in agarose hydrogel in situ measured by improved refractive index method. J Control Release. 2006;115(2):189-96.

448. Mehrotra S, Lynam D, Maloney R, Pawelec KM, Tuszynski MH, Lee I, et al. Time controlled protein release from layer-by-layer assembled multilayer functionalized agarose hydrogels. Adv Funct Mater. 2010;20(2):247-58.

449. Alizadeh R, Zarrintaj P, Kamrava SK, Bagher Z, Farhadi M, Heidari F, et al. Conductive hydrogels based on agarose/alginate/chitosan for neural disorder therapy. Carbohydr Polym. 2019;224:115161.

450. Agterberg MJ, Versnel H, van Dijk LM, de Groot JC, Klis SF. Enhanced survival of spiral ganglion cells after cessation of treatment with brain-derived neurotrophic factor in deafened guinea pigs. J Assoc Res Otolaryngol. 2009;10(3):355-67.

451. Sakane T, Pardridge WM. Carboxyl-directed pegylation of brain-derived neurotrophic factor markedly reduces systemic clearance with minimal loss of biologic activity. Pharm Res. 1997;14(8):1085-91.

452. Soderquist RG, Milligan ED, Sloane EM, Harrison JA, Douvas KK, Potter $J M$, et al. PEGylation of brain-derived neurotrophic factor for preserved biological activity and enhanced spinal cord distribution. J Biomed Mater Res A. 2009;91(3):719-29.

453. Zhang Y, Pardridge WM. Conjugation of brain-derived neurotrophic factor to a blood-brain barrier drug targeting system enables neuroprotection in regional brain ischemia following intravenous injection of the neurotrophin. Brain Res. 2001;889(1-2):49-56.

454. Pardridge WM, Wu D, Sakane T. Combined use of carboxyl-directed protein pegylation and vector-mediated blood-brain barrier drug delivery system optimizes brain uptake of brain-derived neurotrophic factor following intravenous administration. Pharm Res. 1998;15(4):576-82.

455. Piao S, Kim IG, Lee JY, Hong SH, Kim SW, Hwang TK, et al. Therapeutic effect of adipose-derived stem cells and BDNF-immobilized PLGA membrane in a rat model of cavernous nerve injury. J Sexual Med. 2012;9(8):1968-79.

456. Patist CM, Mulder MB, Gautier SE, Maquet V, Jerome R, Oudega M. Freeze-dried poly(D, L-lactic acid) macroporous guidance scaffolds impregnated with brain-derived neurotrophic factor in the transected adult rat thoracic spinal cord. Biomaterials. 2004;25(9):1569-82.

457. Liang W, Han Q, Jin W, Xiao Z, Huang J, Ni H, et al. The promotion of neurological recovery in the rat spinal cord crushed injury model by collagen-binding BDNF. Biomaterials. 2010;31(33):8634-41.

458. Han S, Wang B, Jin W, Xiao Z, Li X, Ding W, et al. The linear-ordered collagen scaffold-BDNF complex significantly promotes functional recovery after completely transected spinal cord injury in canine. Biomaterials. 2015;41:89-96.

459. Shi W, Nie D, Jin G, Chen W, Xia L, Wu X, et al. BDNF blended chitosan scaffolds for human umbilical cord MSC transplants in traumatic brain injury therapy. Biomaterials. 2012;33(11):3119-26.

460. Vögelin E, Baker JM, Gates J, Dixit V, Constantinescu MA, Jones NF. Effects of local continuous release of brain derived neurotrophic factor (BDNF) on peripheral nerve regeneration in a rat model. Exp Neurol. 2006;199(2):348-53.

461. Sirianni RW, Olausson P, Chiu AS, Taylor JR, Saltzman WM. The behavioral and biochemical effects of BDNF containing polymers implanted in the hippocampus of rats. Brain Res. 2010;1321:40-50.

462. Günther MI, Weidner N, Müller R, Blesch A. Cell-seeded alginate hydrogel scaffolds promote directed linear axonal regeneration in the injured rat spinal cord. Acta Biomater. 2015;27:140-50.

463. Jain A, Kim Y-T, McKeon RJ, Bellamkonda RV. In situ gelling hydrogels for conformal repair of spinal cord defects, and local delivery of BDNF after spinal cord injury. Biomaterials. 2006;27(3):497-504.

464. Jain A, McKeon RJ, Brady-Kalnay SM, Bellamkonda RV. Sustained delivery of activated Rho GTPases and BDNF promotes axon growth in CSPG-rich regions following spinal cord injury. PLOS ONE. 2011;6(1):e16135.

465. Stokols S, Tuszynski MH. Freeze-dried agarose scaffolds with uniaxial channels stimulate and guide linear axonal growth following spinal cord injury. Biomaterials. 2006;27(3):443-51. 